\section{Pacific Northwest}

National Laboratory

Operated by Battelle for the

U.S. Department of Energy

\title{
Innovative Approach to Establish Root Causes for Cracking in Aggressive Reactor Environments
}

\author{
S. M. Bruemmer \\ J. S. Vetrano \\ L. E. Thomas \\ E. P. Simonen \\ * P. L. Andresen \\ * General Electric Global Research Center
}

October 2003

Prepared for the U.S. Department of Energy under Contract DE-AC06-76RL01830 


\title{
DISCLAIMER
}

This report was prepared as an account of work sponsored by an agency of the United States Government. Neither the United States Government nor any agency thereof, nor Battelle Memorial Institute, nor any of their employees, makes any warranty, express or implied, or assumes any legal liability or responsibility for the accuracy, completeness, or usefulness of any information, apparatus, product, or process disclosed, or represents that its use would not infringe privately owned rights. Reference herein to any specific commercial product, process, or service by trade name, trademark, manufacturer, or otherwise does not necessarily constitute or imply its endorsement, recommendation, or favoring by the United States Government or any agency thereof, or Battelle Memorial Institute. The views and opinions of authors expressed herein do not necessarily state or reflect those of the United States Government or any agency thereof.

\author{
PACIFIC NORTHWEST NATIONAL LABORATORY \\ operated by \\ BATTELLE \\ for the \\ UNITED STATES DEPARTMENT OF ENERGY \\ under Contract DE-AC06-76RL01830
}

Ty 
NUCLEAR ENERGY RESEARCH INITIATIVE

INNOVATIVE APPROACH TO ESTABLISH ROOT CAUSES

FOR CRACKING IN AGGRESSIVE REACTOR ENVIRONMENTS

Phase 1 Annual Report

Proposal Number 2SF020075 (NERI-2002-075)

Pacific Northwest National Laboratory

S. M. Bruemmer, Principal Investigator

L. E. Thomas

J. S. Vetrano

E. P. Simonen

General Electric Global Research Center

P. L. Andresen

October 2003

Prepared for:

U.S. Department of Energy

Idaho Operations Office 850 Energy Falls

Idaho Falls, ID 83401-1563

Attn: Mr. Ken Osborne

U.S. Department of Energy

Office of Advanced Nuclear Research

NE-20/Germantown Building

1000 Independence Ave, SW

Washington, DC 20595

Attn: Mr. Lynn Hall

Pacific Northwest National Laboratory

Richland, Washington 99352 


\section{TABLE OF CONTENTS}

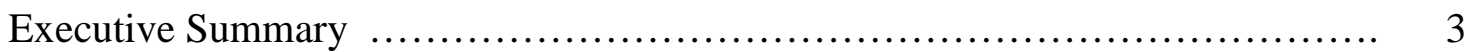

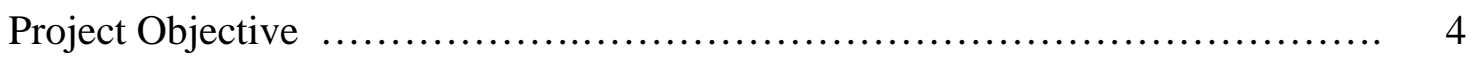

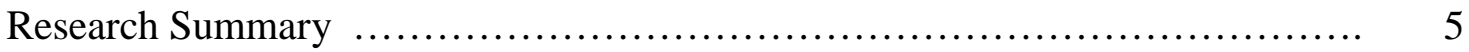

Task A. Single-Variable SCC Experimentation ........................... 5

Background and Approach ...................................... 5

Static SCC Tests.................................................. 6

SCC Crack-Growth-Rate Testing.................................... 9

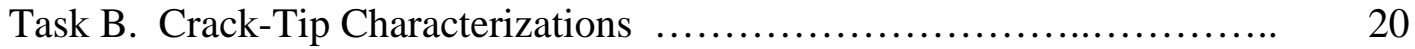

Background and Approach ..................................... $\quad 20$

Alloy 182 Weld Metal ........................................... 20

Pb-Induced IGSCC in Alloy 600 and Alloy 690 ...................... 28

IGSCC and IASCC in Stainless Steel............................... 34

Task C. Modeling Crack-Tip Corrosion Reactions …................... 35

Background and Approach ...................................... $\quad 35$

Thermodynamically Favored Phases ............................. $\quad 35$

Crack Advance Modeling ......................................... $\quad 36$

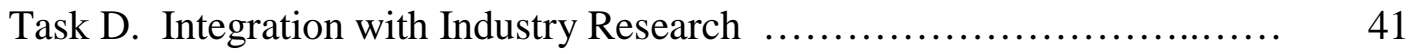

Background and Approach ...................................... 41

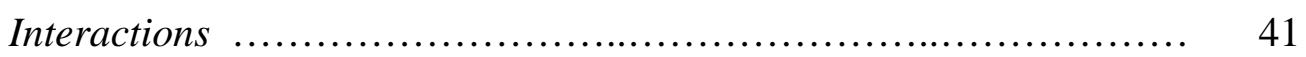

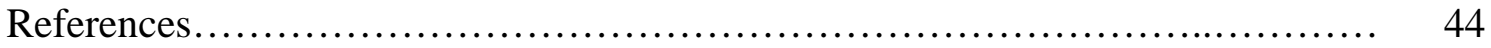

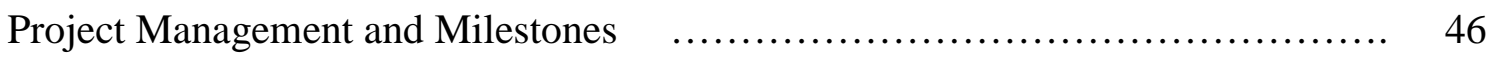

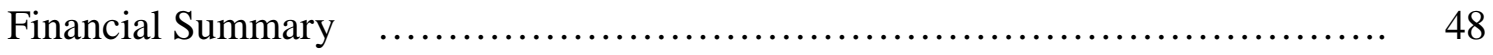




\title{
Executive Summary
}

\author{
Innovative Approach to Establish Root Causes \\ for Cracking in Aggressive Reactor Environments
}

S. M. Bruemmer, Principal Investigator

Pacific Northwest National Laboratory

October 24, 2003

The research focuses on the high-resolution characterization of degradation microstructures and microchemistries in specimens tested under controlled conditions for the environment and for the material where in-service complexities can be minimized. Thermodynamic and kinetic modeling of crack-tip processes is employed to analyze corrosion-induced structures and gain insights into degradation mechanisms. Novel mechanistic "fingerprinting" of crack-tip structures is used to isolate causes of environmental cracking in tandem with quantitative measurements of crack growth. Sample preparation methods and advanced analytical techniques are used to characterize corrosion/oxidation reactions and crack-tip structures at near atomic dimensions in order to gain insight into fundamental environmental cracking mechanisms. Reactions at buried interfaces, not accessible by conventional approaches, are being systematically interrogated. Crack-growth experiments in high-temperature water environments are evaluating and isolating the effects of material condition (matrix strength, grain boundary composition and precipitation) on stress corrosion cracking (SCC). The fundamental understanding of crack advance mechanisms will establish the basis to design new corrosion-resistant alloys for current lightwater reactors and advanced reactor systems.

Research progress was excellent during Phase 1 of this project with all milestones reached or surpassed. Critical SCC experimentation was completed in several areas including crack-growth rate measurements on warm-worked stainless steels in high-temperature water environments and static tests comparing effects on key solution impurities (chloride, thiosulfate, fluoride and lead). These tests provided unique samples for crack-tip characterizations as did several other collaborators who supplied cracking service components from operating commercial nuclear power plants. Crack and crack-tip corrosion structures were documented at near atomic dimensions using analytical transmission electron microscopy (ATEM). First-of-a-kind comparisons were made between Pb-assisted SCC of alloy 600 in high-temperature water for controlled laboratory tests and PWR secondary-side steam generator tube failures. Contrary to current accepted theories, caustic crack solutions were not require to promote rapid intergranular (IG) SCC in alloy 600. Nearly identical crack and crack-tip structures were found in both the laboratory and service samples. Crack tips were also investigated in alloy 182 weld metal for the first time. This material was removed from dissimilar metal weldments in a failed PWR head penetration. Stress-corrosion cracks were identified following grain boundaries and not interdendritic boundaries as reported in the literature. The final key area of research during the first year was in the modeling of crack-tip corrosion reactions. Predictions of solution thermodynamics and corrosion-product phase stabilities were made focused on high-temperature water system with $\mathrm{Pb}$ as an impurity. Important aspects of $\mathrm{Pb}$ migration down cracks and enrichment at crack tips are being explored. Solid-state processes occurring ahead of a growing 
IGSCC crack were also modeled to interpret mechanisms of crack advance. Key comparisons were made to recent high-resolution microchemistry measurements on a crack-tip removed from a section of BWR top guide after more than 20 years of service. Possible explanations for unexpected observations of significant $\mathrm{Cr} / \mathrm{Fe}$ depletion and $\mathrm{Ni}$ enrichment extending up to 100 $\mathrm{nm}$ ahead of the tip were evaluated relative to crack advance rates and known diffusion processes. Selective dissolution and corrosion-induced vacancy injection was shown to be required for the measured crack-tip compositional changes.

\section{Project Objective}

This research project focuses on the characterization of critical Fe- and Ni-base stainless alloys tested under well-controlled conditions where in-service complexities can be minimized. Quantitative assessment of crack-growth rates is used to isolate effects of key variables, while high-resolution analytical transmission electron microscopy provides mechanistic insights by interrogating crack-tip corrosion/oxidation reactions and crack-tip structures at near atomic dimensions. Reactions at buried interfaces, not accessible by conventional approaches, are being systematically interrogated for the first time. Novel mechanistic "fingerprinting" of crack-tip structures tied to thermodynamic and kinetic modeling of crack-tip processes will be used to isolate causes of environmental cracking. Comparisons will be made with results on failed components removed from LWR service (funded separately by industry collaborators).

The research strategy capitalizes on unique national laboratory, industry and university capabilities to generate basic materials and corrosion science results with immediate impact to next generation nuclear power systems. Project activities will be integrated with existing NERI projects, with fundamental research funded by the DOE Office of Basic Energy Sciences and with focused U.S. and international projects dealing with current LWR degradation issues. This leveraged approach will facilitate the revolutionary advances envisioned in NERI by creating a multi-faceted effort combining the basic and applied science necessary to drive mechanistic understanding and promote development of next generation materials that meet advanced reactor performance goals. 


\section{Research Summary}

Research activities are divided into four major tasks: (A) Single-Variable SCC Experimentation; (B) Crack-Tip Characterization; (C) Modeling Crack-Tip Corrosion Reactions; and (D) Integration with Industry Research. Research summaries are supplied for each task in the following sections. Significant progress has been made in each area achieving and surpassing planned milestones.

\section{Task A. Single-Variable SCC Experimentation}

\section{Background and Approach}

An essential first step to elucidate environmental cracking mechanisms is experimentation under well-controlled material, environmental and stress conditions. The selection of these conditions is critical to produce degradation where crack initiation and advance processes are best understood. Material, environmental and electrochemical conditions are being controlled to promote degradation by slip dissolution, hydrogen-induced cracking or internal oxidation. This enables production of unique samples with known cracking mechanisms for crack-tip characterizations in Task B. A key limitation in extracting useful information from examinations on failed service components (e.g., from LWRs) is that material and environmental conditions are uncontrolled. As a result, off-normal conditions often contribute to the cracking process and complicate interpretation of basic environmental degradation mechanisms.

Experimentation focuses on two important unresolved LWR reliability issues: (1) intergranular and interdendritic SCC of nickel-base stainless alloys with application to steam generators, penetration heads and dissimilar metal weldments; and (2) IGSCC of high-strength Fe-base stainless alloys with application to stainless steel core components. To address these issues, single-mechanism experiments will examine cracking in Ni-base stainless alloys investigating the influence of higher matrix chromium levels and the presence of grain boundary precipitation on IGSCC crack growth and crack-tip characteristics. The research on the austenitic stainless steels continues work started on our prior NERI project (99-0280) where strength effects on IGSCC crack growth were established. New work is evaluating and isolating the effect of grain boundary segregation and precipitation on IGSCC growth rate and crack-tip characteristics. Tests are being performed as part of this program at General Electric Global Research Center (GE) and PNNL, but many samples will be obtained from existing/collaborative work at Framatome, EPRI, University of Michigan and Rockwell International. Interactions with some of these collaborative projects are described in Task D.

Environmental cracking is being evaluated using a combination of quantitative crack-growth tests (at GE) and various static-loaded samples (e.g., reverse U-bend and C-ring specimens at PNNL and from collaborative projects). The SCC experiments are performed on specially tailored materials and environmental conditions to isolate mechanistic issues. Critical variables for the high-temperature water environment include electrochemical potential (ECP), conductivity, $\mathrm{pH}$, temperature and impurities (such as $\mathrm{S}$ and $\mathrm{Pb}$ ). Because LWR cracking is predominantly IG, the most important material variables relate to the grain boundary structure (orientation and second phases) and composition (chromium depletion and impurity segregation). In addition, matrix strength (modified by cold/warm work) and composition (higher chromium to modify bulk corrosion behavior) are being examined because of their welldocumented effects on IGSCC susceptibility. 
The particular test method and environment/material combinations are selected based on prior SCC experience and mechanistic issue of interest. Critical combinations are being evaluated to establish representative crack-tip characteristics when a particular environmental cracking mechanism is operating, then comparisons will be made to environment/material combinations where controlling mechanisms are unknown. For example, grain boundary chromium depletion will be employed as one method to evaluate active-path slip dissolution/oxidation. Sensitized alloys will be tested in oxidizing (high ECP) water environments where strong circumstantial evidence exists that slip dissolution/oxidation controls crack growth. The comparison of cracktip characteristics for this "known" condition to those produced during IGSCC under poorly understood conditions is essential to build the fundamental understanding of corrosion processes driving degradation. By one or more controlled changes to the water environment and/or the material (e.g., reduce ECP, increase $\mathrm{pH}$, increase test temperature, alter grain boundary composition and increase alloy strength), mechanisms controlling IGSCC in different cracking regimes can be assessed. Crack-growth tests performed at GE are systematically altering environmental and electrochemical conditions on a single sample quantifying the influence of these specific aspects on the rate of crack advance.

\section{Static SCC Tests}

\section{Materials and Test Environments}

Two approaches were taken in this subtask to generate SCC samples for crack-tip characterizations: (1) obtain and tailor specific alloys for SCC testing (primarily U-bend) at PNNL and (2) work collaboratively with outside laboratories to get SCC tests performed under critical conditions. The first base material selected for single-mechanism tests was a high-carbon 304SS. This alloy was solution annealed at $1050^{\circ} \mathrm{C}$ and sensitized at $650^{\circ} \mathrm{C}$ for $24 \mathrm{~h}$ before fabrication into standard U-bend samples as illustrated in Figure 1(a). SCC tests were then performed at $80^{\circ} \mathrm{C}$ in three high-purity water environments with an impurity addition, i.e., either $\mathrm{NaCl}, \mathrm{Na}_{2} \mathrm{~S}_{2} \mathrm{O}_{3}$ or $\mathrm{NaF}$ as shown in Table 1. Each impurity was added at a concentration of 100 ppm, but the thiosulfate was increased to $200 \mathrm{ppm}$ when cracking was not detected in $800 \mathrm{~h}$.

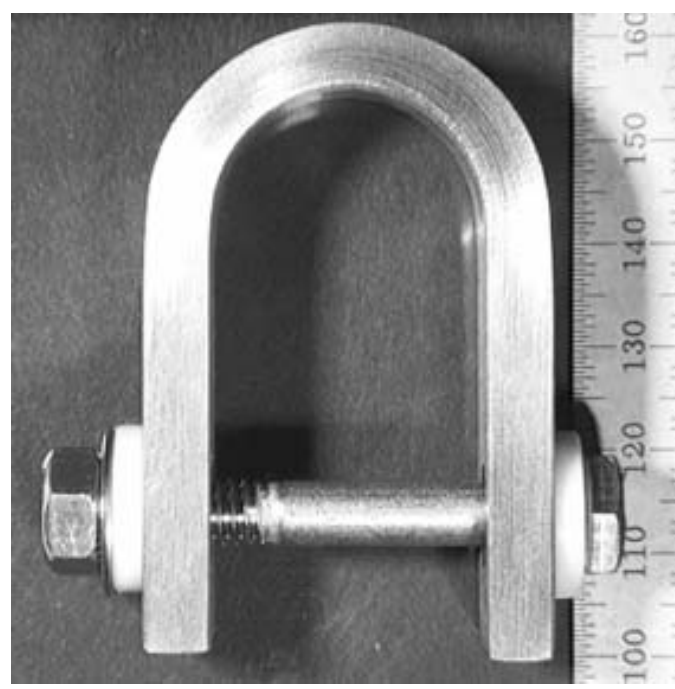

(a)

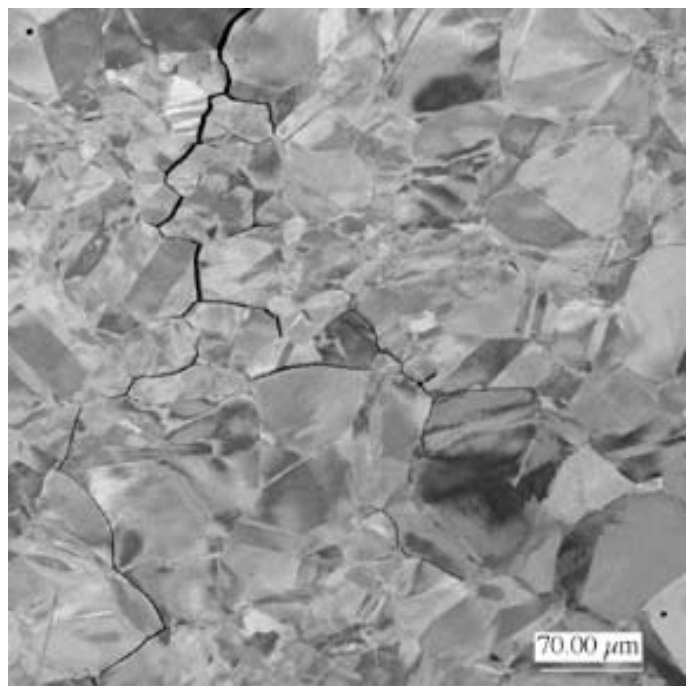

(b)

Figure 1. U-bend test sample (a) for low-temperature SCC tests in chloride, thiosulfate or fluoride environments and example of intergranular cracks produced (b). 
Table 1. SCC Test Conditions and Results for PNNL U-bend Samples

\begin{tabular}{|l|c|l|c|c|}
\hline \multicolumn{1}{|c|}{ Material } & Test Temp, $^{\mathbf{}} \mathbf{C}$ & \multicolumn{1}{|c|}{ Environment } & Test Time, $\mathbf{h}$ & Comments \\
\hline Sensitized 304SS & 80 & DI Water $+100 \mathrm{ppm} \mathrm{NaCl}$ & 500 & IGSCC \\
\hline Sensitized 304SS & 80 & DI Water $+100 \mathrm{ppm} \mathrm{NaCl}$ & 1600 & IGSCC \\
\hline Sensitized 304SS & 80 & DI Water $+100 \mathrm{ppm} \mathrm{Na}_{2} \mathrm{~S}_{2} \mathrm{O}_{3}$ & 800 & No cracking \\
\hline Sensitized 304SS & 80 & DI Water $+200 \mathrm{ppm} \mathrm{Na}_{2} \mathrm{~S}_{2} \mathrm{O}_{3}$ & 800 & IGSCC \\
\hline Sensitized 304SS & 80 & DI Water $+100 \mathrm{ppm} \mathrm{NaCl}$ & 1600 & IGSCC \\
\hline
\end{tabular}

A second base material selected was an industry-standard alloy 600 steam generator tubing, obtained from Dr. Alan McIlree of EPRI. Heat treatments were completed to assess secondphase precipitate evolution in the alloy 600 and samples were prepared for scanning and transmission electron microscopy. Chromium carbide and nickel boride distributions at grain boundaries were documented as a function of annealing temperature. The intent will be to conduct high-temperature SCC tests in simulated PWR water environments and evaluate the influence of these second phases on cracking response. Two high-temperature autoclave systems were set up at PNNL and capabilities for environmental control and electrochemical measurements were assessed. Decisions will be made early in year 2 concerning pursuing such tests at PNNL or working with one of our collaborators to get SCC tests conducted. In addition, alloy 690 tubing for SCC tests at PNNL and plate materials for crack-growth tests at GE have been identified and discussions are ongoing to obtain this material. The heats of alloy 690 are being used as part of an EPRI-industry testing program that may allow additional data and SCC samples to be obtained for crack-tip characterizations.

As noted above the second approach within this subtask was an assessment of available tested samples at various research laboratories in the U.S., Europe and Japan. Contacts were made with several key laboratories to determine if previously tested samples might still be available for use in this NERI project. The first important series was found from work at CIEMAT in Spain. A critical series of SCC tests were performed systematically evaluating $\mathrm{Pb}$ effects on cracking susceptibility in alloy 600 and alloy 690 in secondary PWR-water environments. Nine samples were selected and obtained as summarized in Table 2. A second collaboration examining the influence of $\mathrm{Pb}$ on SCC was established with EPRI and Rockwell International. Testing on alloy 600 and 690 samples is underway in complex secondary-side PWR environments $\left(330^{\circ} \mathrm{C}\right.$ water with sulfate, alumina and silicate at a $\mathrm{pH}$ of $~ 9$ ) with and without $\mathrm{Pb}$ additions. After exposures of 3 months, SCC has only been seen in mill-annealed alloy 600 and not in thermally treated alloy 600 or alloy 690. One sample has been supplied to PNNL for characterization investigating $\mathrm{Pb}$ solubility in solution and determining whether $\mathrm{Pb}$ is available to promote $\mathrm{SCC}$.

In addition, collaborations have continued with the University of Michigan investigating mechanisms of irradiation-assisted (IA) SCC in 300-series stainless steels. Proton-irradiated specimens were obtained after slow-strain-rate SCC tests in high-temperature water environments. Two variables have been altered in these IASCC tests: (1) the corrosive environment comparing oxidizing BWR water conditions to non-oxidizing, hydrogenated water and (2) comparing response of a high-purity 304LSS to a 304LSS+Si. Distinct differences in 
Table 2. SCC Test Samples Obtained from CIEMAT and Summary of Results

\begin{tabular}{|c|c|c|c|c|}
\hline Material & Test Temp, ${ }^{\circ} \mathrm{C}$ & Environment & Test Time, $\mathrm{h}$ & Comments \\
\hline Alloy 600 MA, G & 320 & $\mathrm{AVT}+0.002 \mathrm{M} \mathrm{PbO}$ & 1500 & $23 \%$ IGSCC \\
\hline Alloy $600 \mathrm{MA}, \mathrm{G}$ & 320 & $4 \% \mathrm{NaOH}+0.002 \mathrm{M} \mathrm{PbO}$ & 1500 & $4 \%$ IGA-SCC \\
\hline Alloy $600 \mathrm{MA}, \mathrm{G}$ & 320 & $4 \% \mathrm{NaOH}$ & 1000 & $20 \%$ IGSCC \\
\hline Alloy 600 TT, H & 320 & $\mathrm{AVT}+0.01 \mathrm{M}$ PbO & 1500 & $27 \%$ TG + IGSCC \\
\hline Alloy 690 TT, B & 350 & $10 \% \mathrm{NaOH}+0.01 \mathrm{M} \mathrm{PbO}$ & 600 & $63 \%$ TGSCC \\
\hline Alloy $600 \mathrm{MA}, \mathrm{G}$ & 350 & $10 \% \mathrm{NaOH}+0.01 \mathrm{M} \mathrm{PbO}$ & 500 & $10 \%$ IGA-SCC \\
\hline Alloy $600 \mathrm{MA}, \mathrm{G}$ & 350 & $10 \% \mathrm{NaOH}$ & 500 & $45 \%$ IGSCC \\
\hline Alloy 800 MA, D & 350 & $10 \% \mathrm{NaOH}$ & 500 & $70 \%$ IGSCC \\
\hline Alloy $600 \mathrm{MA}, \mathrm{G}$ & 320 & $\mathrm{AVT}+0.01 \mathrm{M} \mathrm{PbO}$ & 1500 & $43 \%$ IGSCC \\
\hline
\end{tabular}

IASCC response has been observed for tests in BWR and PWR water that may be reflected in their crack-tip characteristics. Very recent results also suggest that Si alloy additions may have a detrimental effect on IGSCC behavior, particular in low-potential, hydrogenated water. For both the Ni-base alloys SCC and Fe-base alloy IASCC cases, direct comparisons will be made between these well-controlled laboratory tests and cracks removed from light-water reactor components.

\section{SCC Test Results}

The goal of the low-temperature SCC tests is to known detrimental solution impurities on the crack and crack-tip corrosion films. Classic impurities, known to promote SCC of sensitized stainless steels, were evaluated. General results for these tests are summarized in Table 1 with sample examined for cracks every $200 \mathrm{~h}$. All tests were successful in producing IG cracking for cross-section sample preparation. First cracking was identified for the chloride and fluoride tests at $\sim 400 \mathrm{~h}$, while the $100 \mathrm{pm}$ thiosulfate solution did not show cracking at $\sim 800 \mathrm{~h}$. Since thiosulfate breaks down in solution over time, an additional $100 \mathrm{pm}$ was placed in solution and the test continued until $1600 \mathrm{~h}$. First cracks were identified at $\sim 1200 \mathrm{~h}$ or $400 \mathrm{~h}$ in solution after the extra thiosulfate was added. A second $\mathrm{NaCl}$ sample was tested for a shortened duration, because of extensive cracking in the first 1600-h exposure sample. There was a concern that cracks may be too deep and open in the first sample limiting the ability to conduct viable crosssection ATEM examinations of the crack-tip regions. As indicated above, the $\mathrm{Pb}$-series tests and the IASCC experiments were not performed on this project but obtained from collaborators. 


\section{SCC Crack-Growth-Rate Testing}

The objective of the GE Global Research effort in this program is to create stress corrosion cracks (SCC) under very well-defined laboratory conditions, then to provide these specimens to PNNL for detailed microchemical and microstructural characterization of the crack tip, primarily by analytical electron microscopy. These efforts are designed to elucidate the mechanisms and controlling thermodynamic and kinetic processes involved in environmentally assisted cracking in water reactor systems. This requires the use of single-variable (e.g., no change in water chemistry), well-controlled laboratory experiments on commercial and tailored alloys to isolate key metallurgical and environmental factors on IGSCC, which in turn requires good characterization of the SCC growth rate response - the literature makes it abundantly clear that simple-minded exposures of SCC specimens is no guarantee of well-behaved response.

\section{Materials and Test Environments}

Candidate commercial and custom-melted heats of stainless steel, alloy 600 and alloy 182 weld metal from among those archived at GE have been reviewed, and a number have been identified as optimal for this program. The compositions and properties are shown in the table below. Other materials may be added during the program as they become available or as interesting observations and issues surface during the investigation.

\begin{tabular}{|c|c|c|c|c|c|c|c|c|c|c|c|}
\hline $\begin{array}{c}\text { Alloy } \\
\text { (Heat) }\end{array}$ & $\mathbf{F e}$ & $\mathbf{C}$ & $\mathbf{N}$ & $\mathbf{P}$ & $\mathbf{S}$ & $\mathbf{C r}$ & $\mathbf{N i}$ & $\mathbf{M o}$ & $\mathbf{M n}$ & $\mathbf{S i}$ & $\mathbf{C u}$ \\
\hline $\begin{array}{c}304 \\
\text { AJ9139 }\end{array}$ & bal. & 0.066 & 0.048 & 0.026 & 0.028 & 18.37 & 8.13 & 0.25 & 0.93 & 0.47 & 0.29 \\
\hline
\end{tabular}

38.0 ksi yield strength, 86.5 ksi tensile strength, 70.0\% elongation; 75.0\% RA, BHN 163

\begin{tabular}{|c|c|c|c|c|c|c|c|c|c|c|c|}
\hline $\begin{array}{c}\text { Alloy } \\
\text { (Heat) }\end{array}$ & $\mathbf{F e}$ & $\mathbf{C}$ & $\mathbf{N}$ & $\mathbf{P}$ & $\mathbf{S}$ & $\mathbf{C r}$ & $\mathbf{N i}$ & $\mathbf{M o}$ & $\mathbf{M n}$ & $\mathbf{S i}$ & $\mathbf{C u}$ \\
\hline $\begin{array}{c}316 \mathrm{~L} \\
\text { A14128 }\end{array}$ & bal. & 0.014 & 0.085 & 0.015 & 0.001 & 17.64 & 12.40 & 2.60 & 1.78 & 0.47 & -- \\
\hline
\end{tabular}

38.0 ksi yield strength, 83.1 ksi tensile strength, 57.0\% elongation; 82.8\% RA, 80 RB @ 25C

\begin{tabular}{|c|c|c|c|c|c|c|c|c|c|c|c|}
\hline $\begin{array}{c}\text { Alloy } \\
\text { (Heat) }\end{array}$ & $\mathbf{F e}$ & $\mathbf{C}$ & $\mathbf{N}$ & $\mathbf{P}$ & $\mathbf{S}$ & $\mathbf{C r}$ & $\mathbf{N i}$ & $\mathbf{T i}$ & $\mathbf{A l}$ & $\mathbf{M n}$ & $\mathbf{S i}$ \\
\hline $\begin{array}{c}600 \\
3110439\end{array}$ & 7.37 & 0.045 & 0.005 & 0.008 & 0.0001 & 15.58 & 75.92 & 0.25 & 0.12 & 0.25 & 0.18 \\
\hline
\end{tabular}

37.1 ksi yield strength, 93.9 ksi tensile strength, 48.0\% elongation; 69.0\% RA, BHN 152

The objective is to develop well-defined stress corrosion cracks under well-defined material and environmental conditions, and ensuring that the SCC growth rate response is reproducible and characteristic of the test conditions. These experiments are being performed using fracture mechanics specimens (0.5T or $1 \mathrm{~T} \mathrm{CT}$ specimens) in sophisticated equipment involving precision control and monitoring of water chemistry and corrosion potential; digital servo-control loading systems under computer control; high pressure / high temperature autoclave systems with digital temperature controllers; continuous high resolution dc potential drop monitoring of crack length; and computer data acquisition and test control (Figure 2). The data will be obtained at $25-30$ ksi $\sqrt{ }$ in in high temperature water, which encompasses both (1) $288^{\circ} \mathrm{C}$ high purity water containing $2000 \mathrm{ppb} \mathrm{O}_{2}$ or $100 \mathrm{ppb} \mathrm{H}_{2}$ representative of typical boiling water reactor (BWR) conditions, and (2) $290-360^{\circ} \mathrm{C}$ water containing appropriate $\mathrm{B}, \mathrm{Li}$, and dissolved $\mathrm{H}_{2}$ additions 


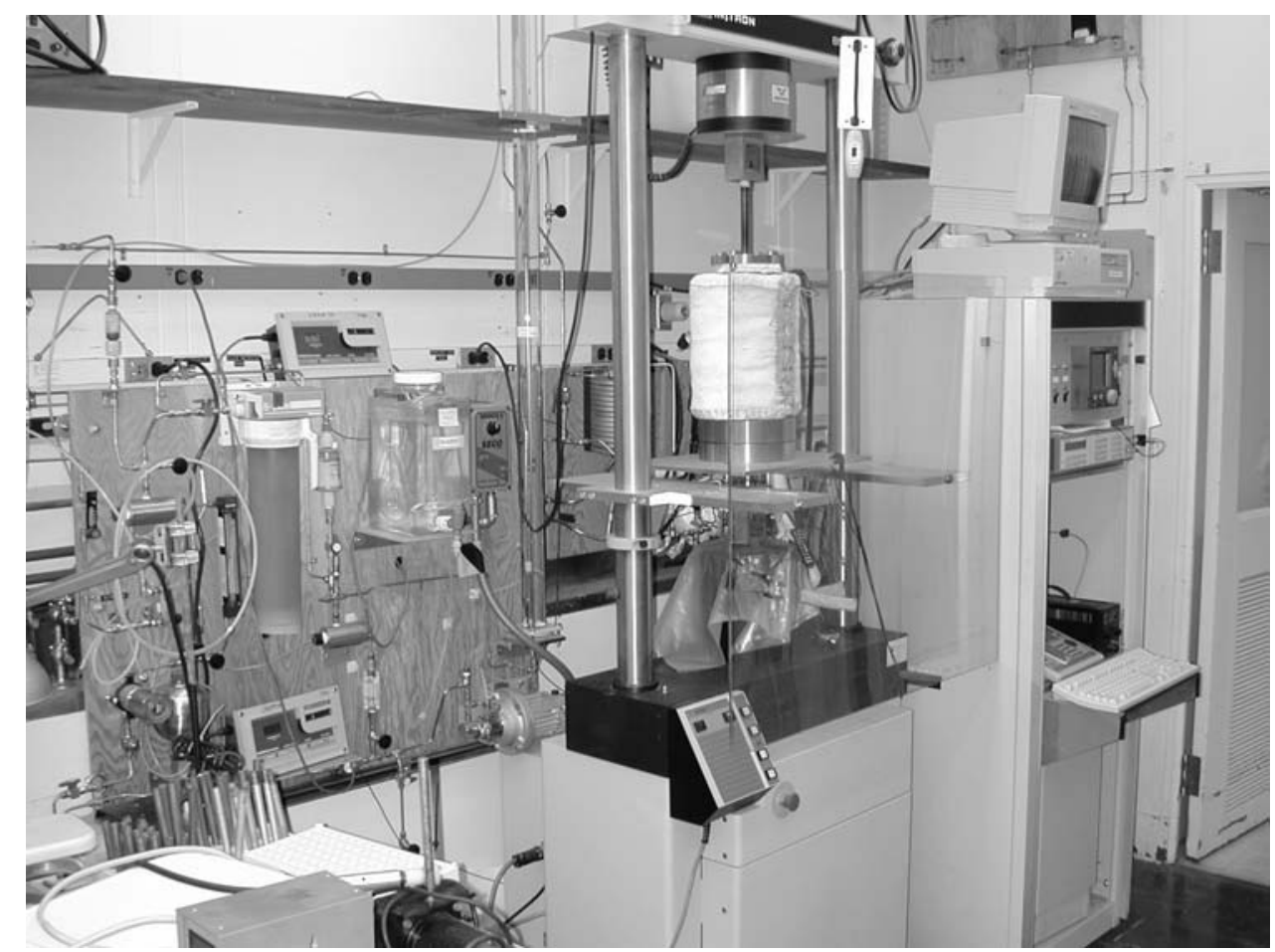

Figure 2. Photograph of a typical system for performing fatigue precracking, and corrosion fatigue and stress corrosion crack growth rate studies in high temperature water.

representative of typical pressurized water reactor (PWR) primary and secondary conditions. Other environments may also be employed.

On completion of testing, the specimens will not be fatigued apart, but will be cooled, disassembled, and kept moist during shipment to PNNL. In some cases under the specimens will be cooled under load, so that the crack can be maintained in its high temperature geometry; it will then be wedged open and sent to PNNL. After examination there is typically some of the original specimen intact (e.g., half), and this will be fatigued apart at GE Research and evaluated by scanning electron microscopy.

After fabrication, heat treatment, and machining, the specimens were measured for exact dimensions, stamped, and individually fatigue precracked in air (described later). They were then loaded into an autoclave system, which involves spot welding Pt-wire current and potential leads for the reversing dc potential drop measurements, installing the specimens with ceramic sleeve insulators on the loading pins for electrical isolation from the clevises. For electrochemical measurements, a custom-made Pt electrode and zirconia membrane reference electrode $\left(\mathrm{ZrO}_{2} / \mathrm{Cu}_{2} \mathrm{O} / \mathrm{Cu}\right)$ were also installed. The autoclave is then closed, filled with high purity water containing $2000 \mathrm{ppb}$ dissolved $\mathrm{O}_{2}$, and heated to $288^{\circ} \mathrm{C}$. After equilibration, the specimens are loaded, and testing is commenced.

\section{$\underline{\text { SCC Experimental Procedures }}$}

The experimental procedures for fabrication and testing of all crack growth rate specimens in this program are summarized below. The crack growth specimens are 1-inch (1T CT) or 0.5-inch (0.5T CT) compact tension type with 5\% side grooves on each side (Figure 3). 


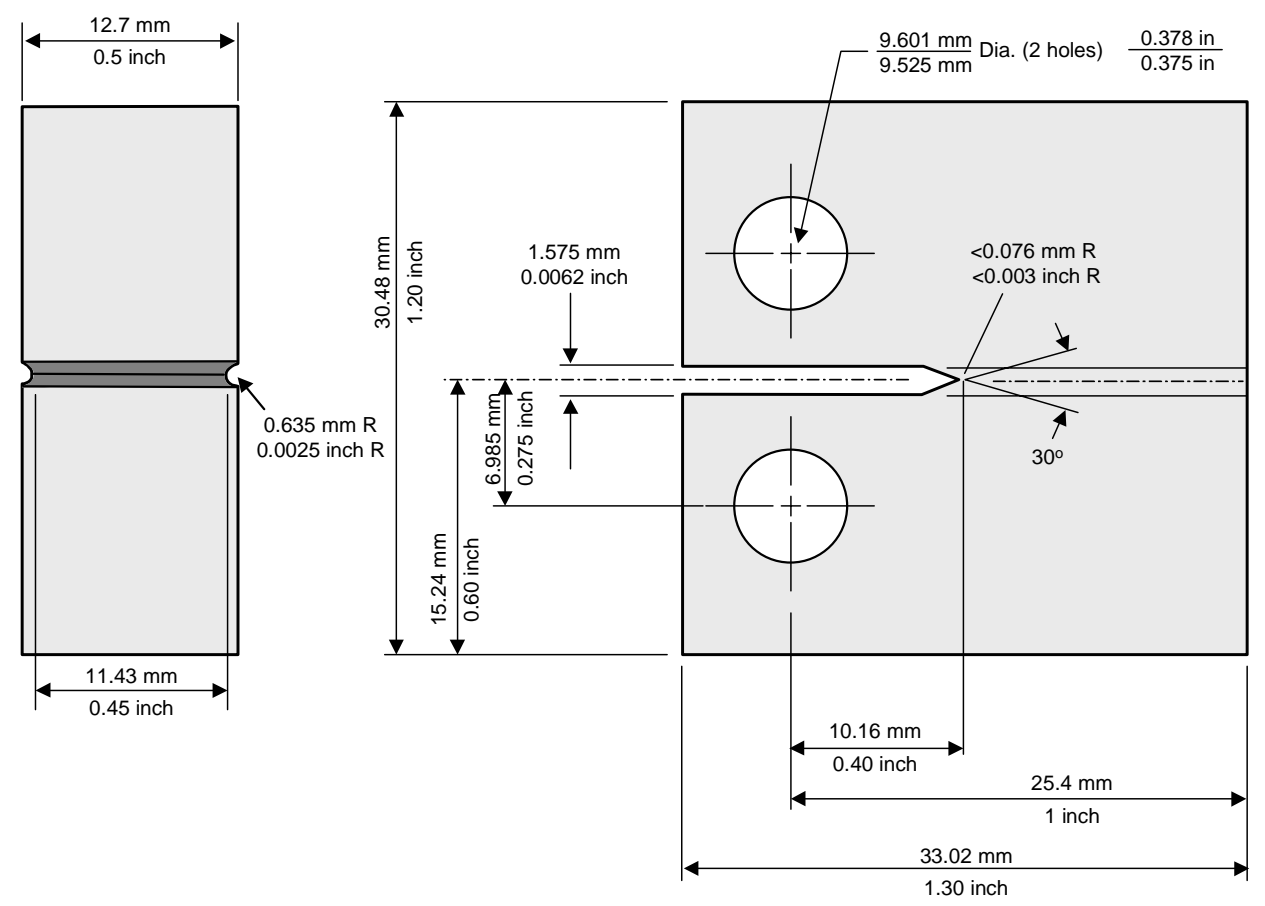

Figure 3. Schematic drawing of a 0.5TCT specimen. Oversized loading holes of about $9.5 \mathrm{~mm}$ diameter were used in most specimens to accommodate ceramic inserts that provided electrical isolation between the CT specimen and clevise. All dimensions for 1TCT specimens doubled.

Specimens were instrumented with platinum current and potential probe leads for dc potential drop measurements of crack length. In this technique, current flow through the sample is reversed about once per second primarily to reduce measurement errors associated with thermocouple effects and amplifier offsets. The computer control of current reversal, data acquisition, data averaging techniques, and the relationship between measured potential and crack length have been presented previously. [1-4] Depending on the test conditions, data are stored in a permanent disk file approximately once every 0.3 to $6 \mathrm{~h}$. In addition to the data record number, total elapsed and incremental time, and crack length, the system measures and stores the temperature, current corrosion potential, effluent dissolved oxygen, effluent conductivity, load and time/date. Statistical information on temperature and current fluctuations are also recorded. Additionally, messages describing changes in test conditions, etc. are a permanent part of the data record.

Most CT specimens were electrically insulated from the pins, clevises, and pull rods (which are machined from Nitronic 50 "stainless steel"). When electrical insulation is not used (zirconia sleeves on the loading pins), it is very unlikely to be a problem because the corrosion potential of all high alloy (high $\mathrm{Cr}$ ) materials is similar in hot water, and within the autoclave a zirconia washer always isolates the upper pull rod from the internal load frame. The lower pull rod is electrically isolated from the autoclave using an Omniseal pressure seal and from the loading actuator using an insulating washer. Ground isolated instrumentation is used for the platinum current and potential probe attachments to the specimen.

Initial crack extension from the machined notch by 0.5 to $1.0 \mathrm{~mm}$ is performed in the environment typically at $1 \mathrm{~Hz}$ at a load ratio $\left(\mathrm{K}_{\min } / \mathrm{K}_{\max }\right) \mathrm{R}=0.5$ and a $\mathrm{K}_{\max }$ somewhat below 
the test value of $33 . \mathrm{MPa} \sqrt{\mathrm{m}}$. Testing was performed using closed-loop servo-controlled systems with computer control capability, e.g., Interactive Instruments digital load controllers, Instron Model 1362 servo-electric testing machines or Model 1350 servo-hydraulic machines equipped with a single stage, slow strain servo valve to ensure optimal (non-noisy) response. All systems are equipped with digital controls, which provide improved machine control and full computer interface/control capabilities. The potential drop software has been modified to interface with the control electronics to provide constant $\mathrm{K}$ testing, to sequence through a table of test conditions triggered by crack length, and to provide a varying-K profile vs. crack depth. The crack length is not allowed to decrease to avoid "hunting" problems associated with unnecessary changes in load from noise in the potential drop measurement. Threshold adjustments control the minimum increments that must occur before corrections are applied; typically, only very small increases in stress intensity, typically $<0.1 \%$, occur prior to load correction.

Crack growth rates can be treated as statistically significant when the crack growth increment is at least 10 times the limiting resolution of the technique, which is typically $<0.002$ to $0.005 \mathrm{~mm}$. Thus, crack length increments are typically $\geq 0.05 \mathrm{~mm}$, although for very low growth rate conditions, smaller increments are occasionally used to reduce testing time from several months per datum to several weeks. The correlation coefficients from linear regression analyses of the crack lengths vs. time data from which growth rates are calculated are typically $>0.98$.

Optimization of the reversed DC potential drop technique has provided incremental crack length resolution on a micron scale. For example, even without compensation for minor fluctuations in temperature and applied current, Figure 4 shows the typical resolution on a 1TCT specimen in $288^{\circ} \mathrm{C}$ water to be, $2-5 \mu \mathrm{m}-\mathrm{h}$, corresponding to $\approx 1 \mu \mathrm{m}$ resolution if data are averaged over a 5 - $\mathrm{h}$ period. A recent analysis of the accuracy of the technique based on eleven Type 304L, 316L and $316 \mathrm{NG}$ stainless steel ITCT specimens tested in $288^{\circ} \mathrm{C}$ water revealed that the crack depth determined by potential drop was, on average, $2.2 \%$ below the actual depth (with a standard deviation, $\sigma_{\mathrm{n}}$, of $5.2 \%$ ) on growth increments of 4.2 to $13.6 \mathrm{~mm}$ from an initial (as-machined) a/W of 0.384 to 0.463 . The worst case error was $11 \%$ on $20 \mathrm{~mm}$ of growth; the errors for 6 of 11 specimens were $<2 \%$. Similar results have also been observed for sensitized Type 304 stainless steel and turbine steel specimens. Complex microstructures - esp. Ni alloy weld metals like alloy 182 - always maintain uncracked ligaments (that act as current shorting paths) in the wake of the crack. Agreement between dc potential drop and post-test fractography can show errors of $>>50 \%$ in some instances, although the problems are less with the transitioning and intermittent use of periodic unloading during testing.

Deaereated, demineralized water (Figure 5) is drawn through another demineralizer and submicron filter to ensure ultra-high purity $(\approx 0.055 \mu \mathrm{S} / \mathrm{cm})$ and then into a glass column $(6.4$ $\mathrm{cm}$ diameter by $183-\mathrm{cm}$ long). A low-pressure pump provides positive pressure to the highpressure pump, and draws water from and recirculates excess water (water that did not go into the high-pressure pump) back into the glass column. The autoclave effluent is back-pressure regulated, then measured for conductivity using a Sybron Barnstead Model PM-512 and dissolved oxygen using an Orbisphere Model 2606. The oxygen concentration is controlled by bubbling gas blended by a Tylan Model RO-20-A mass flow controller. Impurities are added to the glass column using a metering pump (Fluid Metering Model RP-G50/H1 GKC) that was controlled by the Sybron Barnstead conductivity meter. 


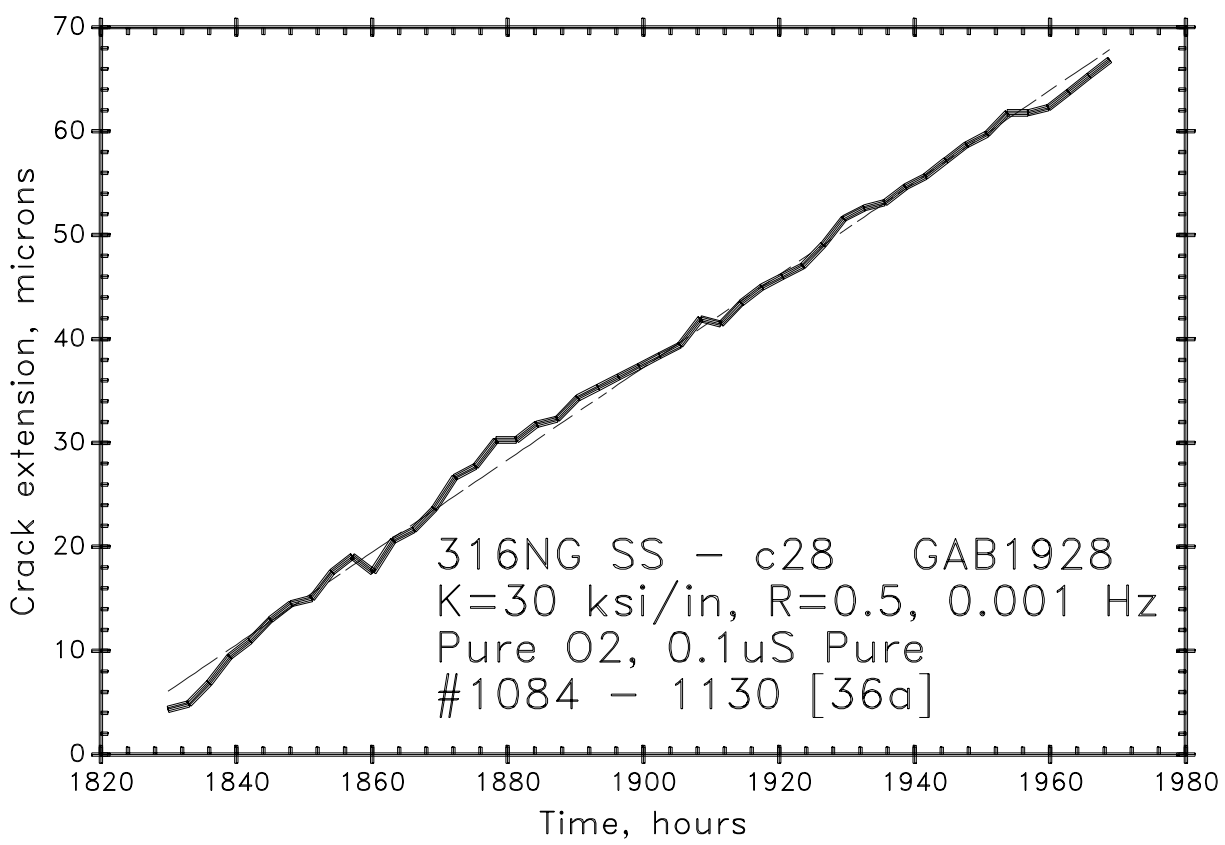

Figure 4. Crack extension vs. time for a $1 \mathrm{TCT}$ specimen in $288^{\circ} \mathrm{C}$ water showing the resolution of the reversing dc potential drop technique. Even without compensation for minor fluctuations in temperature and applied current, a resolution of $\approx 2$ to $5 \mu \mathrm{m}$ is attainable.

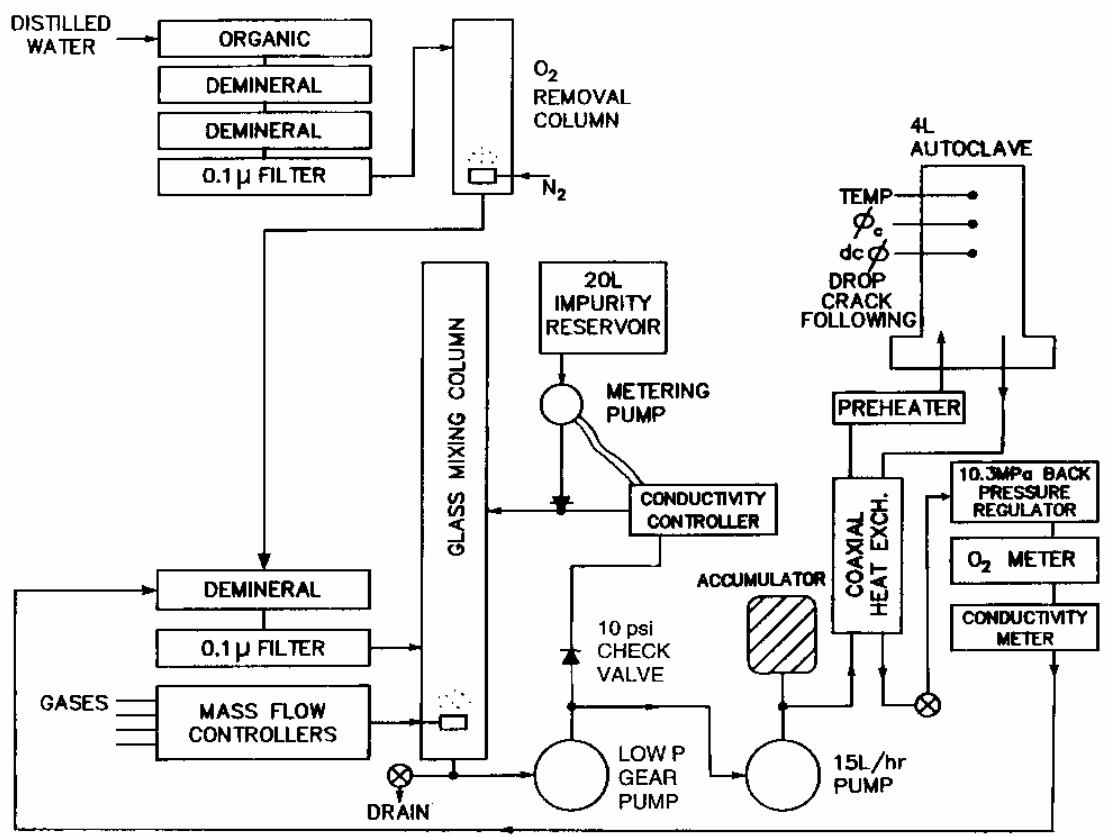

Figure 5. Schematic design of the water chemistry measurement and control, and the highpressure pumping system.

Tests were performed in 4-liter stainless steel autoclaves at pressures above the vapor pressure (e.g., $10.3 \mathrm{MPa}$ at $288^{\circ} \mathrm{C}$ ). The autoclave effluent water was continuously monitored for solution conductivity using a second Sybron Barnstead Model PM-512 meter and periodically monitored for dissolved oxygen using an Orbisphere Model 2606. A zirconia membrane reference 
electrode [5] was employed for continuous measurement of the corrosion potential of the CT specimen. To help ensure state-of-the-art water chemistry, both influent and effluent water was continuously monitored. Influent water will be $\approx 18 \mathrm{M} \Omega-\mathrm{cm}(0.055 \mu \mathrm{S} / \mathrm{cm})$.

In the absence of impurity additions, the effluent was generally $>14 \mathrm{M} \Omega-\mathrm{cm}(<0.07 \mu \mathrm{S} / \mathrm{cm})$, which requires (among other things) that the autoclave flow rate be moderately high, typically $>150$ $\mathrm{cc} / \mathrm{min}$. Two major contributions to degraded effluent water purity may be identified as chromic acid release from the passive film on the stainless steel autoclave components and carbonic acid from thermal decomposition of organics. The effect of chromic acid on effluent conductivity was small in de-aerated environments (using nitrogen or argon $-6 \%$ hydrogen); although in oxygenated environments its effect could be appreciable. Details of these issues have been discussed previously. [6]

For tests in PWR primary water (containing, e.g., 1500 ppm B as $\mathrm{H}_{2} \mathrm{BO}_{3}$ and 2 ppm $\mathrm{Li}$ as $\mathrm{LiOH}$ ), a mixed bed demineralizer was equilibrated to this chemistry and installed in the water loop. This not only removed all impurities like chloride and sulfate, but also helped maintain stable B and Li concentrations during the test.

\section{$\underline{\text { SCC Testing Results }}$}

Type 304L Stainless Steel (c241) in BWR Water. The overview and air fatigue precracking response of warm-worked $\left(20 \%\right.$ reduction in thickness at $\left.140^{\circ} \mathrm{C}\right)$ stainless steel specimen c241 are shown in Figures 6 and 7. At about 83 h, the specimen was assembled into the autoclave, and the initial environmental cracking response in $288^{\circ} \mathrm{C}$ in water containing $2000 \mathrm{ppb} \mathrm{O}_{2}$ is shown in Figure 8.

A major error in most stress corrosion crack growth rate testing is the assumption that an air fatigue precrack will immediately respond like a stress corrosion crack upon exposure to the environment. An air fatigue precrack not only possesses a highly hardened plastic zone inherent in precracking, but the crack morphology is transgranular, whereas stress corrosion cracking in these materials occurs by intergranular crack advance. Thus, a slow, controlled transition must be made to static load conditions (or constant stress intensity factor conditions, which requires load shedding as the crack grows) as the crack shifts to an intergranular morphology. The mechanical transition is partly performed during fatigue precracking by increasing the load ratio, $\mathrm{R}$, to 0.7 toward the end of precracking.

Initial testing in high temperature water involves cycling under similar conditions to encourage the entire crack front to continue to grow and transition to intergranular SCC. This is very effectively accomplished by starting with low frequency, low stress intensity amplitude $(\Delta \mathrm{K})$ conditions, typically a load ratio, $\mathrm{R}=0.7$ and $0.001 \mathrm{~Hz}$. A hold time at $\mathrm{K}_{\max }$ is then introduced (soon in this test), e.g., of 9,000 s, then if the response is well-behaved, constant $\mathrm{K}$ conditions are implemented, as shown in Figure 8. 


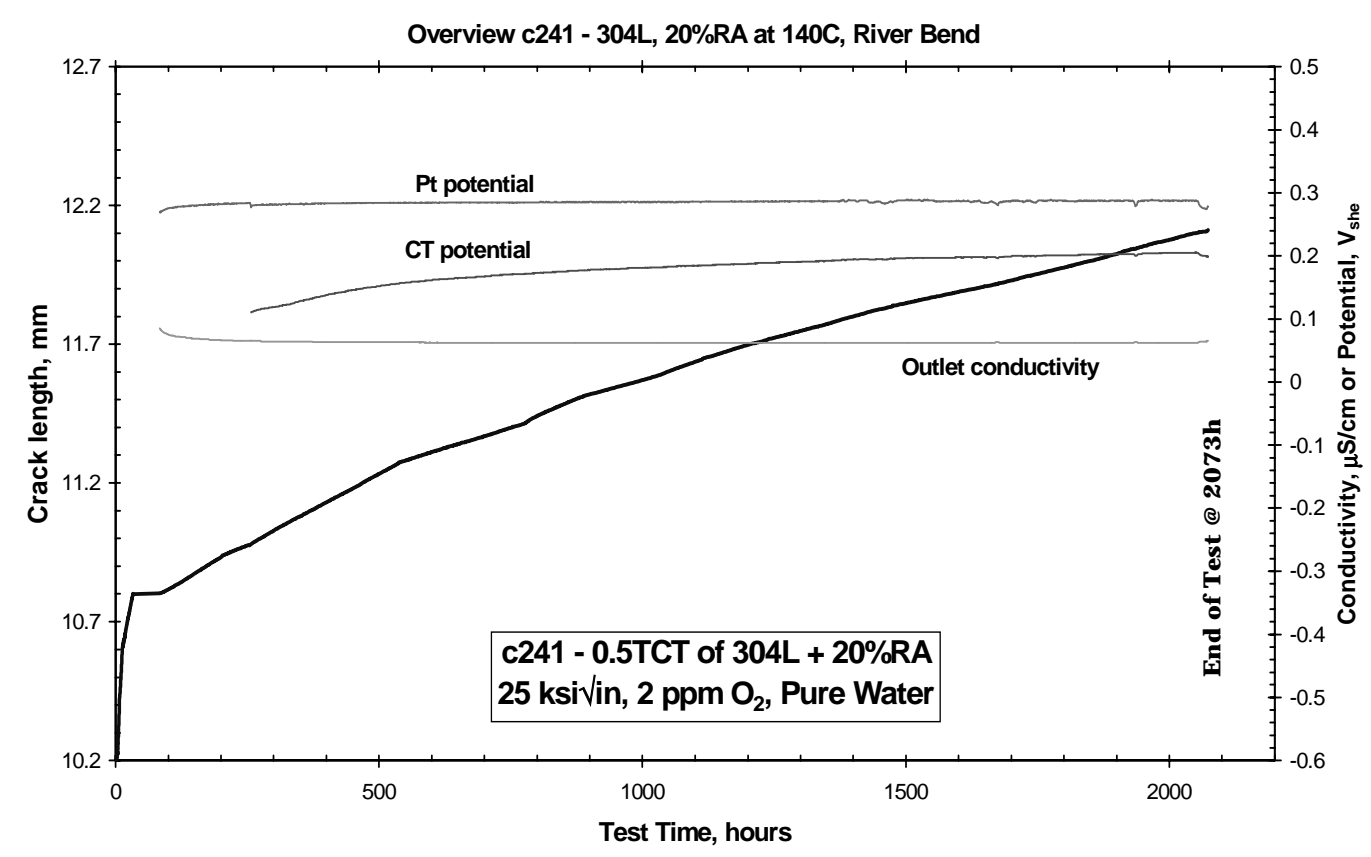

Figure 6. Overview of SCC growth rate response of warm-worked 304L stainless steel (River Bend shroud) tested in $288^{\circ} \mathrm{C}$ pure water.

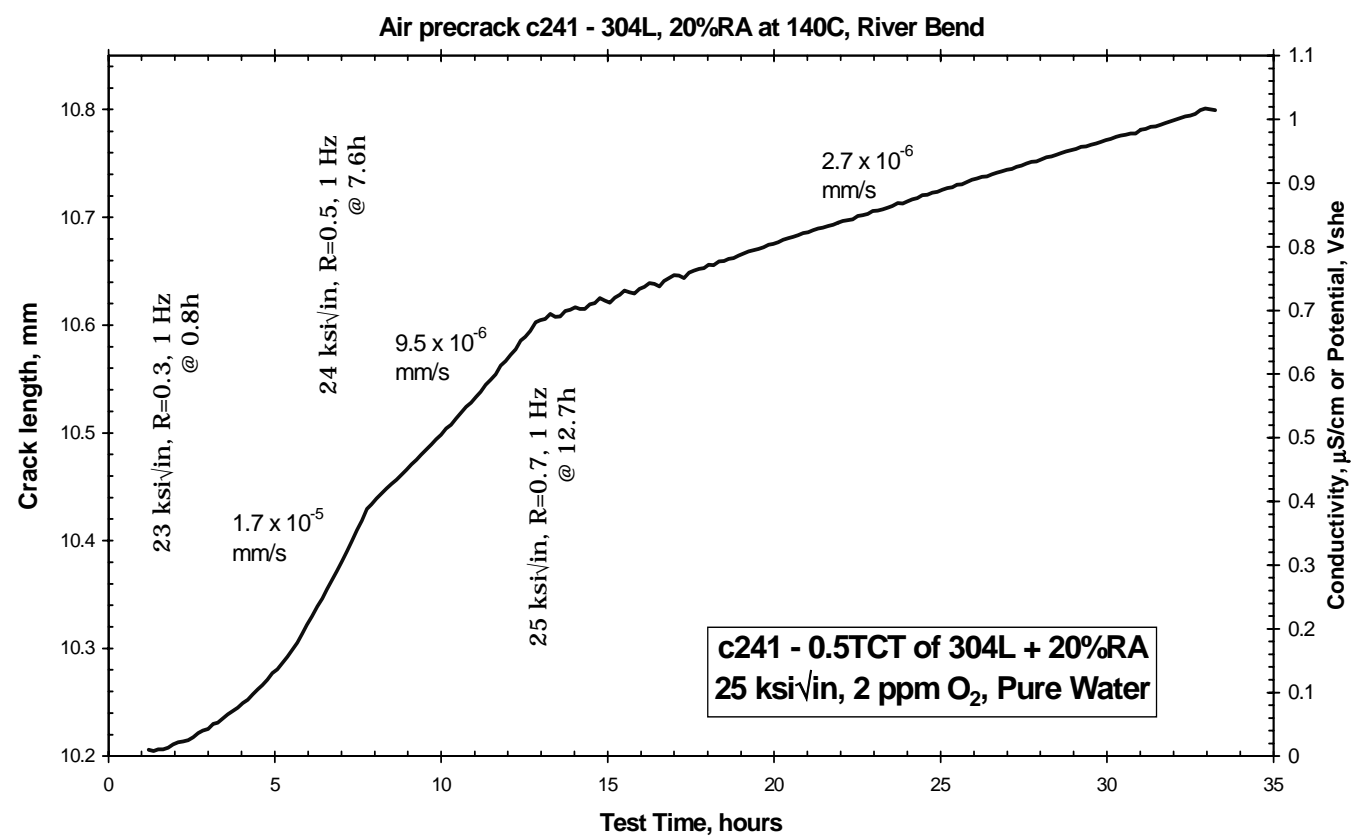

Figure 7. Air fatigue precracking response of warm-worked 304L stainless steel (River Bend shroud) and transition to test in $288^{\circ} \mathrm{C}$ pure water.

To ensure that a good response is obtained, a 9,000 s hold at $\mathrm{K}_{\max }$ is introduced at $776 \mathrm{~h}$ (Figures 8 and 9). This produces a slight acceleration in crack growth rate, as expected for the slightly more aggressive loading conditions. At $895 \mathrm{~h}$, the loading is returned to constant $\mathrm{K}$ conditions, with load shedding on a regular basis (typically load is shed in $\approx 5 \mathrm{lb}$ increments). The SCC response is quite well behaved, and at 2,073 h, the test was ended. The specimen was disassembled from the autoclave, put into a sealed plastic pouch, and shipped to PNNL. 


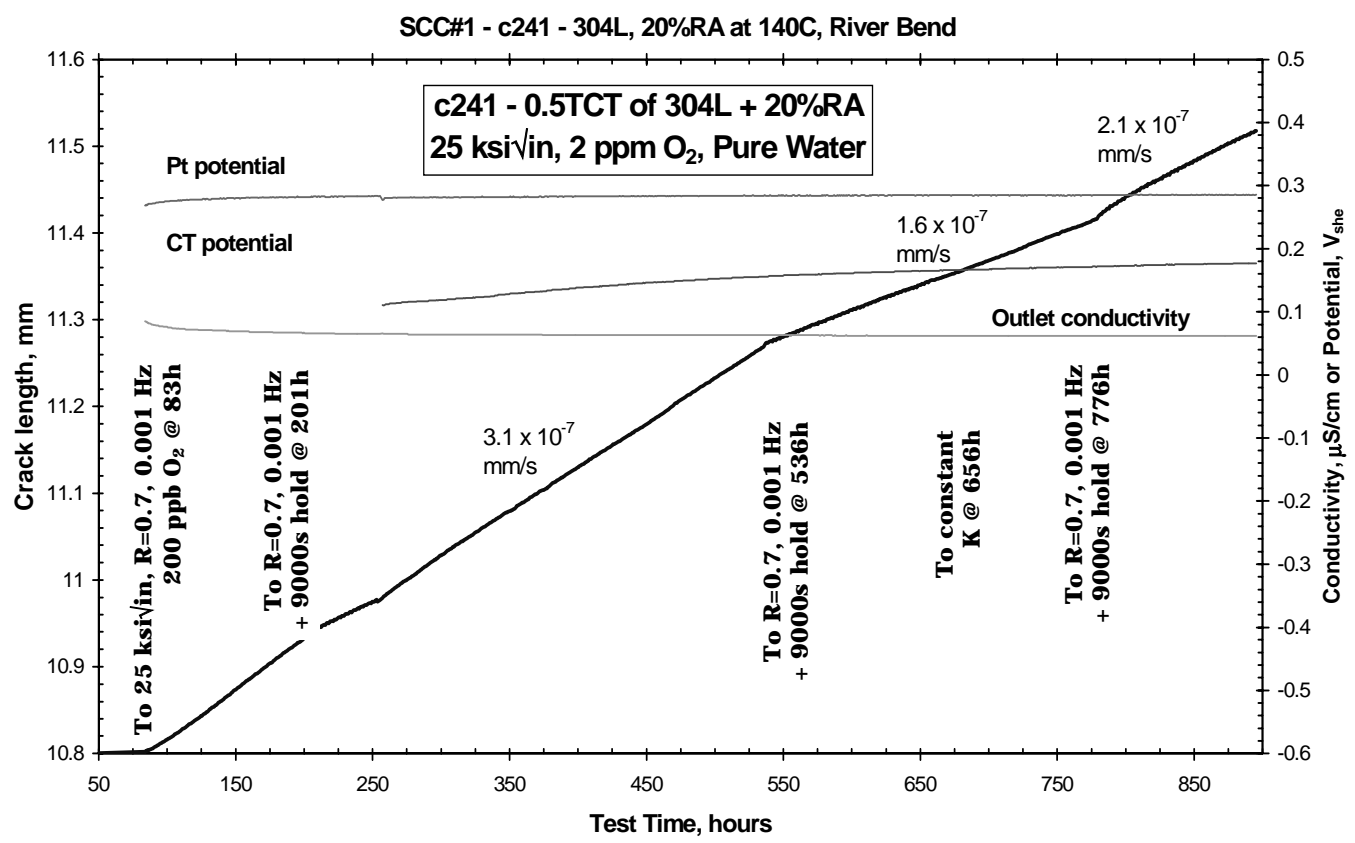

Figure 8. Transitioning and early SCC response of warm-worked 304L stainless steel (River Bend shroud) tested in $288^{\circ} \mathrm{C}$ pure water.

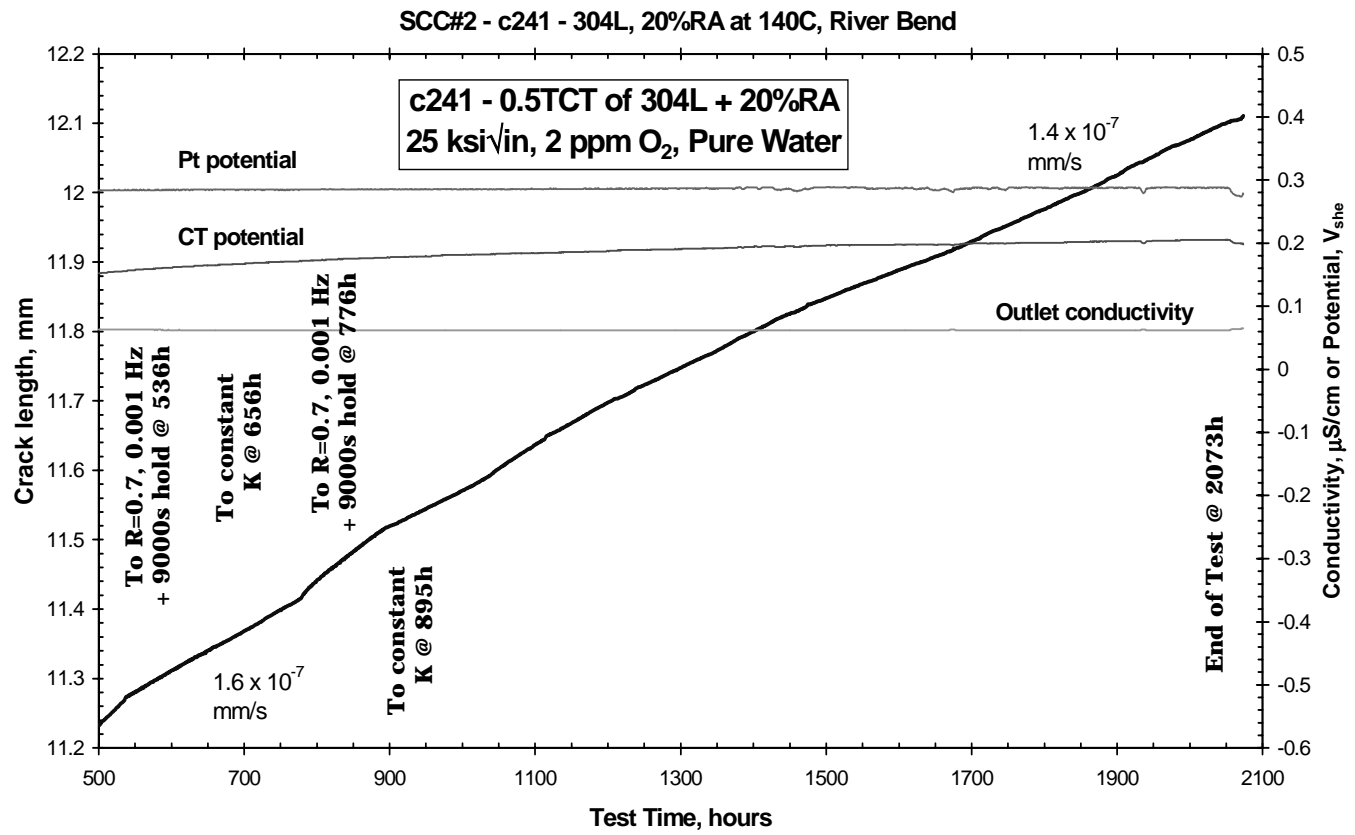

Figure 9. SCC response of warm-worked $304 \mathrm{~L}$ stainless steel tested in $288^{\circ} \mathrm{C}$ pure water.

Type 316L Stainless Steel (c242, heat A14128) in BWR Water. The overview and air-fatigue precracking response of warm-worked $\left(20 \%\right.$ reduction in thickness at $\left.140^{\circ} \mathrm{C}\right)$ stainless steel specimen c241 are shown in Figures 10 and 11. The specimen was assembled into the autoclave at $\approx 83 \mathrm{~h}$, and Figure 12 shows the initial environmental cracking response in $288^{\circ} \mathrm{C}$ in water containing $2000 \mathrm{ppb} \mathrm{O}$. 


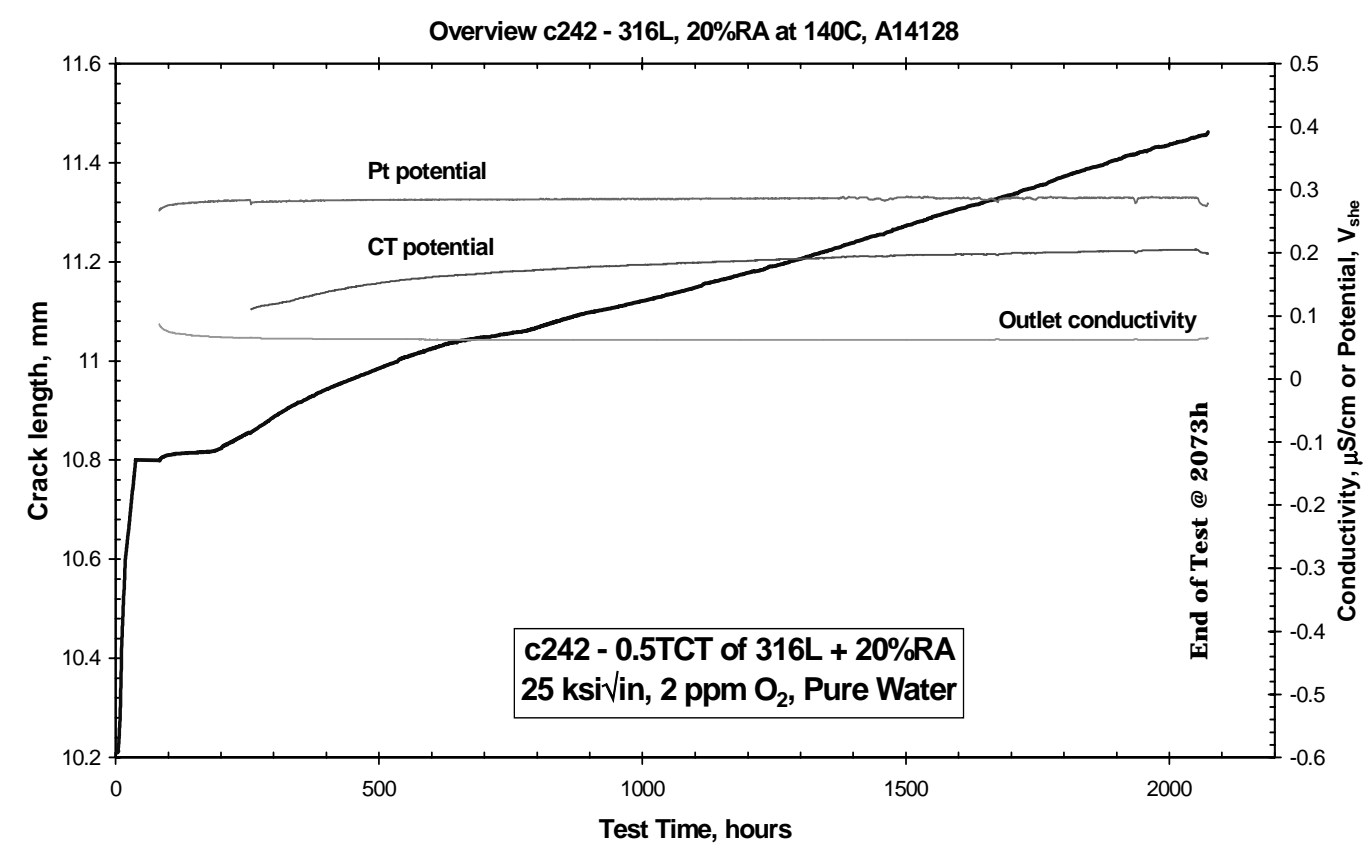

Figure 10. Overview of SCC growth rate response of warm-worked 316L stainless steel (heat A14128) tested in $288^{\circ} \mathrm{C}$ pure water.

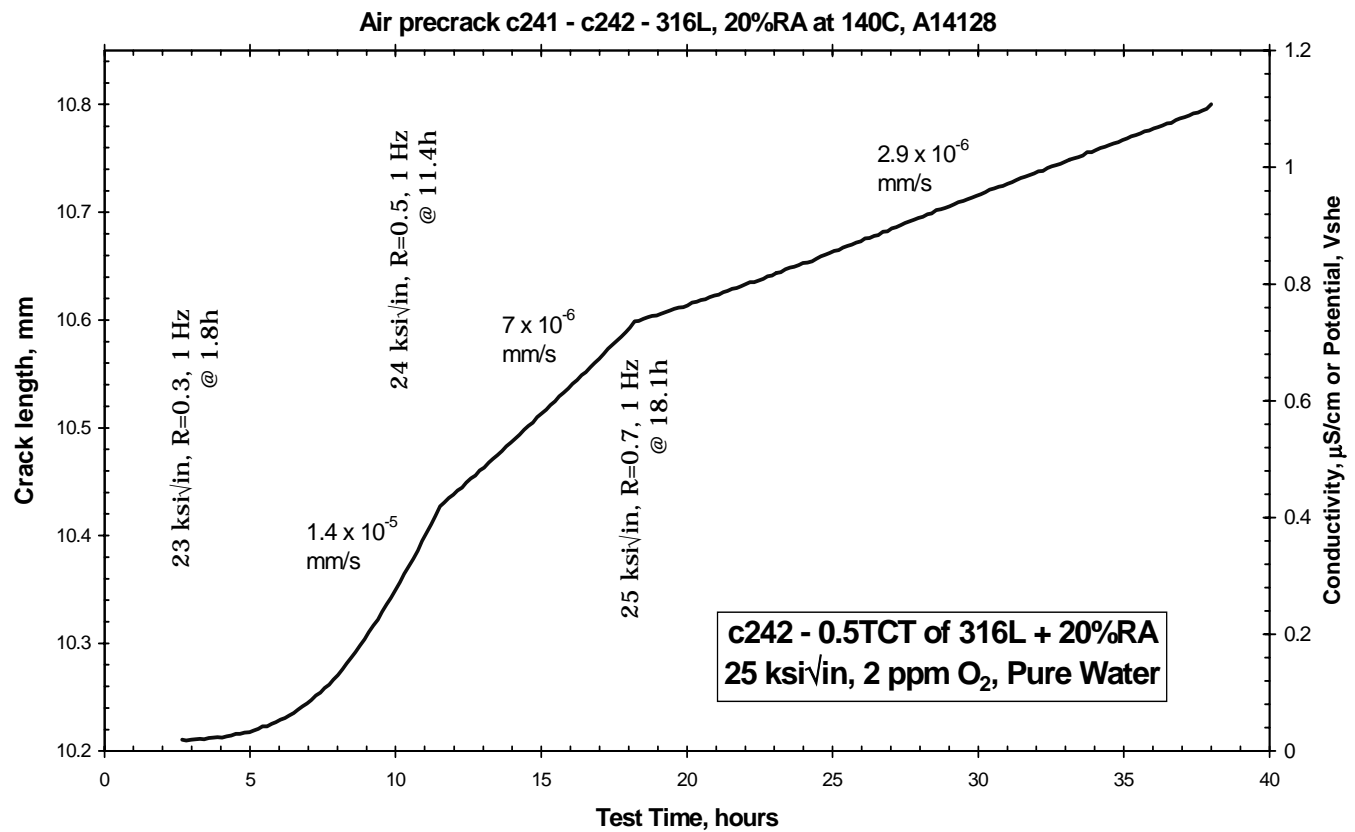

Figure 11. Air fatigue precracking response of warm-worked 316L stainless steel (heat A14128) tested in $288^{\circ} \mathrm{C}$ pure water.

It is unwise to assume that an accurate or reproducible stress corrosion crack growth rate can be obtained if a specimen with an air fatigue precrack is simply loaded and exposed to the environment. Fatigue cracks possess both a highly hardened plastic zone and a transgranular crack morphology; stress corrosion cracking in these materials occurs intergranularly and under monotonic loading. Thus, a slow, controlled transition must be made to static load conditions (or 


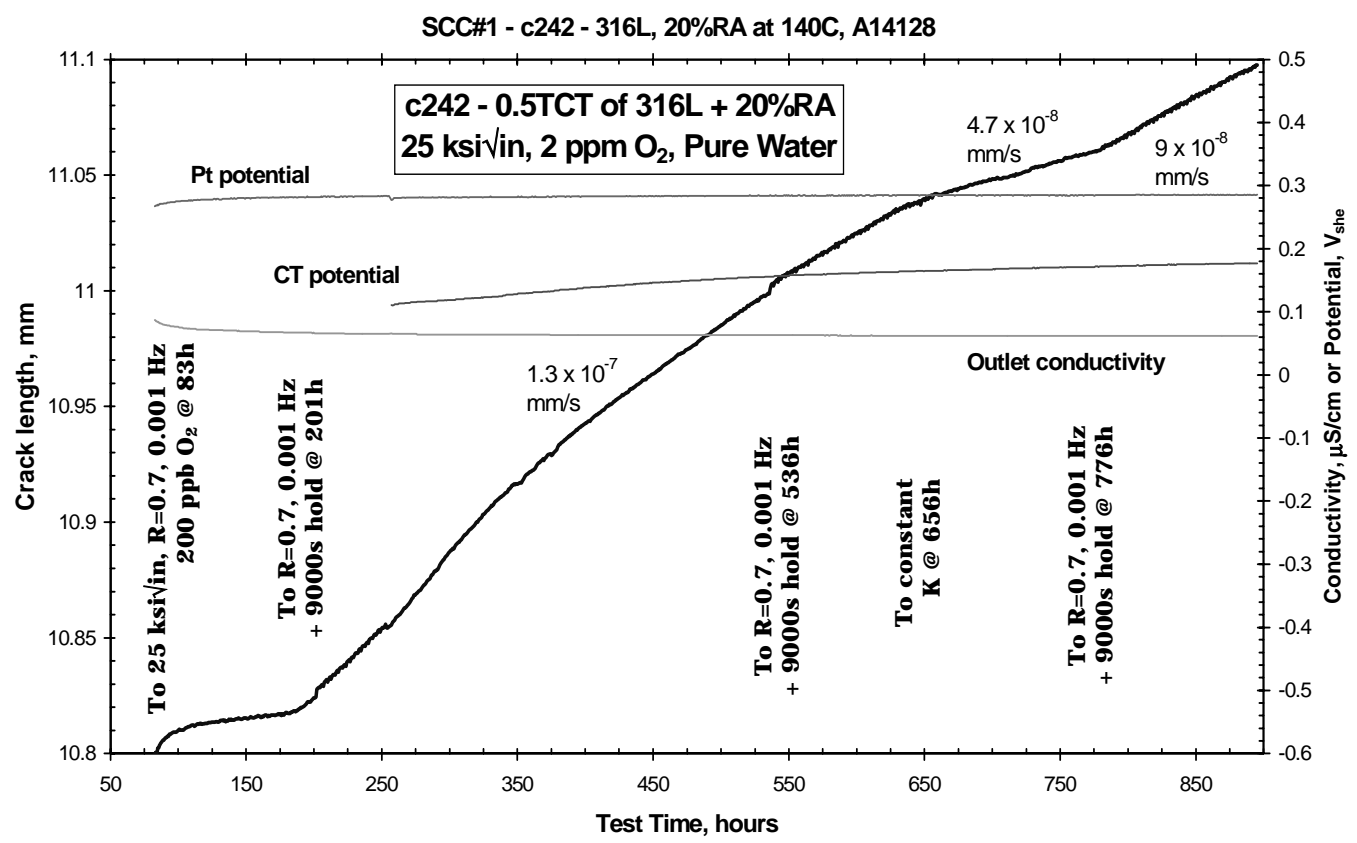

Figure 12. Transitioning and early SCC response of warm-worked 316L stainless steel (heat A14128) tested in $288^{\circ} \mathrm{C}$ pure water.

constant stress intensity factor conditions, which requires load shedding as the crack grows) as the crack shifts to an intergranular morphology. During fatigue precracking, this transition is partially accomplished by increasing the load ratio, $\mathrm{R}$, to 0.7 .

Gentle cycling under similar conditions is employed during initial testing in high temperature water to encourage the entire crack front to continue to grow and transition to intergranular SCC. Low frequency, low stress intensity amplitude $(\Delta \mathrm{K})$ conditions with a load ratio, $\mathrm{R}=0.7$ and $0.001 \mathrm{~Hz}$ is typically used. A hold time at $\mathrm{K}_{\max }$ is then introduced, e.g., of 9,000 s, then if the response is well-behaved, constant $\mathrm{K}$ conditions are implemented (Figure 12).

Well behaved and reproducible response is verified by returning to a $9,000 \mathrm{~s}$ hold at $\mathrm{K}_{\max }$ at $776 \mathrm{~h}$ (Figures 12 and 13). A slight acceleration in crack growth rate occurs, as is expected for the slightly more aggressive loading conditions. At $895 \mathrm{~h}$, the loading is returned to constant $\mathrm{K}$ conditions, with load shedding on a regular basis (typically load is shed in $\approx 5$ pounds increments). The SCC response is quite well behaved, and at 2,073 h, the test was ended. The specimen was disassembled from the autoclave, put into a sealed plastic pouch, and shipped to PNNL.

Alloy 600 (c252, heat 3110439) in BWR Water. Figures 14 and 15 show the overview and air fatigue precracking response of cold-worked alloy 600 specimen c252. This material has been cross-rolled to $28 \%$ reduction in thickness at room temperature, and is being supplied by GE Research for an international Round Robin on SCC testing that involves 23 laboratories throughout the world.

After air fatigue precracking, the specimen was assembled into the autoclave at $\approx 46 \mathrm{~h}$, and Figure 16 shows the initial environmental cracking response in $288^{\circ} \mathrm{C}$ water containing $2000 \mathrm{ppb}$ 


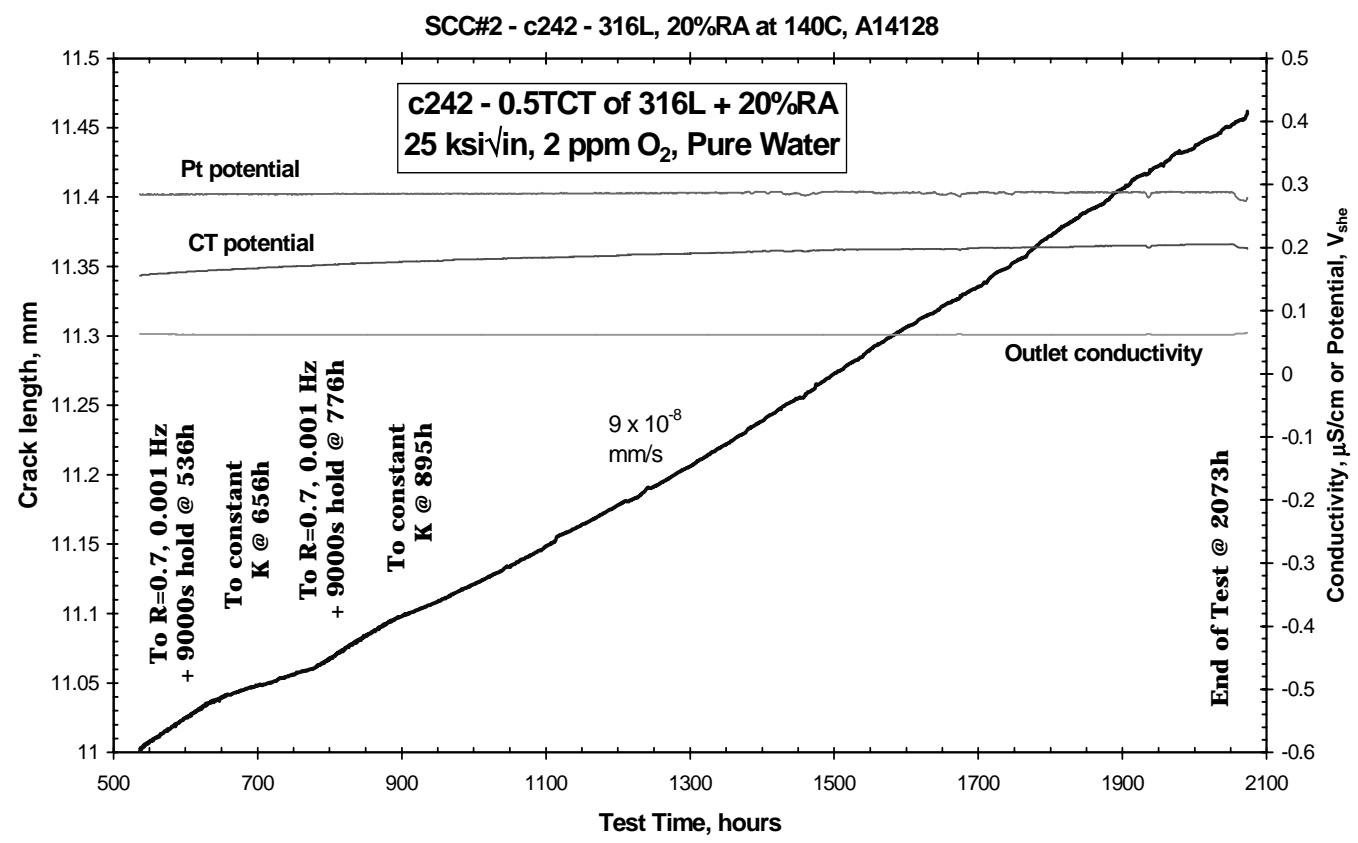

Figure 13. SCC response of warm-worked 316L stainless steel (heat A14128) tested in $288^{\circ} \mathrm{C}$ pure water.

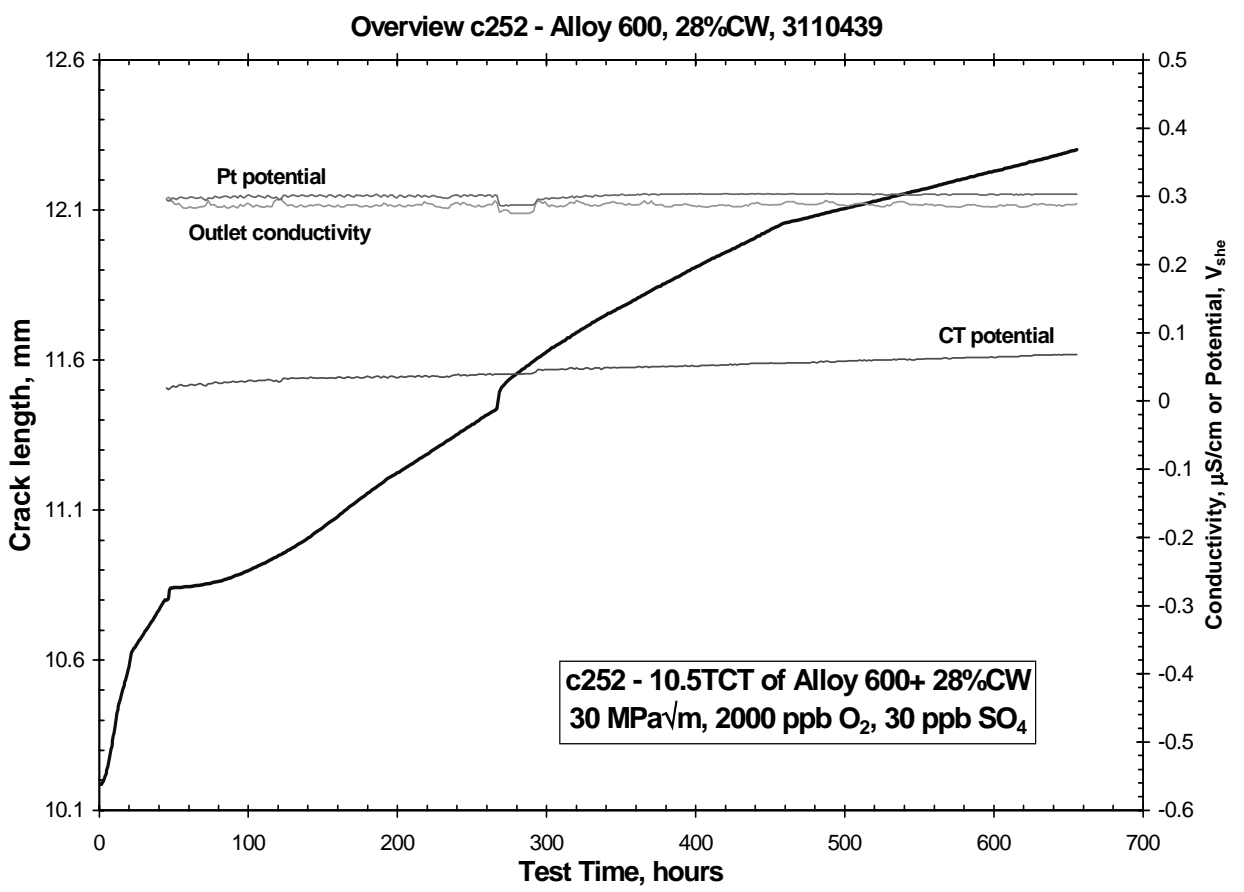

Figure 14. Overview of SCC growth rate response of cold-worked Alloy 600 (heat 3110439 ) tested in $288^{\circ} \mathrm{C}$ water with $2000 \mathrm{ppb} \mathrm{O}_{2}$ and $30 \mathrm{ppb}$ sulfate.

$\mathrm{O}_{2}$ and $30 \mathrm{ppb}$ sulfate as $\mathrm{H}_{2} \mathrm{SO}_{4}$. As in other tests, a transition from transgranular fatigue to intergranular SCC is achieved by loading at $30 \mathrm{MPa} \sqrt{\mathrm{m}}, \mathrm{R}=0.7,0.001 \mathrm{~Hz}$. Over the next $50-$ $100 \mathrm{~h}$, the initially sluggish crack growth response approaches a steady state value. 


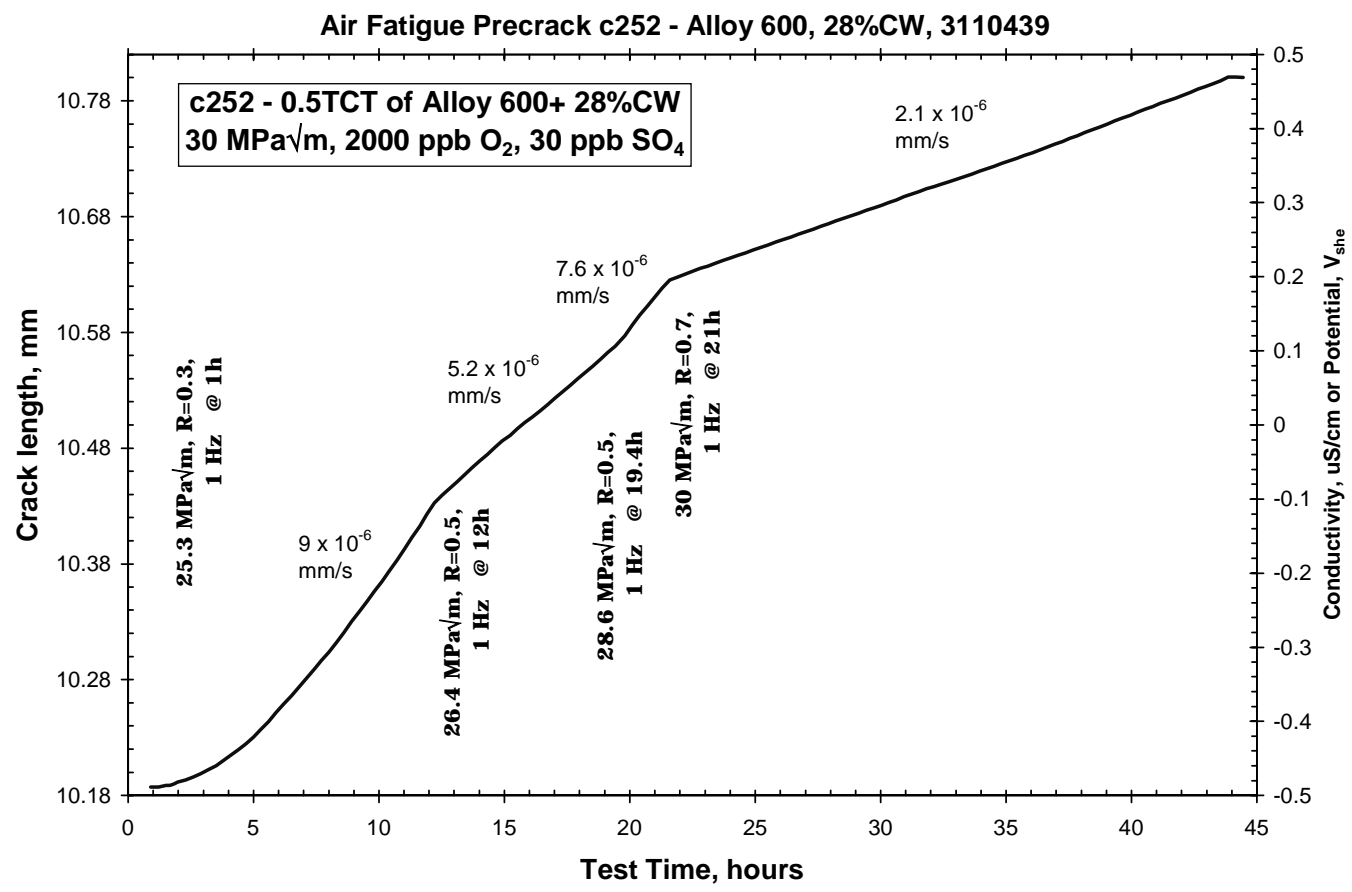

Figure 15. Air fatigue precracking response of cold-worked Alloy 600 (heat 3110439 ) tested in $288^{\circ} \mathrm{C}$ water with $2000 \mathrm{ppb} \mathrm{O}_{2}$ and $30 \mathrm{ppb}$ sulfate.

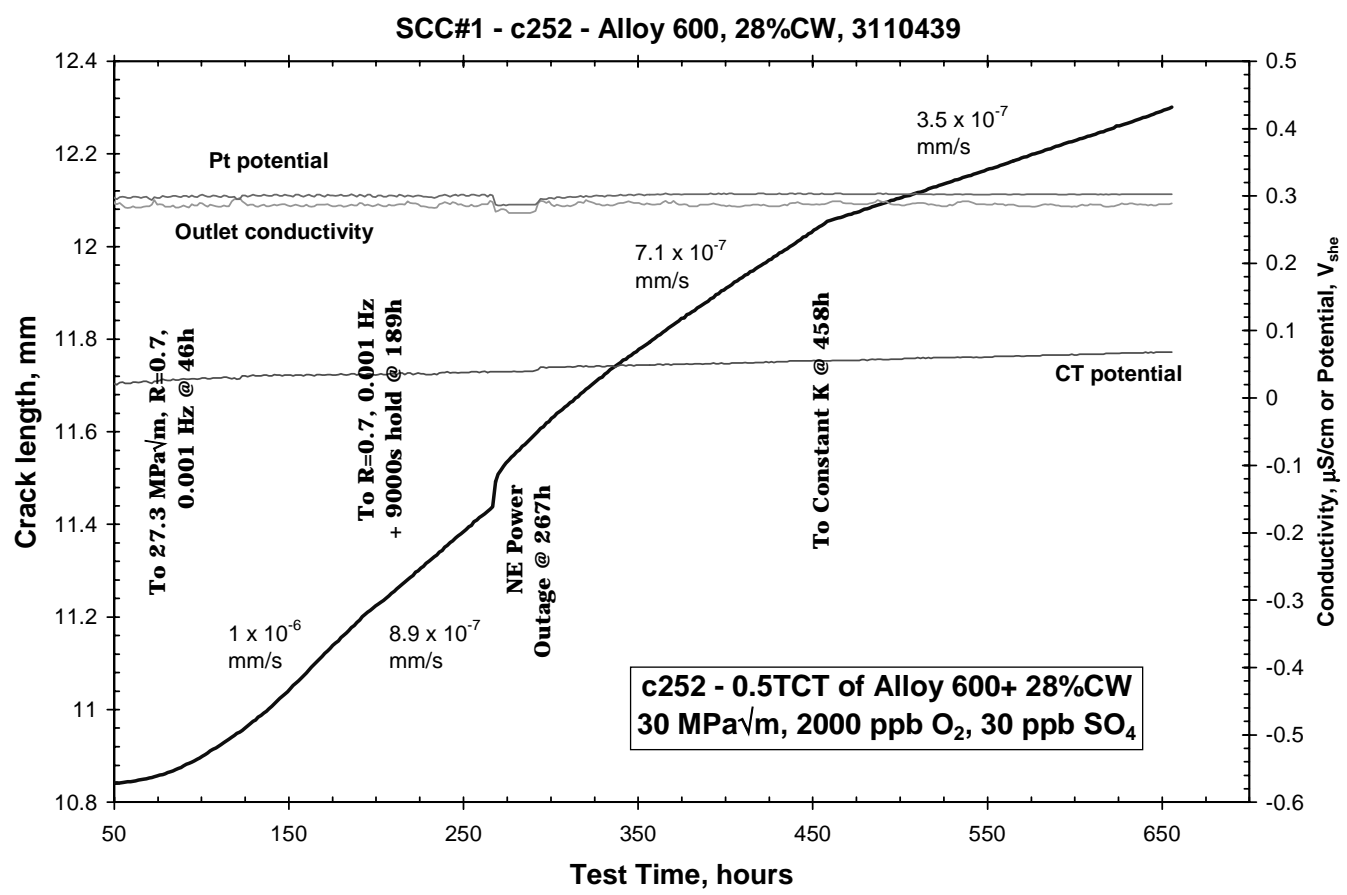

Figure 16. Transitioning and early SCC response of cold-worked Alloy 600 (heat 3110439 ) tested in $288^{\circ} \mathrm{C}$ water with $2000 \mathrm{ppb} \mathrm{O}_{2}$ and $30 \mathrm{ppb}$ sulfate.

The transition to a 9,000 s hold time at $\mathrm{K}_{\max }$ is very smooth, with only a limited change in crack growth rate (Figure 16). The power outage in the Northeast in early August 2003 caused the 
specimen to be unloaded and cooled for several days, and produced a slight transient response when the test was restarted. The eventual change at $458 \mathrm{~h}$ to constant $\mathrm{K}$ testing was also very well-behaved, and a stable growth rate has been observed throughout the last $200 \mathrm{~h}$ of testing. The test remains in progress.

Cold-Worked Alloy 600 (c253, heat 3110439) in PWR Water. This alloy 600 material was in the same cross-rolled condition (28\% reduction in thickness at room temperature) as for the previous test. The specimen has been air-fatigue precracked, and is in the process of being installed in an autoclave where it will be tested at $325^{\circ} \mathrm{C}$ in PWR primary water (about 1500 ppm $\mathrm{B}$ as $\mathrm{H}_{3} \mathrm{BO}_{3}$, $2 \mathrm{ppm} \mathrm{Li}$ as $\mathrm{LiOH}$, and $30 \mathrm{cc} / \mathrm{kg} \mathrm{H}_{2}$ ). The high-temperature water phase of testing should commence by mid-September.

Cold-Worked Alloy 600 (c254, heat 67167) in PWR Water. This second heat of alloy has been cross-rolled to $26 \%$ reduction in thickness at room temperature reaching a similar yield strength condition as for the heat 3110439 samples. As above, the specimen has been air-fatigue precracked, and is in the process of being installed in an autoclave where it will be tested at $325^{\circ} \mathrm{C}$ in PWR primary water (about $1500 \mathrm{ppm} \mathrm{B}$ as $\mathrm{H}_{3} \mathrm{BO}_{3}, 2 \mathrm{ppm} \mathrm{Li}$ as $\mathrm{LiOH}$, and $30 \mathrm{cc} / \mathrm{kg}$ $\mathrm{H}_{2}$ ). The high-temperature water phase of testing should commence by mid-September.

\section{Future Plans}

Many possible relevant materials and conditions, and environments (temperature and water chemistries) exist. A tentative listing has been developed in consultation with PNNL (shown below). It is anticipated that the tests and priorities may be adjusted as the crack tip characterization is performed.

- $20 \%$ warm-worked type 304L SS in BWR water - done.

- $20 \%$ warm-worked type 316L SS in BWR water - done.

- $28 \%$ cold-worked Alloy 600 in BWR water - in progress.

- $28 \%$ cold-worked Alloy 600 in PWR primary water at $325^{\circ} \mathrm{C}$ - in progress.

- Sensitized type 304 SS in BWR water.

- Sensitized type 304 SS in BWR water containing high $\mathrm{SO}_{4}$ (e.g., 100 ppb).

- Alloy 182 weld metal in BWR water containing high $\mathrm{SO}_{4}$ (e.g., 100 ppb).

- $20 \%$ warm-worked type 304 SS in BWR water.

- $20 \%$ warm-worked type $304 \mathrm{SS}$ in PWR primary water at $325^{\circ} \mathrm{C}$.

- Alloy 182 weld metal in BWR water.

- Alloy 182 weld metal in PWR primary water at $325^{\circ} \mathrm{C}$.

- $20 \%$ cold-worked Alloy 600 in PWR primary water at $290^{\circ} \mathrm{C}$.

- $20 \%$ warm-worked "304L SS" with 3\% Si in BWR water. 


\section{Task B. Crack-Tip Characterizations}

\section{Background and Approach}

The goal of this task is to generate a library of high-resolution, crack-tip "fingerprints" of different known mechanisms of environmental cracking (samples from Task A), which can then be used to verify model predictions (Task C) and for comparisons with in-service cracking (Task D). The ATEM technique has proved particularly effective in discriminating different mechanisms of degradation in Ni-base alloy, steam-generator tubes and in stainless steel components removed from high-temperature water service.

Crack-tip cross-section preparation methods are used to backfill, section, thin and polish cracked samples. The general steps required leading to optimum preparation of a TEM disc for highresolution characterization require a series of mechanical polishing and resin back filling steps before final ion milling for TEM examination. Experience has shown that oxidized but uncracked grain boundaries are extremely difficult to locate by optical metallography without prior deformation of the specimen or chemical etching of the cross-section surface. These are clearly unacceptable for the purposes of this investigation. However, secondary-ion mass spectroscopy and field-emission-gun (FEG) scanning electron microscopy (backscattered electron images) have proved highly effective in locating such damage and will be used to document the extent of degradation and guide preparation for high-resolution ATEM using a FEG TEM ( 0.75 nm incident probe). Examinations focus on the crack-tip regions documenting corrosion films and the corrosion-induced material changes ahead of the tip. A variety of ATEM methods are employed to fully characterize the corrosion-affected nanostructure. Lattice imaging and nano-diffraction is employed to determine the structure of thin corrosion films that will be present at the tip and along crack walls. High-resolution microchemical analysis is also performed using energy dispersive x-ray spectroscopy and electron energy loss spectroscopy. This combination of techniques allows the identification of specific oxide and hydroxide phases at the tip involved in the crack advance mechanism. In addition, deformation structures surrounding the oxidized crack-tip are being characterized to assess localized slip and the micromechanics of cracking. These unique crack and crack-tip characteristics will be catalogued for each specific mechanistic condition defined in Task A.

\section{Alloy 182 Weld Metal}

\section{Microstructural Analysis}

The materials examined in this work came from alloy 182 butt welds between the low-alloy steel reactor pressure vessel outlet (hot-leg) nozzles and stainless-steel safe ends. These welds were made by manual arc welding with alloy 182 filler material and did not receive stress-relief heat treatment. Planar axial cracking was indicated by in-service ultrasonic and eddy current inspections and confirmed by SEM and optical metallography of 'boat' samples taken by electrodischarge machining (EDM). Initial characterization of the boat samples was reported by Jenssen, et al. [7] They found that the cracks did not extend into the RPV steel or stainless steel but occurred along the "interdendritic" grain boundaries of the weld metal and showed evidence of both SCC and hot cracking.

Samples for ATEM examination were taken from two boat samples. The TEM samples were prepared from both longitudinal (parallel to the pipe ID surface) and transverse axial sections cut 
from the boats. These samples were examined at depths ranging from $\sim 1 \mathrm{~mm}$ to $6 \mathrm{~mm}$ below the pipe ID surface.

Cross-section TEM samples containing cracks were prepared from the as-received metallographic samples by methods similar to those described previously. [8] In brief, thin slices were cut by slow-speed diamond sawing after backfilling with a low-viscosity resin to protect cracks, metallographically polished, and glued to 3-mm-diameter washers with targeted crack areas at the washer centers. After excess material was trimmed away, the disk samples were dimple ground from the washer side to $\sim 15 \mu \mathrm{m}$ thickness. Ion milling with $5 \mathrm{keV}$ argon ions at $\pm 6^{\circ}$ incidence was used to remove mechanically damaged surface layers before SEM characterization, and was later continued to obtain thin areas suitable for TEM analysis. Final ion milling for TEM was performed at reduced energy and beam incidence $\left(2 \mathrm{keV}, \pm 4^{\circ}\right)$ to minimize radiation damage such as small dislocation loops near the sample surfaces. Repeated cycles of ion milling and examination were used to obtain suitably thin areas of the crack tips and leading grain boundaries.

Before final thinning, samples were examined in the SEM by backscattered electron (BSE) imaging. These images revealed the large-scale characteristics of cracks and second-phase particles by average-atomic-number contrast, and showed the grain structures by crystallographic orientation contrast. Also, elemental maps of the structures were obtained by energy-dispersive $\mathrm{x}$-ray spectrometry (EDS), using an x-ray detector sensitive to elements as light as boron. X-ray maps taken in the SEM had resolutions down to few $\mu \mathrm{m}$, limited by beam spreading in the samples. Analytical TEM was performed with a $200 \mathrm{kV}$ field-emission-gun (FEG) microscope using a wide variety of methods for high-resolution microstructural imaging and analysis. Fineprobe EDS analysis (also with a light-element-sensitive detector) was used to measure grainboundary, precipitate and corrosion-product chemistries at spatial resolutions as low as $\sim 1 \mathrm{~nm}$. EDS mapping in a scanning-transmission mode showed elemental distributions at instrumental drift-limited resolutions as low as $\sim 2 \mathrm{~nm}$. An electron-energy-loss spectrometer (EELS) in the TEM provided supplemental analyses of precipitate phases.

Figure 17 shows the microstructure in two cracked samples as revealed by SEM/BSE imaging after the samples were polished and etched. Crystallographic orientation contrast in the BSE images indicated that the cracks followed grain boundaries in the weld metal. Apparent grain sizes in the samples ranged from $<10 \mu \mathrm{m}$ to several hundred $\mu \mathrm{m}$. One sample (Figure 17a) has a substantially larger grain size than the other which might be the result of repair welding or a post-weld surface heat treatment these welds are sometimes given. Although TEM examinations showed that many small grains were subgrains delineated by low-angle boundaries, the cracking appeared limited to high-angle boundaries.

Higher magnification SEM/BSE images as shown in Figure 18 also revealed many sub- $\mu$ m-size second-phase intragranular particles aligned in periodic structures related to the grain orientations. SEM/EDS analyses indicated that the particles were of mainly two types. The lighter-appearing particles were $\mathrm{Nb}$ carbide, and the darker ones were mostly Ti oxide or Ti-Al oxide. Initially the $\mathrm{Nb}$ carbides were identified as borocarbides based on EDS spectra showing a small peak at the B-K position. However, further investigation revealed that the 'boron' peak was in fact a minor $\mathrm{Nb}$ peak, and supplemental TEM/EELS analyses confirmed that the particles contained no significant boron. Frequent coincidences of the darker oxide particles with the centers of the lighter particles suggested that the $\mathrm{Nb}$ carbides had formed around some of the 


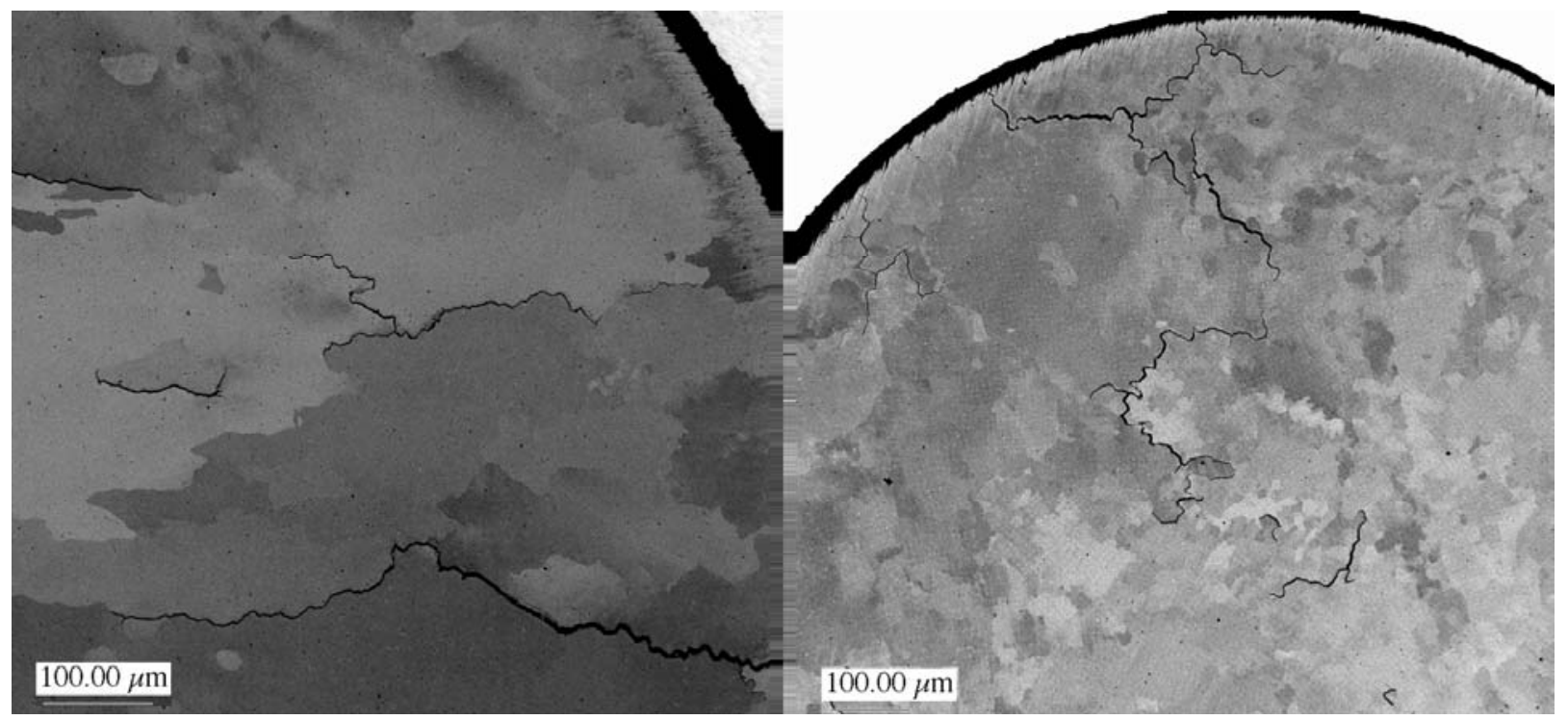

Figure 17. SEM images of two cracked alloy 182 weldments. Cracks occur along high-angle grain boundaries. The grain size of the weld on the left is much larger than the weld on the right, possibly as a result of post-weld heating.

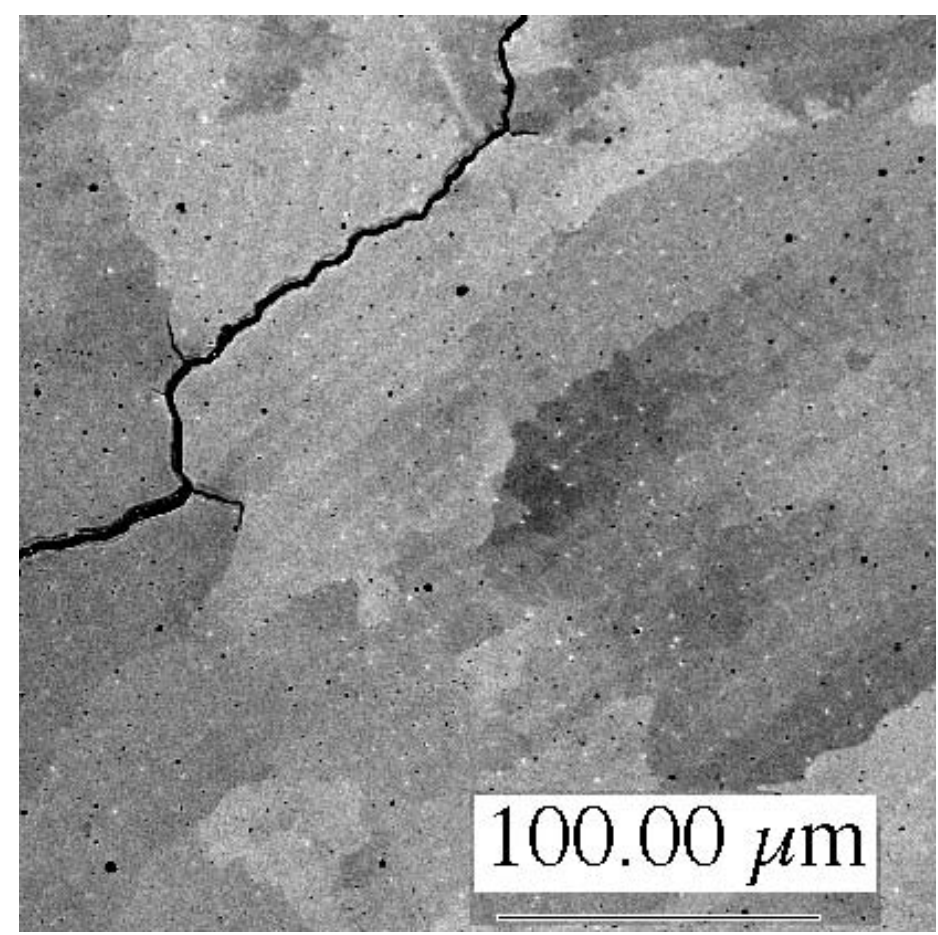

Figure 18. SEM image of a weld revealing high-angle grain boundaries, subgrain boundaries, and the regular array of $\mathrm{NbC}$ (white) particles and the more random Ti-based (dark) particles.

oxide particles. Although average-atomic-number compositional contrast in BSE images clearly showed the second-phase particles in the grain interiors, this imaging mode showed no discernible phase separation, precipitate decoration or compositional fluctuation associated with the cracked grain boundaries. 
EDS elemental mapping of the metallographically polished samples in the SEM further revealed distinctive compositional coring throughout the alloy grain interiors. The maps, shown for example in Figure 19, indicated cellularly segregated structures with regions of local Mn enrichment corresponding to $\mathrm{Fe}$ and $\mathrm{Cr}$ depletion. As another sign that the weld region in Figure 19 had seen significant post-weld heating, similar elemental maps of that sample did not reveal a high degree of compositional coring.

Despite the sectioning/orientational difference between several of the samples with respect to the solidification direction, all the samples showed similar coring periodicities. This observation indicated that the cellular segregation did not depend on the weld solidification direction. The maps in Figure 19 show a typical structure and could have come samples with different orientations. Superimposing same-area maps of different elements showed a nearly 1:1 correspondence between the $\mathrm{Mn}$-rich regions and $\mathrm{Nb}$-rich spots (clearly $\mathrm{NbC}$ particles). Some of the $\mathrm{NbC}$ particles also coincided with Ti concentrations (later identified as Ti-Al oxide particles), but other Ti-oxide particles occurred at random throughout the metal grains. EDS point analysis measurements of high- and low-Mn regions in the cored structures indicated a Mn difference of only $4 \mathrm{wt} \%$, with $\sim 9 \mathrm{wt} \%$ near the NbC particles. These measurements were done in the TEM to avoid the spatial-resolution limitations of SEM/EDS. The x-ray maps also showed no significant Mn enrichment or precipitation along cracks or leading grain boundaries.

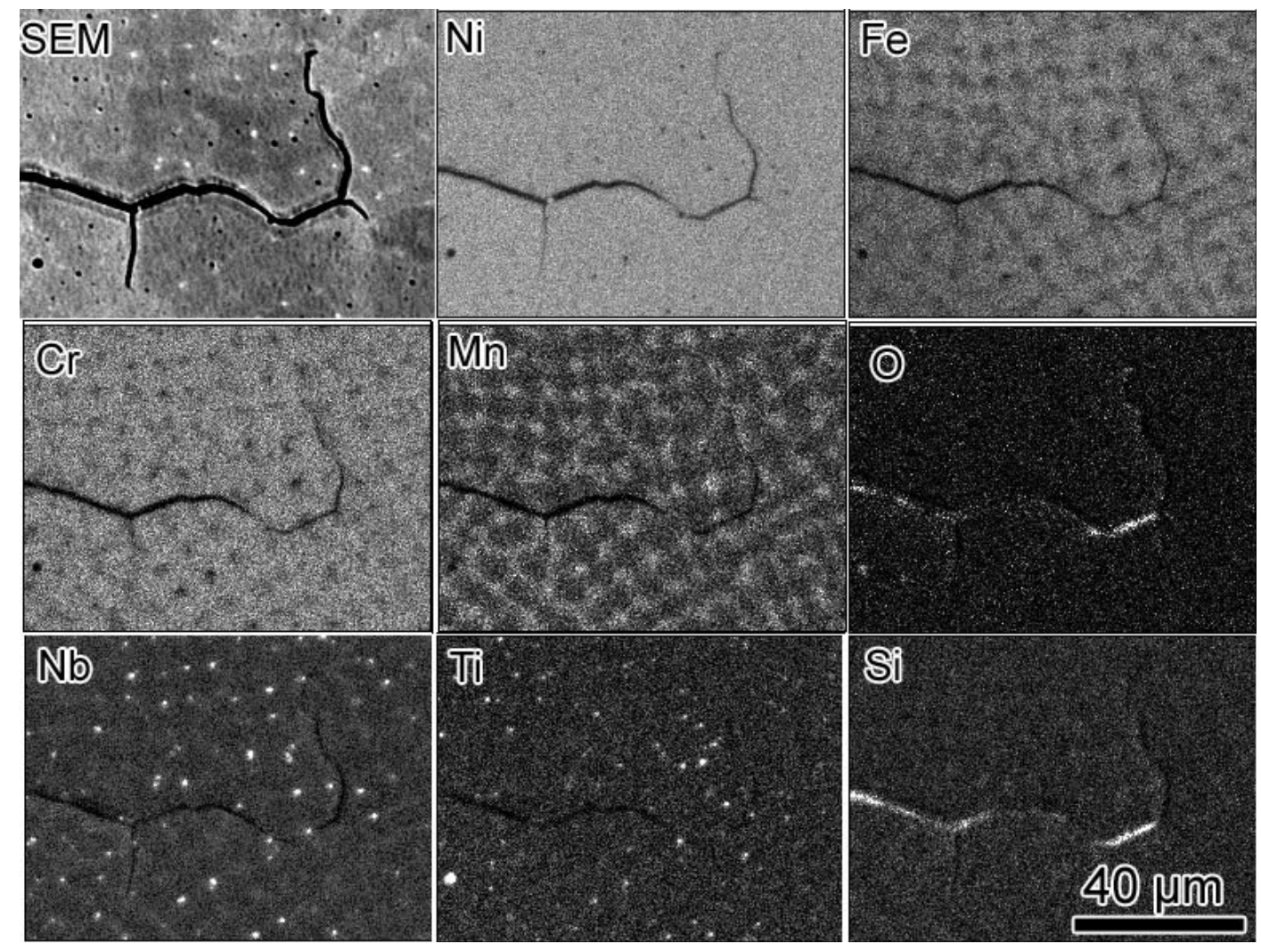

Figure 19. SEM/EDS x-ray maps of alloy 182 weld-crack region. Maps show cellular segregation and precipitation in metal matrix. Nb carbides correlate to high-Mn regions. Cracks occurred along normal grain boundaries unrelated to weld dendrites; contained oxide with high $\mathrm{Si}$ in places. 


\section{Crack Tip Morphology}

TEM observations of the weld-metal microstructures away from or slightly ahead of cracks in several samples showed high dislocation densities in the matrix and intragranular precipitates generally limited to the large $(0.3$ to $1 \mu \mathrm{m}) \mathrm{NbC}$ and Ti oxide particles seen by SEM. Electron diffraction and EDS analyses identified the predominant particle type as $\mathrm{NbC}$ (MC carbides). These particles, found in the Mn-rich regions, occasionally had Ti-Al oxide particles at the centers. Ti oxide and Ti-Al oxide particles with no compositionally differentiated shell also occurred at random throughout the matrix. A third common particle type consisted of Ti-Al oxide particles with Ti nitride shells. Diffraction pattern analysis and dark-field imaging showed no indication of any fine-scale $\gamma^{\prime}$ or MC-carbides in the matrix.

High-angle grain boundaries in the weld metal also showed very limited precipitation and no detectable impurity segregation. Several grain boundaries investigated by selectively thinning the samples just ahead of crack tips contained scattered MC carbides and long precipitate-free spans. Figure 20 shows examples of these structures. The image-contrast conditions of Figure 19(a) reveal the high dislocation density of the matrix in one grain. Small particles identified as $\mathrm{MC}$, where $\mathrm{M}=\mathrm{Nb}+\mathrm{Ti}$, appear on the boundary. Typical sizes of the intergranular $\mathrm{MC}$ particles were 10 to $30 \mathrm{~nm}$. Figures 20(b and c) are a bright-field/precipitate dark-field pair showing the MC particles with a parallel orientation to one of the metal grains. In this example, the dislocations are not visible. Fine-probe EDS analyses on the grain boundaries showed minor amounts of segregation and depletion of major alloying elements such as $\mathrm{Cr}(13 \% \mathrm{bulk}, 9 \%$ boundary) and Mn (8\% bulk, 10\% boundary) and no segregated impurities such as S, P or Si. Although the particles on boundaries immediately leading cracks did not include Cr carbides, examples of minor $\mathrm{Cr}$-carbide precipitation were observed at random high-angle boundaries in the weld metal away from the cracks.
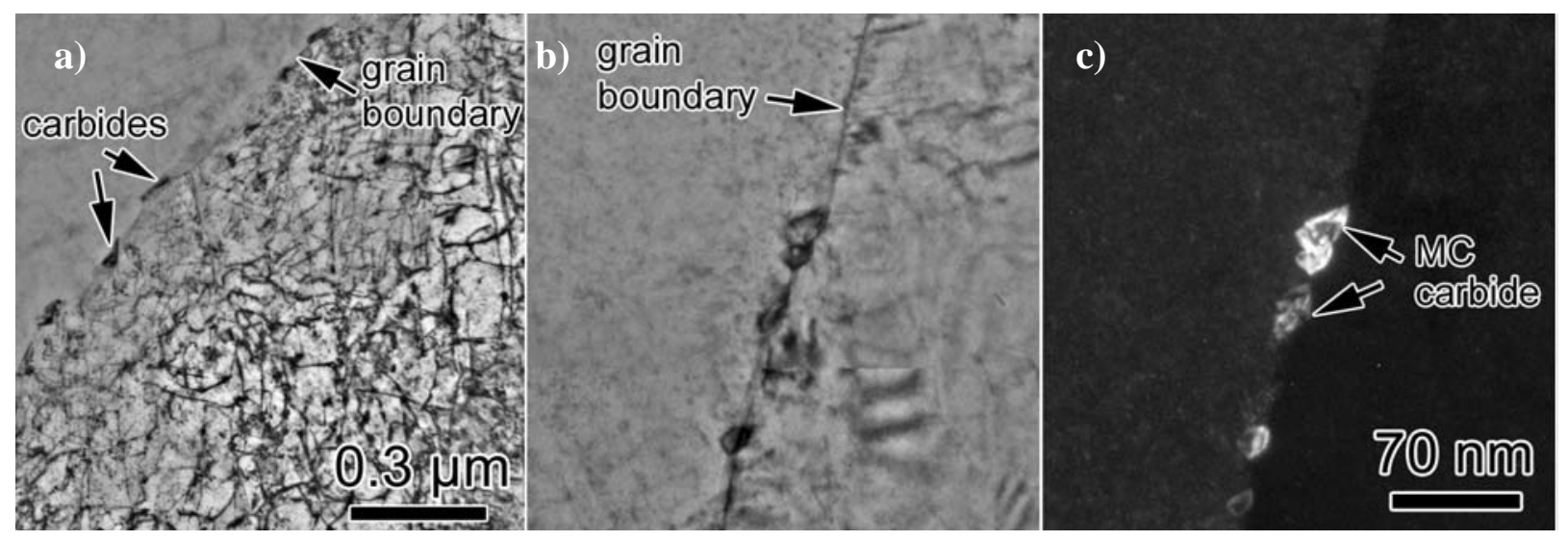

Figure 20. Base microstructure in Alloy 182 weld in the TEM. Dislocation structure on one side of grain boundary is shown on left, and boundary tilted parallel to viewing direction is shown in bright field in center (with dislocations invisible) and using precipitate darkfield image on right.

TEM examinations of open cracks in were performed in several samples and showed a variety of features including oxides, phase separation and some unusual "worm holes" that are apparently oxide tunnels that are perhaps formed along dislocations. One example of a crack tip is presented here and shows predominantly spinel-structure $\mathrm{Ni}-\mathrm{Cr}-\mathrm{Fe}$ oxides both as unconsolidated fill and as corrosion product layers along the crack walls. The oxide compositions varied widely and tended to show enrichment of $\mathrm{Cr}, \mathrm{Nb}$ and $\mathrm{Mn}$ compared to the metal matrix. Narrow crack 
branches off along the major cracks in this material contained apparent corrosion structures consisting of locally alternating $\mathrm{Cr}$-enriched $\mathrm{Ni}-\mathrm{Cr}-\mathrm{Fe}$ spinel oxide and Ni-rich metal. $\mathrm{Ni}$ concentrations in the metal regions of the degraded structures were found as high as $\sim 95 \%$. Figure 21 shows an example of this duplex structure with EDS x-ray maps indicating the oxide and Ni-metal regions. The sample area was $\sim 4 \mathrm{~mm}$ below the pipe ID surface. No unusual concentrations or depletions of other alloying elements were observed at these degraded boundaries, and the structures were generally free of welding impurities. An example of the "tunnels" around the crack is shown in the TEM image of Figure 22, defocused to reveal their structure and morphology.

Several TEM observations in this work indicated that the cracks propagated by SCC in hightemperature water. These included Ni-Cr-Fe-spinel and Ni-silicate corrosion products that apparently formed in water, and microstructural characteristics of cracks similar to IGSCC in alloy 600 tubing. [8, 9] Alternating Ni-metal and $\mathrm{Cr}$-enriched oxide regions observed in narrow cracks and crack tips in the weld samples matched structures seen in alloy 600 cracks produced in PWR primary water. Formation of Ni-rich metal during SCC is considered an indication of local crack conditions in electrochemical regimes near the $\mathrm{Ni} / \mathrm{NiO}$ stability line. Tunnel-like degradation observed along crack walls in several samples appeared unique to this material. High-resolution TEM analyses of these structures, although incomplete, indicated that the 'tunnels' were spinel oxide penetrations formed along dislocations to depths of $\sim 100 \mathrm{~nm}$ at the crack surfaces. These structures have not been found in SCC cracks produced in alloy 600 in a wide variety of primary- or secondary-water environments. [8-11]

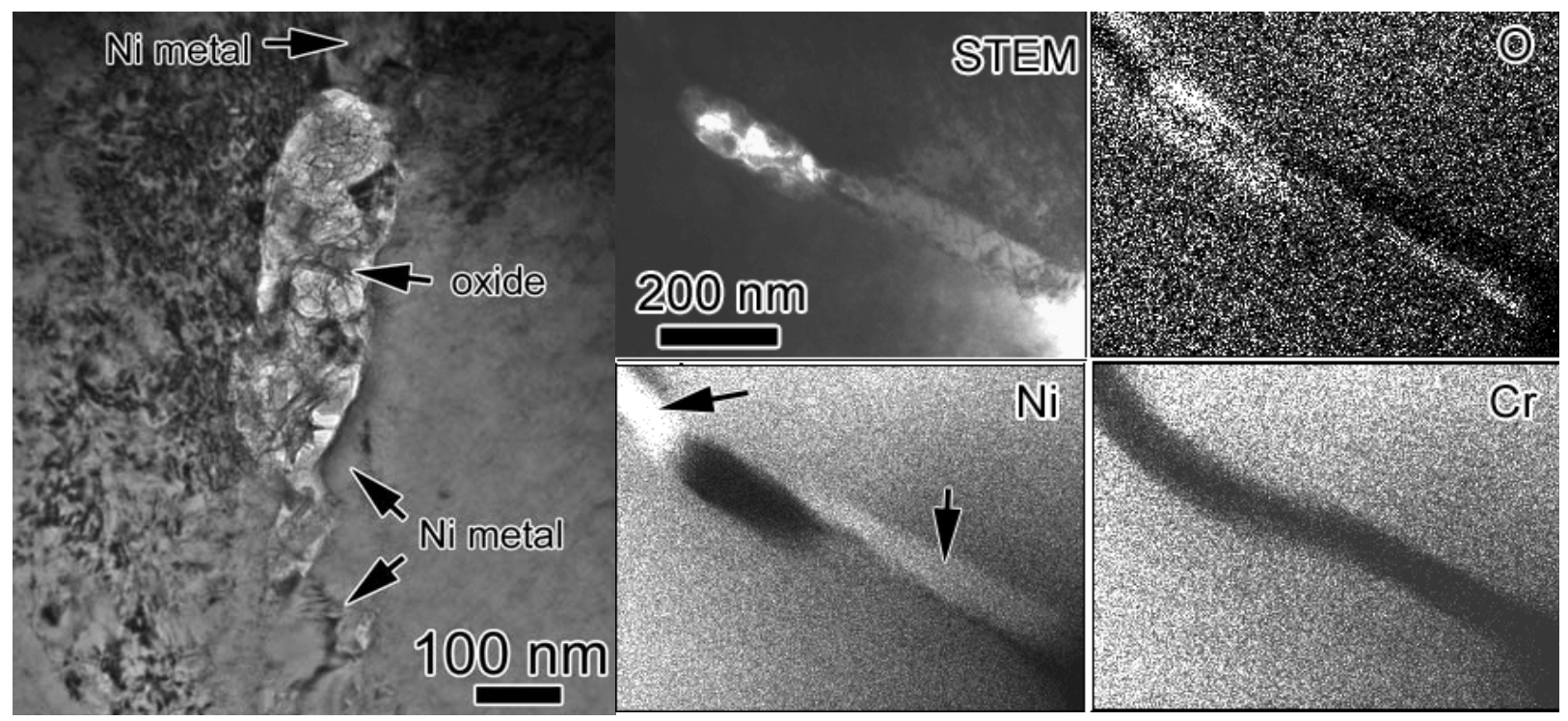

Figure 21. Attacked grain boundary with alternating regions of oxide (spinel) and Ni-metal in an Alloy 182 weld. TEM brightfield of general area is shown on left with four EDS x-ray maps on right. Arrows indicate regions of Ni-rich metal. 


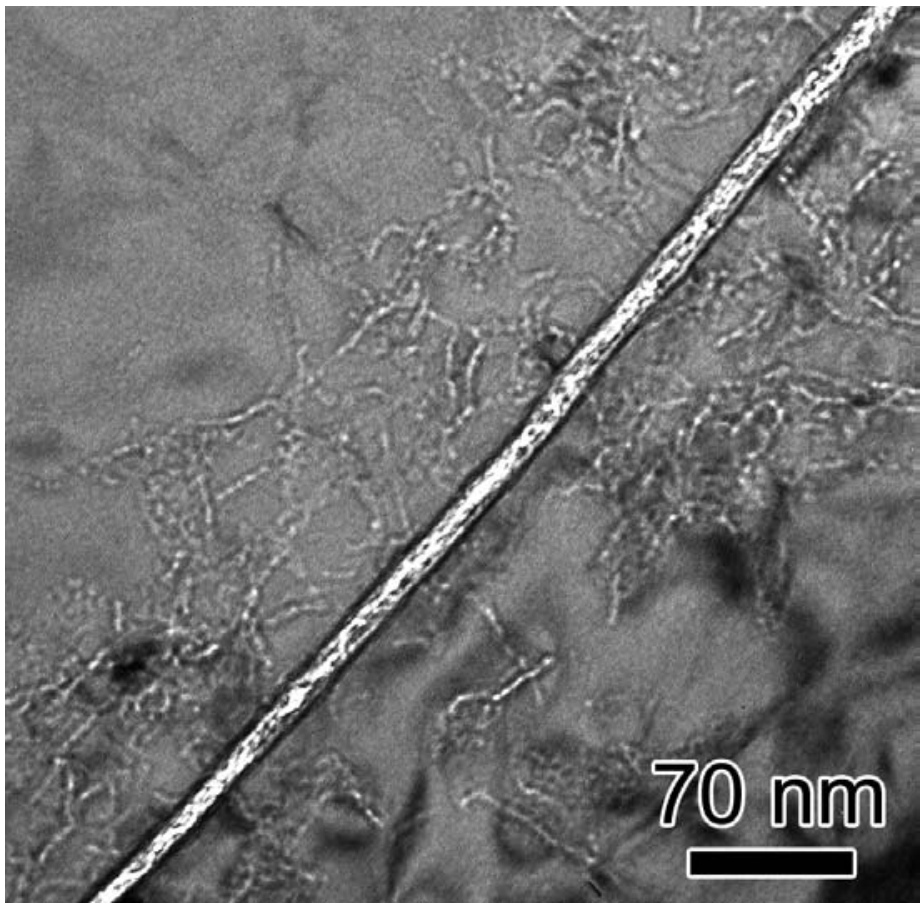

Figure 22. Underfocused TEM image showing tunnel-like structures extending into the matrix from a tight intergranular crack.

\section{$\underline{\text { Summary }}$}

Cracking of alloy 182 weldments is observed to occur along high-angle grain boundaries but not at the boundaries between dendrite arms. The structure of the welds observed consisted of regular arrays of $\mathrm{Nb}$ carbides and random Ti-based particles. In some cases there was also a regular pattern of Mn segregation. Interestingly, little segregation of major elements or impurities was observed along the boundaries that cracked. TEM examination of crack tips revealed a variety of oxide phases and the occurrence of alternating oxide-Ni metal structures. Also present was a series of tunnel-like structures that might be oxide penetrations along dislocations.

\section{Pb-Induced IGSCC in Alloy 600 and Alloy 690}

Initial ATEM characterization examinations have been performed on samples obtained from the CIEMAT tests described in Task A and summarized in Table 2. The first two test samples examined in this work were alloy 600 in mill-annealed (MA) and thermally-treated (TT) conditions. Both of these samples were tested in $320^{\circ} \mathrm{C}$ AVT water containing $\mathrm{Pb}$ added as $\mathrm{PbO}$. These library sample examinations provided direct comparisons with $\mathrm{Pb}$-containing microstructures observed in stress-corrosion-cracked MA alloy 600 tubing from recirculatingtype steam generators in several different pressurized-water reactors (PWRs).

The tubing samples used in this work were received as metallographic mounts with the axial cracks revealed in transverse cross sections. TEM samples containing the cracks and crack tips were prepared from small pieces cut from the tubing. Areas suitably thin for TEM characterization of selected crack regions were prepared by dimple grinding and argon-ion micromilling. The lightly ion-etched samples were examined by SEM backscattered electron 
(BSE) imaging to observe the crack microstructures before final ion thinning for TEM. ATEM characterizations were performed in a $200 \mathrm{kV}$ field-emission-gun TEM using a wide variety of high-resolution imaging, diffraction and compositional analysis methods.

In the MA alloy 600 test sample, the TEM examinations revealed narrow degraded zones containing high $\mathrm{Pb}$ along the crack-intersected grain boundaries as shown in Figures 23 and 24 . These degraded IG structures produced in the laboratory were characteristically similar to the $\mathrm{Pb}$-containing grain-boundary structures previously found in several steam generators. Examples of these service-induced corrosion structures are presented in Figures 25, 26 and 27. Comparable widths and compositions of the attacked and oxidized grain boundaries can be seen.

The first-of-a-kind observations on the laboratory AVT water $+\mathrm{Pb}$ tests supply unique information with respect to PWR secondary-side corrosive attack. One key insight is the lack of "caustic" signature for this degradation as expected by most industry analysis. It is clear that cracking can occur without significant off-normal solution chemistries if $\mathrm{Pb}$ is present.
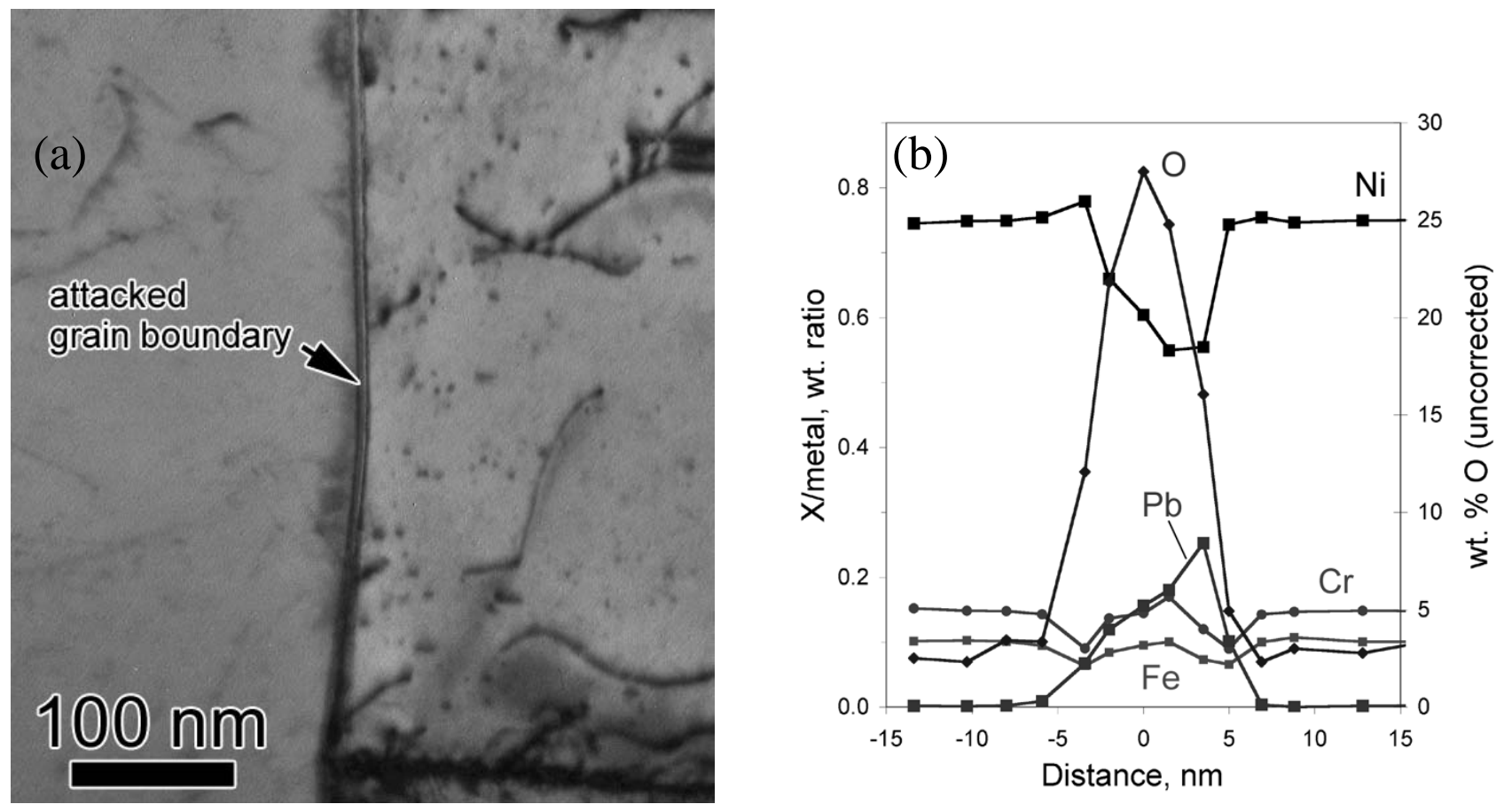

Figure 23. Characteristic IG degradation of mill-annealed alloy 600 in high-temperature water containing $\mathrm{Pb}$. CIEMAT autoclave test with AVT water $+0.002 \mathrm{M} \mathrm{PbO}$ at $320^{\circ} \mathrm{C}$. (a) TEM brightfield image of degraded grain boundary with high $\mathrm{Pb}$ in nanocrystalline $\mathrm{Ni}-\mathrm{Cr}-\mathrm{Fe}$ oxide. (b) Fine-probe EDS composition profile across degraded structure. 


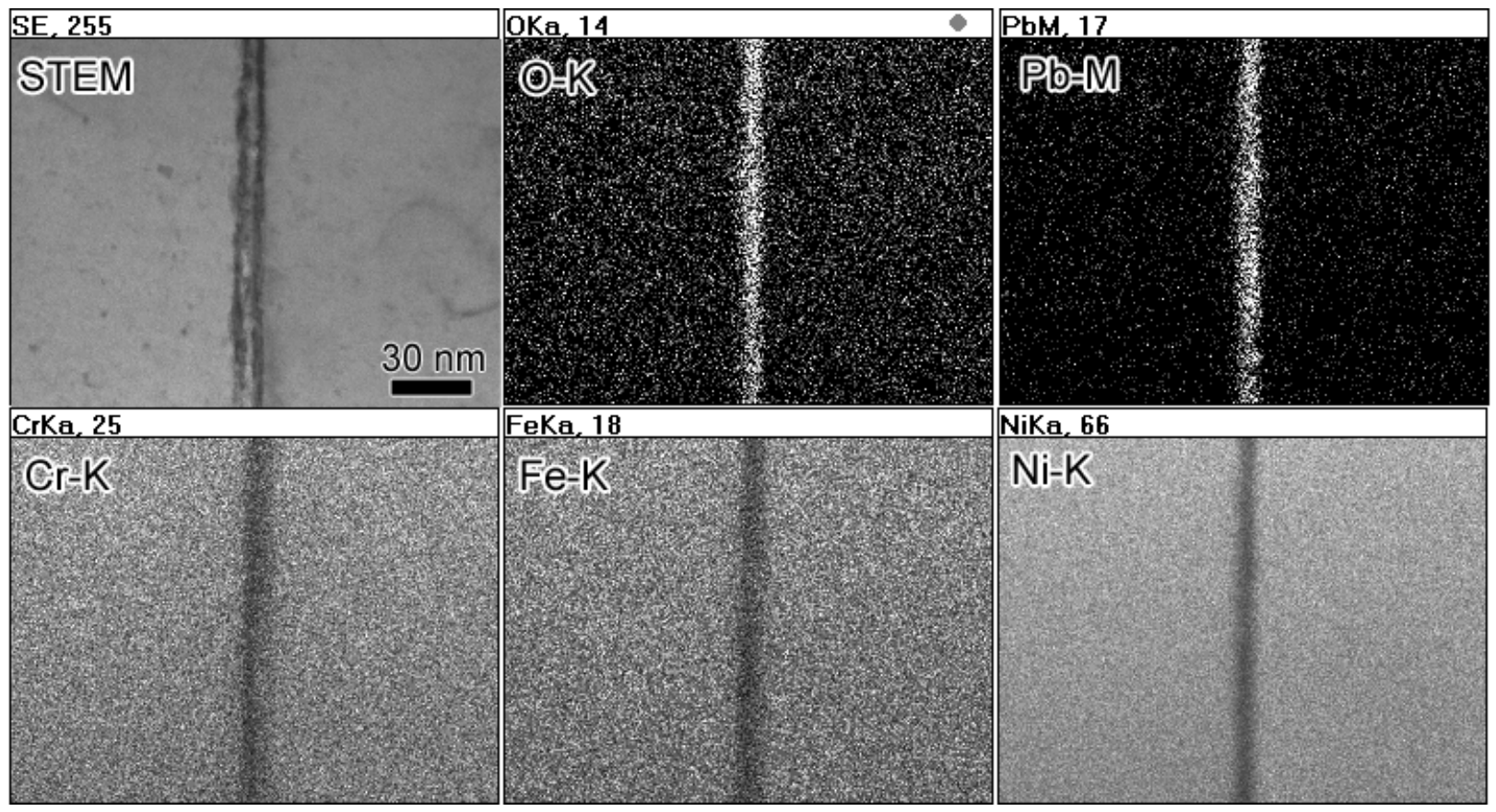

Figure 24. High-resolution EDS elemental maps showing concentrated $\mathrm{Pb}$ in 10 -nm-wide oxidized zone along grain boundary in MA alloy 600. Autoclave test with AVT water $+0.002 \mathrm{M}$ $\mathrm{PbO}$ at $320^{\circ} \mathrm{C}$.

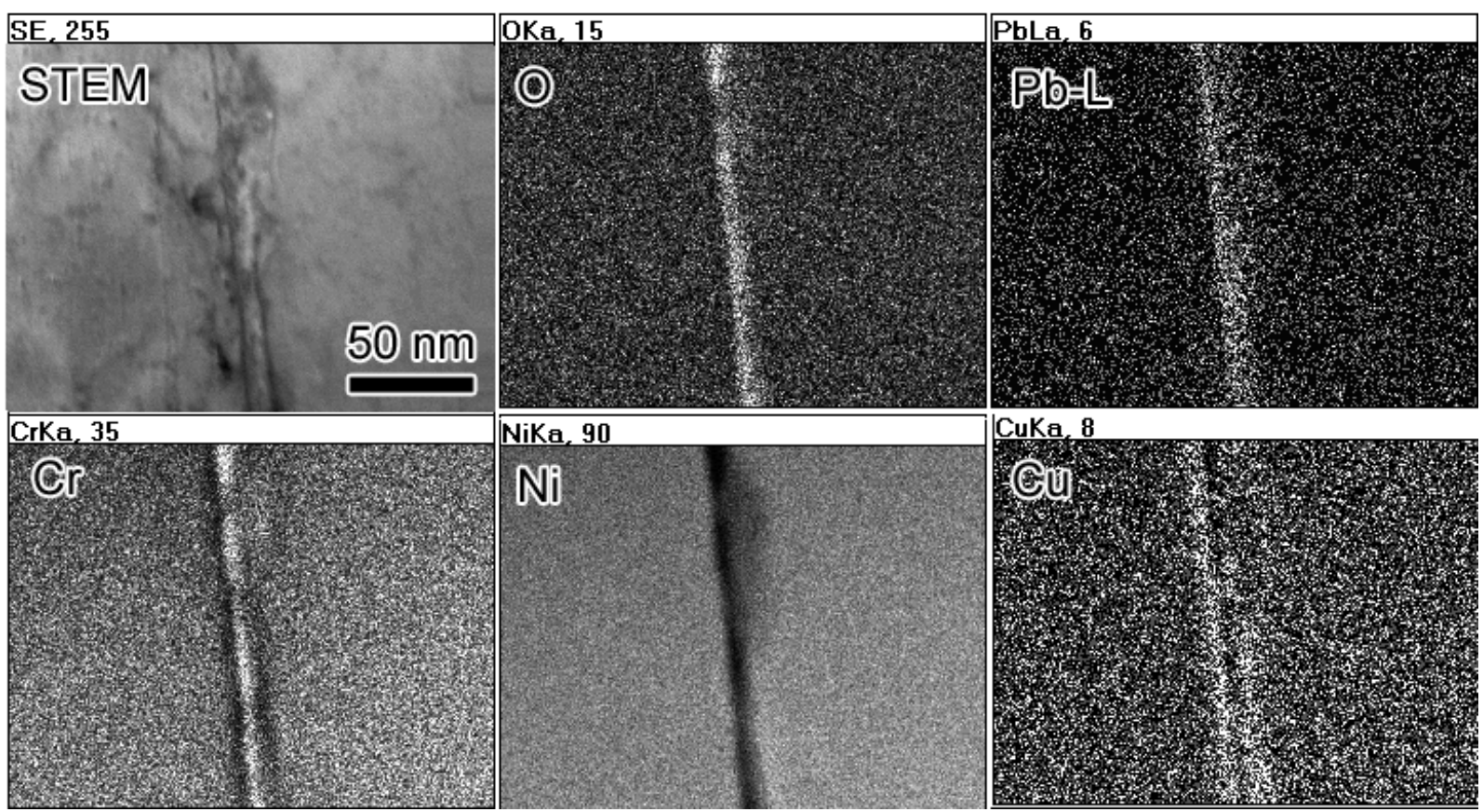

Figure 25. EDS elemental maps of attacked grain boundary in MA alloy 600 removed from $\mathrm{PWR}$ steam-generator service. $\mathrm{Pb}$ is concentrated in the crack oxide and $\mathrm{Cu}$ is enriched at the metal/oxide interfaces. 

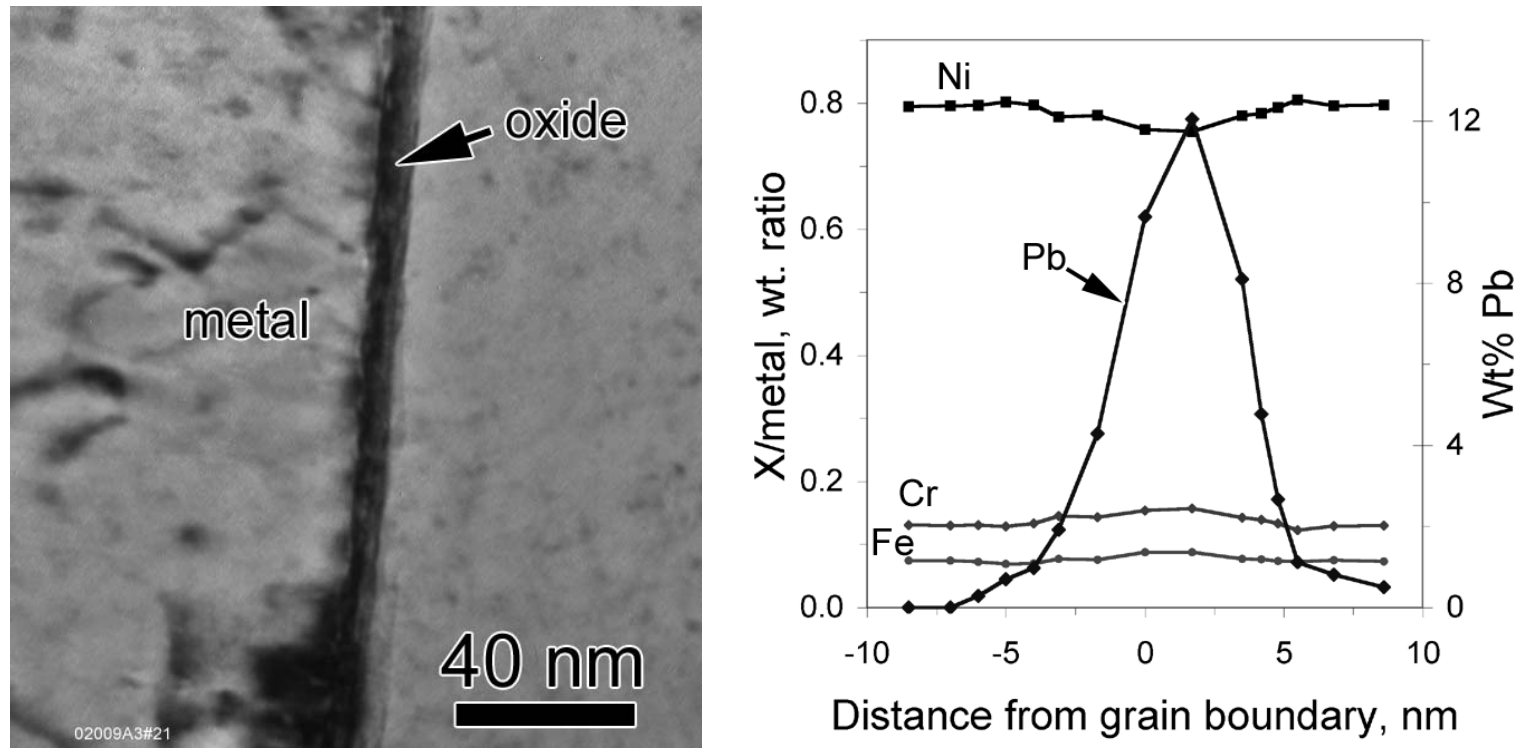

Distance from grain boundary, $\mathrm{nm}$

Figure 26. Pb-containing oxidized zone along grain boundary in MA alloy 600. (a) Brightfield TEM image. (b) Fine-probe composition profile across attacked and oxidized grain boundary. Width of the oxidized region corresponds to width of $\mathrm{Pb}$ profile.

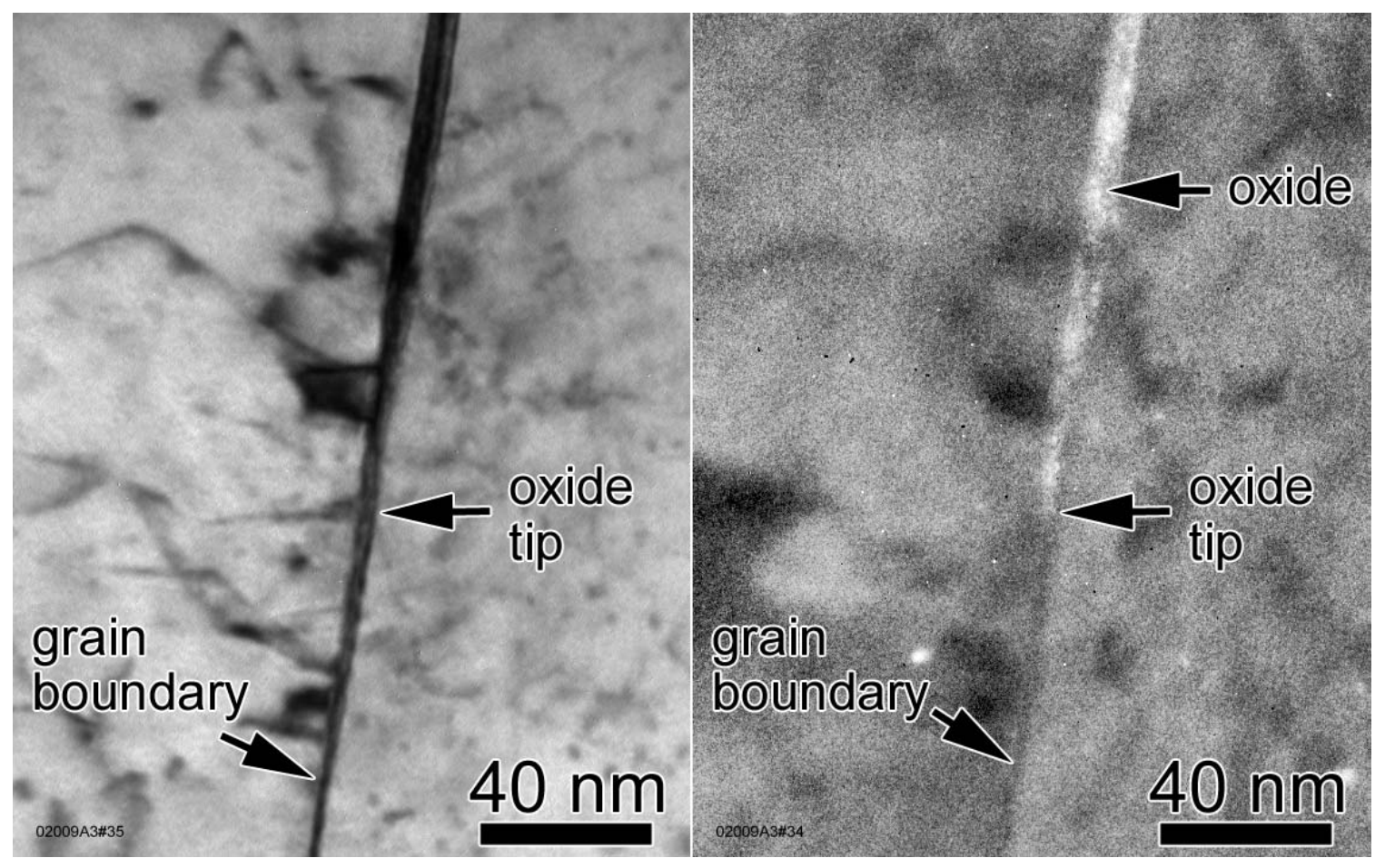

Figure 27. Tip of high- $\mathrm{Pb}$ oxide zone along degraded grain boundary in MA alloy 600 steam generator tubing. (a) Brightfield TEM image. (b) TEM oxide darkfield image.

Work was also initiated on a second CIEMAT sample in AVT + Pb. Thermally treated alloy 600 has been used as a replacement material for cracked MA alloy 600. In the case of the alloy 600TT sample, higher $\mathrm{Pb}$ levels were added to solution producing a mixture of IG and 
transgranular (TG) SCC. This change in cracking morphology results from the presence of a high density of grain boundary carbides and from the higher $\mathrm{Pb}$ concentration in solution. SEM examinations revealed that $\mathrm{Pb}$ had precipitated in wide parts of the cracks. This is illustrated in Figure 28. TEM examinations confirmed that the $\mathrm{Pb}$ seen by SEM consisted of metallic facecentered-cubic $\mathrm{Pb}-\mathrm{Ni}$ alloy containing $\sim 80 \mathrm{wt} \% \mathrm{~Pb}$. The typical structure of the precipitated $\mathrm{Pb}$ in the SCC cracks is shown in Figure 29. No observations on service-induced SCC structures have ever revealed precipitated $\mathrm{Pb}$ and suggest much higher levels of this impurity in the cracks of the CIEMAT laboratory sample. The precipitated $\mathrm{Pb}$ does disappear as crack narrow near tips or leading edges of corrosive attack. Oxide-filled cracks and attacked grain boundaries are similar to most other $\mathrm{Pb}$ examples with a nanocrystalline $\mathrm{NiCrFe}$ oxide with very high $\mathrm{Pb}$ concentrations as shown in Figure 30.

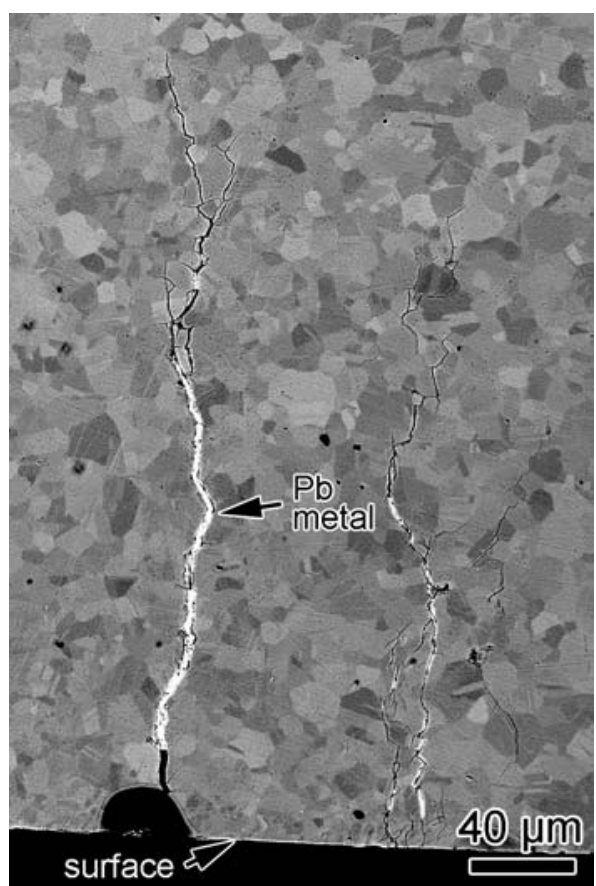

(a)

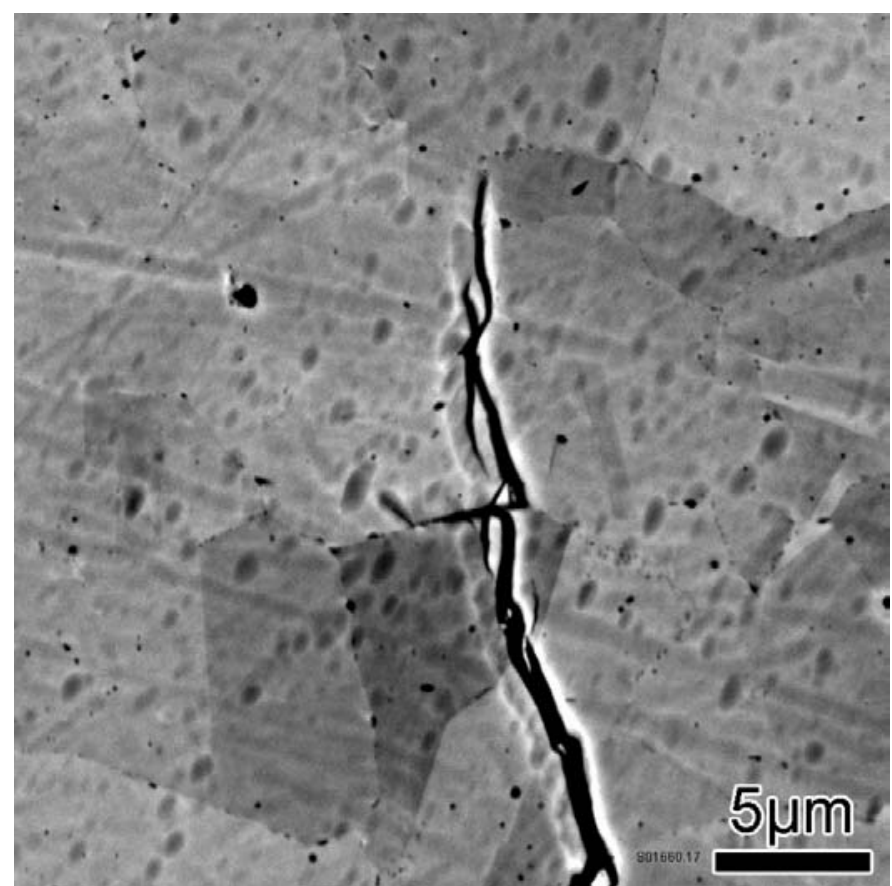

(b)

Figure 28. SEM/BSE images of mixed IG and TGSCC cracks in TT alloy 600 after tests in AVT water $+0.01 \mathrm{M} \mathrm{PbO}$ at $320^{\circ} \mathrm{C}$. (a) $\mathrm{Pb}$ metal precipitated along cracks. (b) Higher magnification view of crack-tip area. 


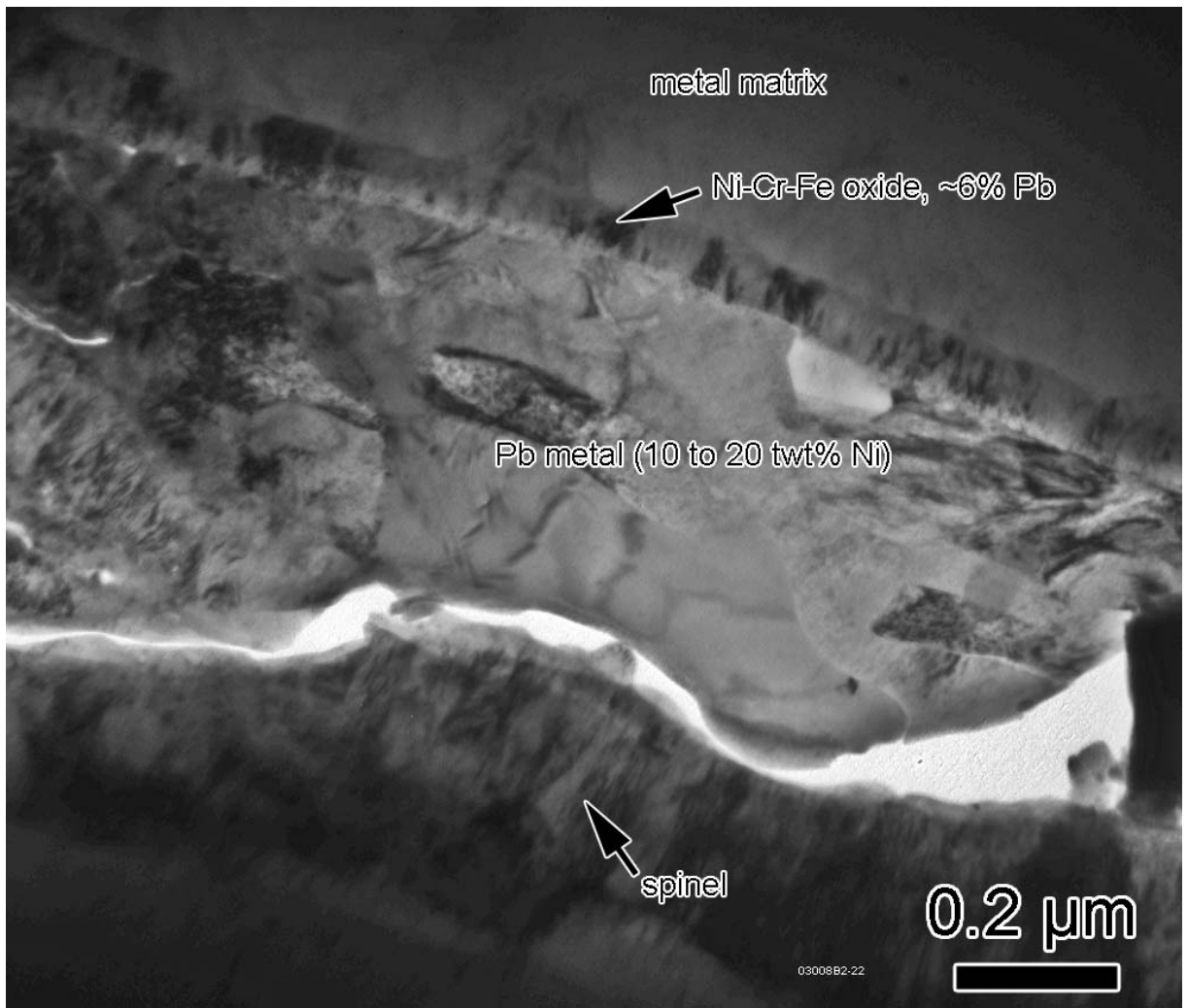

Figure 29. Metallic Pb precipitated in crack from alloy 600TT SCC test sample.

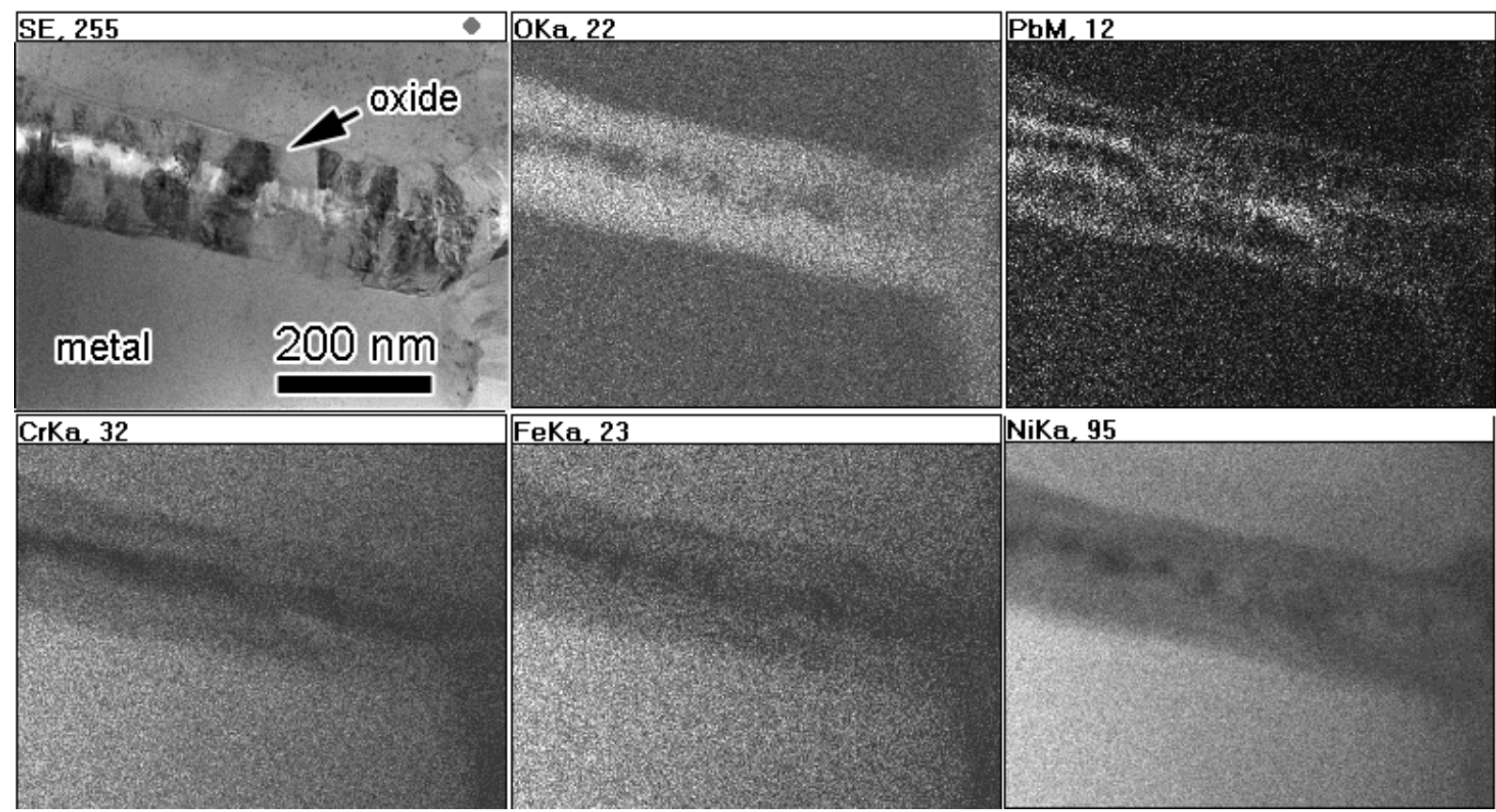

Figure 30. TEM/EDS elemental maps of cracked grain boundary in alloy 600TT after SCC test with $0.01 \mathrm{M} \mathrm{PbO}$ in AVT water. EDS analyses indicated up to $6 \mathrm{wt} \% \mathrm{~Pb}$ in $\mathrm{Ni}-\mathrm{Cr}-\mathrm{Fe}$ oxide. 


\section{IGSCC and IASCC in Stainless Steel}

TEM samples have been prepared from the first two crack-growth samples supplied by GE. The samples consisted of warm-worked Type 304SS and 316SS from tests in oxygenated $288^{\circ} \mathrm{C}$ (BWR) water. Initial TEM observations of the cross-sectioned samples confirmed the IG cracking and showed extensive deformation twinning of the alloys. These examinations are continuing. TEM cross-section samples containing cracks were also prepared from sensitized Type 304SS from the low-temperature $\left(80^{\circ} \mathrm{C}\right)$ water U-bend tests with single-impurity additions of $\mathrm{NaF}, \mathrm{NaCl}$ or $\mathrm{Na}_{2} \mathrm{~S}_{2} \mathrm{O}_{3}$. These samples have not yet been examined. The last stainless steel samples being prepared are proton-irradiated 304L SS from the University of Michigan after slow-strain-rate SCC tests. Tight IG cracks have been identified across the surface and specific regions to be prepared selected. However, the preparation approach is still being worked out for these shallow secondary cracks (proton-irradiated depth and region cracked is only $40 \mu \mathrm{m}$ deep). 


\section{Task C. Modeling Crack-Tip Corrosion Reactions}

\section{Background and Approach}

Observed corrosion products at active crack-tips provide evidence for the crack-tip chemical/ electrochemical and material conditions that affect crack advance. These observations help establish the critical boundary conditions that are required for realistic modeling. The mechanistic models used in Task $C$ relate measured crack advance and corrosion products to predictions using activity, solubility and kinetics of corroding species to rationalize metastable phases observed at crack-tips. During exposure in high-temperature water environments, equilibrium thermodynamics should dictate measured corrosion products in contact with the water. However, crack-tip measurements have revealed that kinetics, stress or other physical constraints inhibit formation of normally favorable phases allowing formation of intermediate metastable phases.

The approach for evaluating cracking mechanisms builds on existing thermodynamic and kinetic models integrated with quantitative measurements of corrosion product structure and composition documented in single-mechanism samples (Task B) and in LWR samples (Task D). Traditional Pourbaix diagrams describe effects of $\mathrm{pH}$ and potential on the thermodynamic stability and solubility of alloy elements and their oxides for unconstrained corrosion. The Pourbaix formalism for unconstrained equilibrium phases is being modified to account for unique constraints at crack-tips that result in measured metastable phase formation.

\section{Thermodynamically Favored Phases}

Rates of chemical reactions dictate phase stability in crack-tip aqueous environments. Alloy corrosion rates establish a source of species that react to form corrosion products. ATEM examinations in Tasks B and D document these products. Chemical reaction and equilibrium software packages offer efficient methods to examine chemical reaction systems relevant to the present crack-tip analyses. In particular, the Geochemist's Workbench (GWB) has been purchased and installed for evaluating documented phases at crack tips. Progress on using the code was to learn the features of the software and to exercise impacts of selected assumptions on calculated Pourbaix diagrams. The GWB software was chosen over alternative options because of the high temperature features and reasonable cost.

The dependence of stable corrosion products on specie concentrations, potential and $\mathrm{pH}$ can be calculated using GWB based on estimated ionic concentrations from corrosion of $\mathrm{Fe}, \mathrm{Cr}$ and $\mathrm{Ni}$ and their oxidation reactions. One goal of the analysis in progress is to rationalize the presence and the chemical state of $\mathrm{Pb}$ at crack tips and at crack walls relevant to secondary side cracking of alloy 600. A preliminary survey of the $\mathrm{Pb}$ reaction literature indicated a variety of proposed reactions including the possible reduction of $\mathrm{PbO}$ to metallic lead by all three corroding elements of interest $\mathrm{Ni}, \mathrm{Fe}$ and $\mathrm{Cr}$. Based on the default GWB thermo.dat file, the only expected $\mathrm{Pb}$ compound is $\mathrm{PbCrO}_{4}$. Compounds of $\mathrm{Pb}$ with $\mathrm{Ni}$ or Fe were not shown on the calculated Pourbaix diagrams. The $\mathrm{PbCrO}_{4}$ oxide was only predicted at much higher potentials and higher $\mathrm{pH}$ than is relevant to the $\mathrm{Pb}$ cracking examined in the present project. The $\mathrm{NiCr}$ spinel, $\mathrm{NiCr}_{2} \mathrm{O}_{4}$, is predicted at relevant potentials and $\mathrm{pH}$ and is a phase observed in ATEM. Metallic $\mathrm{Pb}$ is not included in the default thermodynamic data base but will be added as future progress on this project. A kinetic analysis of $\mathrm{Pb}$ transport to the crack tip indicated a greater degree of 
electro-migration compared to Fickian diffusion. Although a potential gradient down a crack significantly enhances transport, transport in the absence of a potential gradient was still on the same order. This suggests that a potential gradient may not be a required condition to transport $\mathrm{Pb}$ is sufficient quantities to a crack tip.

\section{Crack Advance Modeling}

A paper entitled "Defining the Role of Solute Diffusion Kinetics at Crack Tips in Stainless Steel During Irradiation in Light-Water Reactors" was completed and submitted to the proceedings of the $11^{\text {th }}$ Int. Symp. on Environmental Degradation of Materials in Nuclear Power Systems Water Reactors, Stevenson, WA, August 10-14, 2003. The research provides a mechanistic interpretation that complements characterization of microchemistry in advance of a BWR topguide crack tip. Observations of $\mathrm{Ni}$ enrichment relative to crack advance rates were explained with assumptions of diffusion processes at an advancing crack tip.

Alloy compositions in advance of crack tips critically influence growth of stress corrosion cracks in austenitic stainless steels. A striking example of composition changes ahead of crack tips is the enrichment of $\mathrm{Ni}$ and depletion of $\mathrm{Fe}$ and $\mathrm{Cr}$ in an irradiated 304SS top-guide from a BWR. In this case, an altered alloy composition with up to $55 \% \mathrm{Ni}$ extended about $100 \mathrm{~nm}$ past the crack tips. Analyses of candidate diffusion processes reveal that conventional thermally activated mechanisms for solute transport cannot rationalize the measured compositions. The influences of high temperature, irradiation and corrosion are examined using simplified diffusion analyses and parametric calculations. Corrosion-induced vacancy injection is shown to have the greatest potential impact on local composition. However, predicted times for influencing neartip compositions are much longer than those expected based on average rates of stress corrosion cracking. This result suggests that the compositional changes might have occurred when the cracks were arrested.

Local alloy composition at crack tips affect the propagation of IG cracks during irradiationassisted stress corrosion cracking (IASCC). [12-14] Because IASCC occurs as a result of concurrent processes influenced by high temperature, radiation and corrosion, it is important to understand how these environmental influences might affect alloy composition in advance of a crack tip. A composition process zone analogous to a deformation process zone may exist.

Of particular interest in this study was the observation that local Ni concentration at crack tips can exceed the Fe content in a type 304 stainless-steel BWR component irradiated at $288^{\circ} \mathrm{C}$. [15] An example of one such crack-tip region is shown in Figure 31. The region of Ni enrichment extended 10's of nm in advance of the tip. The crack-front interfaces showed unstable configurations (not completely evident in the figure) which have been attributed to selective dissolution. Observed grain boundary deviations at the tips further suggested a diffusioninduced boundary migration process had operated. These unique observations indicate that local diffusion of solute and vacancies is occurring.

Solid-state diffusion mechanisms can be delineated by the nature of the solute and by the path of diffusion. [16] Solutes are accommodated in the alloy matrix as either a substitutional solute or an interstitial solute. Solute diffusion can be by matrix and grain boundary diffusion or similarly dislocation pipe diffusion. Both substitutional and interstitial solutes diffuse by similar mechanisms in the grain boundary as in the matrix. 


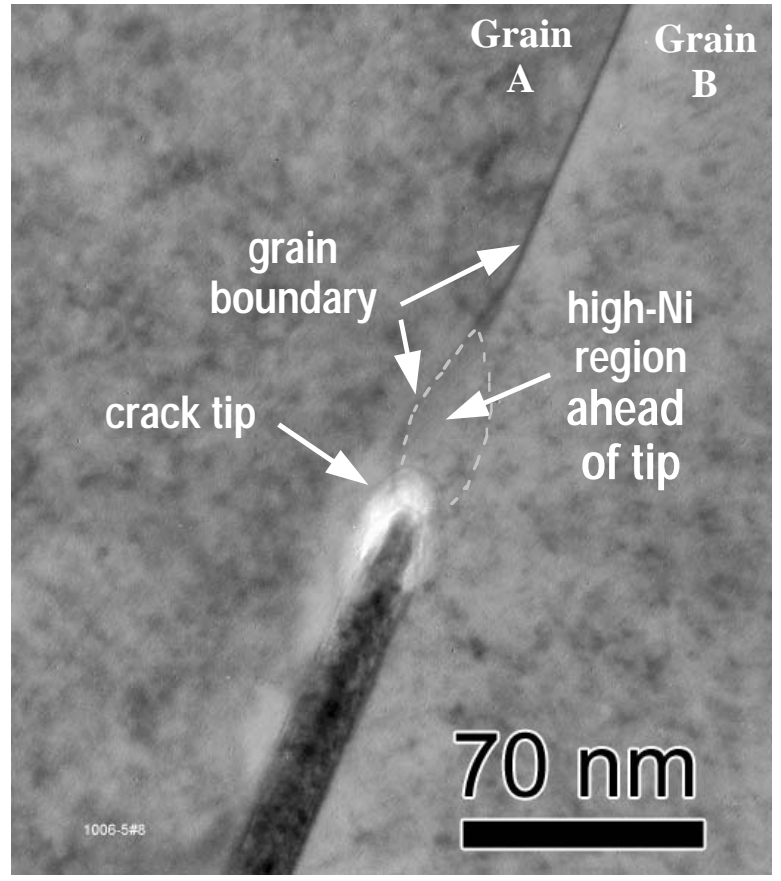

Figure 31. ATEM reveals a $\mathrm{Cr} / \mathrm{Fe}$-depleted, Ni-rich region in advance of an oxide-filled IGSCC crack tip in irradiated 304SS. [15]

Radiation-enhanced diffusion has a significant influence on matrix substitutional solute diffusion. [17] The enhancement derives from the high numbers of vacancies that are produced by displacement damage. The probability of a solute having a neighboring vacancy is higher during irradiation compared to the absence of irradiation. The radiation induced vacancy concentration can be calculated from rate theory based on the estimated production rate of vacancies and the annihilation rates by a variety of mechanisms.

Corrosion also is a process that can create vacancy concentrations in excess of the thermal equilibrium concentration. $[18,19]$ When an atom is removed from the alloy by general corrosion, selective dissolution or selective oxidation, a surface vacancy is created. Typically, these surface vacancies collect on the surface resulting in advance of the corrosion front. There is, however, the possibility that a subsurface atom will exchange with the surface vacancy resulting in a subsurface or matrix vacancy. Similarly, an alloy atom may enter a surface oxide leaving behind a vacancy at the oxide/alloy interface. These injected vacancies occur with a low but finite probability and are significant when compared to the thermal equilibrium concentration.

Radiation-induced segregation (RIS) is distinct from radiation-enhanced diffusion in that it causes nonequilibrium redistribution of solute. [20-22] Radiation-induced segregation results from the flow of defects and the preferential coupling of the defects with specific solute. The defect flow causes an induced solute flow. The degree of segregation depends on the strength of the defect flow and the strength of defect/solute interactions.

Inverse-Kirkendall segregation is a redistribution of solutes induced by a flow of vacancies. During irradiation, vacancies are produced by atomic displacements. The vacancies migrate to 
defect sinks resulting in vacancy flow. In austenitic stainless steels, fast-diffusing Cr depletes at sinks and slow-diffusing Ni enriches at sinks. Unlike radiation-enhanced diffusion, RIS does not act instantaneously but rather requires time (dose) to develop non-equilibrium concentration profiles. Significant RIS occurs at about one displacement per atom (dpa) that corresponds to years for the lower dose rates of components near the core such as a top guide.

When a crack front advances, it will encounter material characteristics that have changed during the entire exposure and will encounter material characteristics that are associated with the local presence of the crack tip. In this research, the rates of alloy composition changes are evaluated to isolate the influences of thermal, radiation and corrosion exposures.

\section{Results from Calculations}

Two approaches can be used to evaluate the diffusion kinetics: (1) calculate the diffusion front penetration ahead of a stationary crack front and (2) calculate the penetration ahead of a crack that moves discontinuously. The first case calculates the long-range diffusion over long component lifetimes. The second case calculates the short-range diffusion over short times associated with the local crack advance. Because of the parabolic diffusion penetration length dependence on time, there is a short-range, rapid penetration followed by a long-range, slow penetration. The diffusion field develops slowly far in advance of a stationary crack front. However, the local diffusion field can develop rapidly provided a fresh interface occurs at frequent rates.

Thermally-Induced Diffusion. Comparisons of diffusion distances and times for matrix diffusion and for grain boundary diffusion of $\mathrm{Cr}$ are shown in Figure 32. The assumed crack front advance distance is compared with the diffusion front advance distance as a function of time and temperature. The calculated distances and times are compared to an average crack advance rate of $10^{-7} \mathrm{~mm} / \mathrm{s}$ and were selected as an intermediate crack growth rate for stainless steels. [23] The diffusion times for both matrix and grain boundary diffusion are not short enough to maintain crack growth at $10^{-7} \mathrm{~mm} / \mathrm{s}$. The matrix diffusion times are several orders of magnitude longer than required for the assumed crack growth rate, i.e., diffusion rates are not fast enough. The grain boundary diffusion times are up to two orders of magnitude longer than required. At high temperature $\left(350^{\circ} \mathrm{C}\right.$ ) and short incremental advances (few nanometers), grain boundary diffusion may influence crack advance.

Radiation Enhanced Diffusion. Calculated radiation enhanced diffusivity of Cr compared to diffusivity in the absence of irradiation is shown in Figure 33. Dose rates and temperatures relevant to LWR near-core structures are shown. A low dose rate of $10^{-10} \mathrm{dpa} / \mathrm{s}$ reflects rates experienced in components such as a top guide low dose region $(0.07 \mathrm{dpa})$. A high dose rate of $10^{-8} \mathrm{dpa} / \mathrm{s}$ reflects rates experienced in near-core regions such as baffle plates and bolts. The condition of the top guide ATEM analysis is intermediate between the two rates. The effect of radiation-enhanced diffusion is greater at higher dose rates and lower temperatures. An enhancement of five orders of magnitude is predicted at $250^{\circ} \mathrm{C}$ and a dose rate of $10^{-8} \mathrm{dpa} / \mathrm{s}$. In all cases, the enhancement is not large compared to enhancements that would be required to allow bulk diffusion to occur at a rate consistent with a crack advance rate as shown in Figure 32 . 


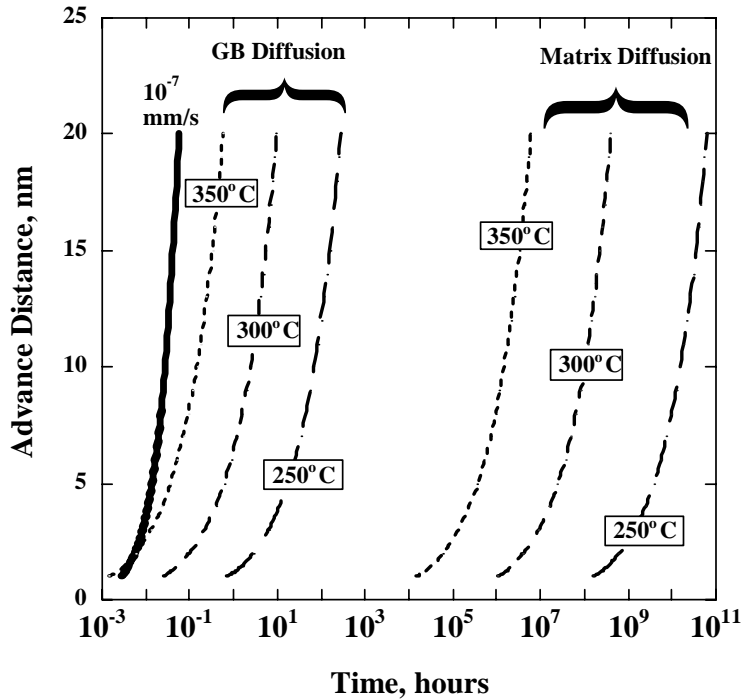

Figure 32. The rate of crack advance is compared to the times required to advance the diffusion front. Diffusion by matrix and grain boundary diffusion are shown.

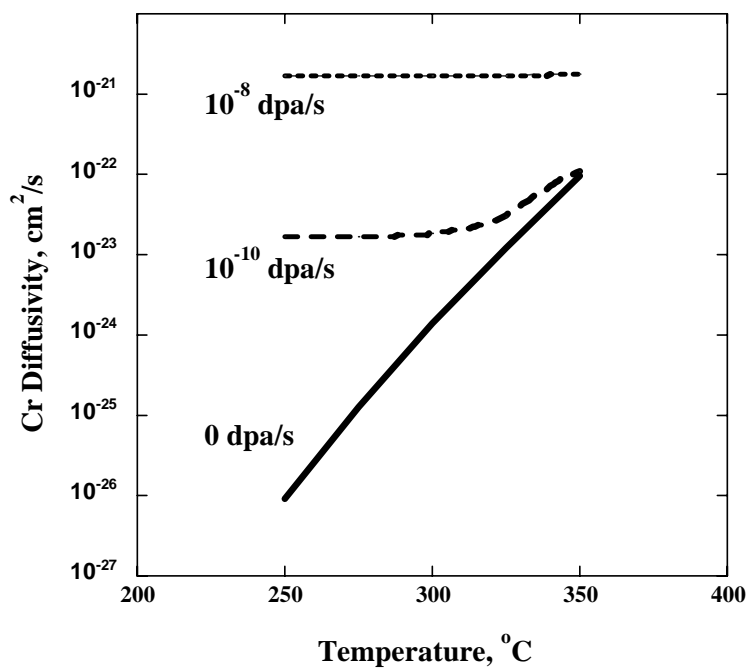

Figure 33. Radiation enhanced diffusivities are compared with thermal diffusivities $(0 \mathrm{dpa} / \mathrm{s})$. The enhancement is greater for higher damage rate and lower temperature.

Inverse-Kirkendall Segregation. Grain boundary $\mathrm{Cr}$ concentration was calculated as a function of dose rate, dose and temperature and is shown in Figure 34 compared to measured top-guide values (squares) and baffle-bolt values (circles). [24] Calculated concentrations are based on an incident probe size of $0.7 \mathrm{~nm}$. The measured and calculate values are in reasonable agreement.

The top-guide case shown in Figure 31 is expected to exhibit little $\mathrm{Cr}$ depletion at grain boundaries. Greater degrees of $\mathrm{Cr}$ depletion are predicted for lower temperatures, higher dose rates and higher doses. At the low dose rate $\left(10^{-10} \mathrm{dpa} / \mathrm{s}\right)$, only $0.1 \mathrm{dpa}$ can be achieved in 30 years. At this low dose, little change in grain boundary $\mathrm{Cr}$ concentration is predicted. At the higher dose rate $\left(10^{-8} \mathrm{dpa} / \mathrm{s}\right), 10 \mathrm{dpa}$ can be achieved and significant change in $\mathrm{Cr}$ grain boundary concentration is predicted. Greater segregation is predicted at lower temperatures. The large 


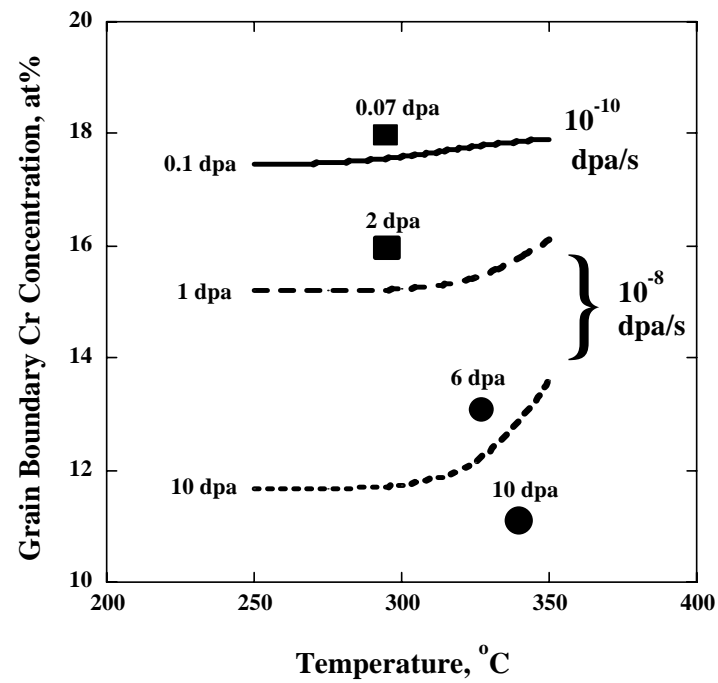

Figure 34. Radiation-induced grain boundary $\mathrm{Cr}$ concentration dependence on dose rate, dose and temperature. After 30 years or irradiation, $0.1 \mathrm{dpa}$ is achieved at $10^{-10} \mathrm{dpa} / \mathrm{s}$ and about 10 $\mathrm{dpa}$ is achieved at $10^{-8} \mathrm{dpa} / \mathrm{s}$. The dose rates corresponding to the indicated doses are $10^{-10} \mathrm{dpa} / \mathrm{s}$ at $0.07 \mathrm{dpa}, 2 \times 10^{-9} \mathrm{dpa} / \mathrm{s}$ at $2 \mathrm{dpa}, 1 \times 10^{-8} \mathrm{dpa} / \mathrm{s}$ at $6 \mathrm{dpa}$ and about $2 \times 10^{-8} \mathrm{dpa} / \mathrm{s}$ at $10 \mathrm{dpa}$.

segregation magnitudes require long irradiation times (30 years) and will influence crack advance only by altering the long-term, uniform material condition and not by altering the shortterm change in the local crack-tip or surface concentration.

Fixed Boundary Concentration At grain boundaries and at surfaces, the boundary equilibrium concentration of solute can be influenced by the presence of precipitates which is not accounted for in the inverse-Kirkendall model. The inverse-Kirkendall model was modified in the present work to allow a constant fixed concentration of major solutes at the grain boundary (or surface). The boundary concentrations were assumed to be equal to the measured change in concentration immediately ahead of a crack tip. [15] Those measured concentrations were about $55 \% \mathrm{Ni}$, $42 \% \mathrm{Fe}$ and $3 \% \mathrm{Cr}$. With those as fixed boundary concentrations, RIS was calculated as shown in Figure 35. The concentration profiles are noted to be very similar to the case of conventional inverse-Kirkendall segregation. Although the boundary concentration was fixed (and less than predicted by the conventional inverse-Kirkendall mechanism) the nm dimension of the $\mathrm{Cr}$ depletion zone is similar to that of the conventional inverse-Kirkendall mechanism. $\mathrm{Cr}$ enrichment does not occur at the boundary because of the high vacancy concentration at the boundary in contrast to the near zero vacancy boundary concentration during RIS.

Vacancy Injection Influence The influence of corrosion-induced vacancy injection on the calculated vacancy flux is shown in Figure 36 for an intuitively high vacancy injection probability of $10 \%$. In the absence of corrosion, the radiation-induced vacancy concentration profile induces a flux of vacancies to the boundary and vacancies are strongly depleted within about $100 \mathrm{~nm}$ of the boundary. Corrosion-induced vacancies reverse the net flow of vacancies to a direction away from the boundary. The near-boundary vacancy concentration is enhanced by several orders of magnitude compared to radiation alone. Furthermore, the depth of influence is large compared to the case without corrosion. In the example shown in Figure 37, the depth of enhanced vacancy concentration is about one $\mu \mathrm{m}$. The vacancy profile has the potential of influencing the composition to significant depths in advance of the corroding surface. 


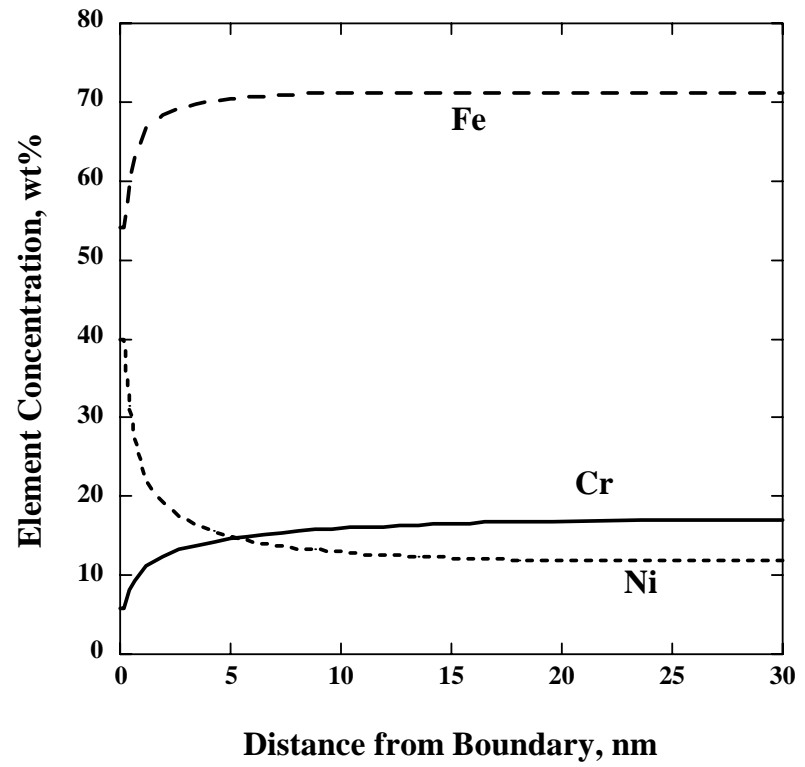

Figure 35. The effect of assuming fixed boundary concentrations is similar to measured concentrations on RIS profiles. Only minor change in the near-boundary concentrations result compared to RIS. Significant concentration gradients only develop within several $\mathrm{nm}$ of the boundary similar to RIS.

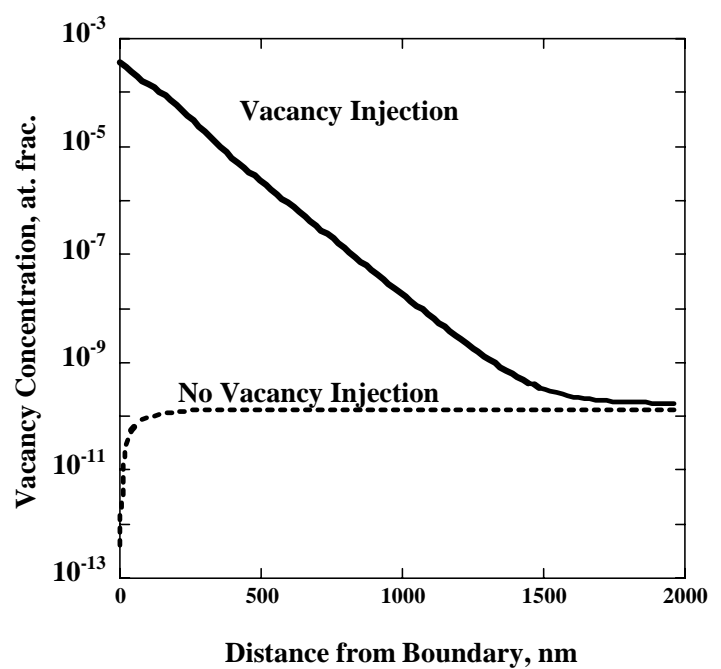

Figure 36. The effect of corrosion-induced vacancies on the vacancy concentration profile. The high vacancy concentration with injection can promote diffusion far from the boundary.

If the crack advance times of 1,000 s and 10,000 s are assumed, the composition profile emerges as shown in Figure 37. The time of 1,000s corresponds to an advance increment of 100nm for a rate of $10^{-7} \mathrm{~mm} / \mathrm{s}$. Therefore, although vacancy injection has a potential long-range influence, the impact on composition none-the-less requires long times relative to the rate of crack advance. Note that this profile is much deeper than that shown in Figure 35 but much less than shown in Figure 36. The assumed long time and high vacancy injection efficiency (10\%) suggests that corrosion occurred without significant crack advance. An arrested crack would allow these long times for deep penetration of the compositions profiles. 


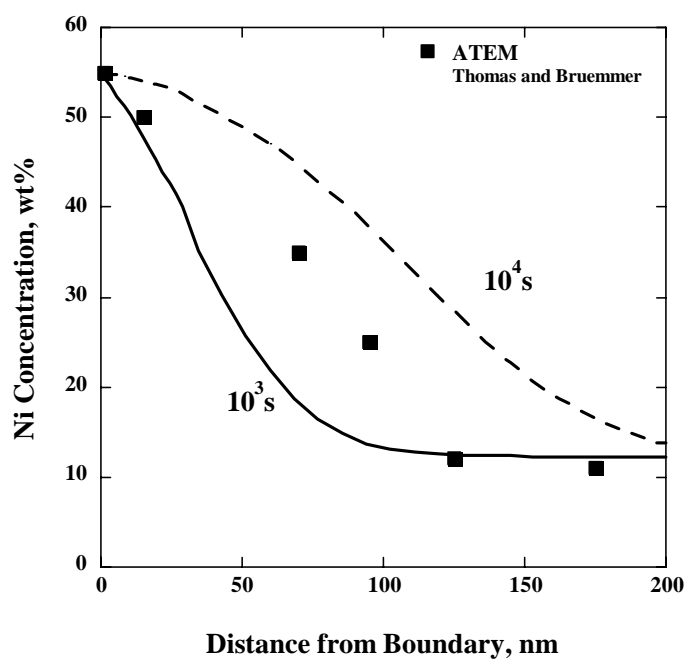

Figure 37. Solute concentration profiles affected by injected vacancies shown in Figure 36. The incremental times for corrosion are assumed to be $1,000 \mathrm{~s}$ or $10,000 \mathrm{~s}$ and the injected vacancy efficiency is assumed to be $10 \%$.

\section{Summary}

Solid-state diffusion ahead of a crack tip during crack advance is possible from a variety of thermal, radiation and corrosion influences on diffusion. In the absence of irradiation or corrosion, diffusion times are orders of magnitude longer than required to respond to a moving crack. This is true for major substitutional alloy solutes diffusing in either the matrix or along a grain boundary. Minor interstitial diffusion is rapid and could potentially influence composition ahead of a crack tip. Radiation-enhanced diffusion is not sufficient to promote diffusion at a rate necessary for crack advance. RIS at grain boundaries throughout the alloy is important for higher dose rates and doses but requires long times to achieve a significant effect compared to the short times associated with the local advance of a crack. Corrosion-induced vacancy injection has the potential to impact solute diffusion to long distances ahead of a crack front. However, as in the case of RIS, the times to achieve a significant effect are long compared to the times for advance of a crack front. Furthermore, an unrealistically high vacancy injection probability had to be assumed. These results suggest that the unusual compositions and interfacial morphologies observed at crack tips in an irradiated stainless steel component might have formed after the cracks had arrested. 


\section{Task D. Integration with Industry Research}

\section{Background and Approach}

The last component of this research effort is the use of Task $\mathrm{B}$ and $\mathrm{C}$ results to interpret more complex environmental cracking in LWRs and define characteristics of corrosion-resistant alloys for next generation nuclear power systems. A key aspect of this task is the integration of industry-funded crack-tip characterization activities including examinations of cracking in steam generator tubing, vessel head penetration and core internals. This work is being conducted on plant components using techniques described in Task B. Collaborative steam generator research is being supported by EPRI and U.S. utilities (B\&W Owners Group) to understand IG attack and SCC in once-through steam generators, and by EPRI, Framatome and the Swedish Nuclear Power Inspectorate (SKI) to understand IG attack and SCC in recirculating steam generators. Both of these designs employ lower-Cr alloy 600 tubing, either in the mill-annealed or stressrelieved (sensitized) condition. This underpins the material conditions to be tested in Task A for the higher-Cr alloy 690 and enables direct comparisons of crack-tip characteristics. Although alloy 690 is the primary steam generator replacement material and it has been shown to fail by IGSCC in high-temperature steam and in secondary water with certain impurities, there has been little industry interest in examining failure mechanisms since they have not yet been a problem in service. Alloy 600 and alloy 690 issues are also critically important to recent cracking of PWR vessel head penetrations where mill-annealed alloy 600 penetration heads and alloy 182 weldments have shown extensive SCC. Once again, alloy 690 is the replacement material for alloy 600 while weldments are being made from alloy 52 or 152.

\section{Interactions}

Direct collaborations were established with a variety of nuclear power industry representatives to identify and obtain important materials for project research activities. The most important contacts have been established with EPRI, Framatome-ANP, SKI and the U.S. Nuclear Regulatory Commission. The results of these contacts are discussed within the summaries for Tasks A and B previously. These include key testing and supplied samples on alloy 600 and alloy 182 IGSCC from EPRI, Rockwell, CIEMAT, SKI and Ringhals. Cracked samples of the alloy 600 penetration head and alloy 182 weldment removed from the Davis Besse reactor were received at PNNL and negotiation is underway with EPRI and the U.S. Nuclear Regulatory Commission (NRC) to get access to similar samples from the North Anna 2 PWR. The North Anna 2 upper-head penetrations were recently shipped to PNNL for comprehensive nondestructive examinations as part of a joint EPRI-NRC coordinated effort. 


\section{References}

1. P. L. Andresen and C. L. Briant, Corrosion, 45, p. 448-463, 1989.

2. P. L. Andresen and C. L. Briant, in Proc. 3rd Int. Symp. on Environmental Degradation of Materials in Nuclear Power Systems - Water Reactors, TMS-AIME, p. 371-382, 1988.

3. P. L. Andresen, Corrosion, 44, p. 450, 1988.

4. P. L. Andresen, "The Effects of Aqueous Impurities on Intergranular Stress Corrosion Cracking of Sensitized Type 304 Stainless Steel," Final Report NP3384 Contract T115-3, EPRI, 1983. See also, "Innovations in Experimental Techniques for Testing in High Temperature Aqueous Environments,” Report No. 81CRD088, GE-CRD, 1981.

5. L. W. Niedrach, J Electrochem Soc, 127, p. 2122, 1980.

6. P. L. Andresen, et al., "In-Reactor Monitoring for Component Life Prediction", Interim Technical Progress Report \#2, EPRI project RP2006-17, August 1988.

7. A. Jenssen, in Proc. $10^{\text {th }}$ Int. Conf. Environmental Degradation of Materials in Nuclear Power Systems-Water Reactors, NACE, 2002, paper .

8. L. E. Thomas and S. M. Bruemmer, Corrosion J., 56 (2000) 572.

9. N. Lewis, S. A. Attanasio, D. S. Morton and G. A. Young, in Proc. Chemistry and Electrochemistry of Corrosion and Stress Corrosion Cracking, ed. R. H. Jones, TMS, 2001, 421-446.

10. S. M. Bruemmer and L. E. Thomas, J. Surface and Interface Analysis, 31 (2001) 571.

11. L. E. Thomas and S. M. Bruemmer, ibid 7, Paper 26.

12. P. L. Andresen, F. P. Ford, S. M. Murphy and J. M Perks, in Proc. $4^{\text {th }}$ Int. Symp. Environmental Degradation of Materials in Nuclear Power Systems-Water Reactors, NACE, p. 1-83, (1990).

13. P. M. Scott, J. Nucl. Mater., 211, 101 (1994).

14. S. M. Bruemmer, E. P. Simonen, P. M. Scott, P. L. Andresen, G. S. Was and J. L. Nelson, J. Nucl. Mater., 274, 299 (1999).

15. L. E. Thomas and S. M. Bruemmer, in Proc. $11^{\text {th }}$ Int. Conf. Environmental Degradation of Materials in Nuclear Power Systems-Water Reactors, ANS, 2003, in press.

16. P. G. Shewmon, Diffusion in Solids, McGraw-Hill, New York, New York, (1963).

17. M. P. Macht, A. Muller And V. Naundorf, in Proc. Radiation-Induced Changes in Microstructure: $13^{\text {th }}$ International Symposium, ASTM STP 955, F. A. Garner, N. H. Packan, and A. S. Kumar, Eds., American Society for Testing and Materials, Philadelphia, pp. 5-13 (1987).

18. T. Saario, P. Aaltonen, P. Karjalainen-Roikonen, J. Piippo, K. Makela, S. Tahtinen And H. Hanninen, in Proc. $7^{\text {th }}$ Int. Symp. on Environmental Degradation of Materials in Nuclear Power Systems - Water Reactors, NACE, pp. 841-854 (1995).

19. K. E. Heusler,Corr. Sci., 39 No. 7, 11 (1997).

20. R. A. Johnson And N. Q. Lam, Phys. Rev. B13, 4364 (1976). 
21. J. M. Perks And S. M. Murphy, in: Proc. Materials for Nuclear Reactor Core Applications, 1, 117 (London BNES, 1987).

22. E. P. Simonen And S. M. Bruemmer, J. Nucl. Mater., 239, 185 (1996).

23. F. P. Ford, Corrosion, 52, No. 5, 375 (1996).

24. D. J. Edwards, E. P. Simonen, F. A. Garner, L. R. Greenwood, B. M. Oliver, and S. M. Bruemmer, J. Nucl. Mater., 317, 32 (2003). 


\section{Program Management and Milestones}

No major issues or problem areas were identified during this first year of the project. Milestones were completed on schedule or slightly ahead of schedule as shown in the status table below. The only exception was setting up the initial subcontract with General Electric Global Research. This caused an early delay in getting materials prepared and crack-growth testing underway. The milestones targeted for phase 2 tasks are also shown below. Several of these areas began in phase 1 and have shown excellent progress toward completion on schedule in FY04.

One issue during the first year was the transfer of DOE Office responsibilities for this work. This did cause some complications with existing project commitments and subcontracts since essentially a new project had to be created to finish year 1 (money transferred between Offices) and begin year 2 activities. However, problems have now been solved and no continuing issues are expected.

Milestone Status Table:

\begin{tabular}{|l|c|c|c|}
\hline $\begin{array}{c}\text { Phase 1 (FY03) } \\
\text { Milestone/Task Description }\end{array}$ & $\begin{array}{c}\text { Planned } \\
\text { Completion Date }\end{array}$ & $\begin{array}{c}\text { Actual Completion } \\
\text { Date }\end{array}$ & $\begin{array}{c}\text { Percent } \\
\text { Complete }\end{array}$ \\
\hline Set up GE Subcontract & October 2002 & November 2002 & $100 \%$ \\
\hline $\begin{array}{l}\text { Select/Obtain Baseline Alloys } \\
\text { for FY03 SCC Testing }\end{array}$ & January 2003 & January 2003 & $100 \%$ \\
\hline $\begin{array}{l}\text { Complete Exploratory Crack- } \\
\text { Tip Characterizations }\end{array}$ & June 2003 & May 2003 & $100 \%$ \\
\hline Complete FY03 SCC Testing & September 2003 & September 2003 & $100 \%$ \\
\hline $\begin{array}{l}\text { Select/Obtain Baseline Alloys } \\
\text { for FY04 SCC Testing }\end{array}$ & September 2003 & September 2003 & $100 \%$ \\
\hline
\end{tabular}

\begin{tabular}{|l|c|c|c|}
\hline \multicolumn{1}{|c|}{$\begin{array}{c}\text { Phase 2 (FY04) } \\
\text { Milestone/Task Description }\end{array}$} & $\begin{array}{c}\text { Planned } \\
\text { Completion Date }\end{array}$ & $\begin{array}{c}\text { Actual Completion } \\
\text { Date }\end{array}$ & $\begin{array}{c}\text { Percent } \\
\text { Complete }\end{array}$ \\
\hline $\begin{array}{l}\text { Complete Initial Series of SCC } \\
\text { Tests on Stainless Steels }\end{array}$ & February 2004 & & $60 \%$ \\
\hline $\begin{array}{l}\text { Complete Crack-Tip Exams on } \\
\text { Stainless Steels SCC Samples }\end{array}$ & May 2004 & & $20 \%$ \\
\hline $\begin{array}{l}\text { Complete Crack-Tip Exams on } \\
\text { Alloy 600 Pb-SCC Samples }\end{array}$ & August 2004 & & $50 \%$ \\
\hline $\begin{array}{l}\text { Complete Initial Series of SCC } \\
\text { Tests on Ni-Base Alloys }\end{array}$ & September 2004 & & $0 \%$ \\
\hline $\begin{array}{l}\text { Select/Obtain Baseline Alloys } \\
\text { for FY05 SCC Testing }\end{array}$ & September 2004 & & $0 \%$ \\
\hline
\end{tabular}


Publications/Presentations:

L. E. Thomas, J. S. Vetrano and S. M. Bruemmer, "High-Resolution Analytical Microscopy of Environmental Cracks in Alloy 182 Weldments," 11th International Conference Environmental Degradation of Materials in Nuclear Power Systems - Water Reactors, ANS, August 2003, in press.

E. P. Simonen, L. E. Thomas and S. M. Bruemmer, "Defining the Role Solute Diffusion Kinetics at Crack Tips in Stain Steel During Irradiation in Light-Water Reactors," 11th International Conference Environmental Degradation of Materials in Nuclear Power Systems - Water Reactors, ANS, August 2003, in press.

S. M. Bruemmer, “Alloy 600 Stress Corrosion Crack Tips Produced in PWR Secondary Water Environments - Influence of Lead," International Cooperative Group on Environment-Assisted Cracking, Ottawa, Canada, May 2003.

S. M. Bruemmer, "Innovative Approaches to Establish Root Causes for Cracking in Aggressive Reactor Environments," NERI Program Review, Panel F5-1, Washington D. C., May 2003.

Students Involved in Project Research

Undergraduate: $\quad$ Dan Parks, Whitman College (Summer 2003) Crack-Tip Modeling Task

Post-Doctorial: $\quad$ Mychailo Toloczko Crack-Tip Deformation Issues 


\section{Financial Summary}

Total expenditures over the first 13 months have been approximately $\$ 380,000$ or $\sim 100 \%$ of the year 1 (September 2002 to September 2003) budget of $\$ 379,729$. This spending rate was exactly as predicted with a significant increase in activity at General Electric over the last 2 months. The transfer of funding between DOE Offices caused some difficulty in financial management at the end of FY03, but is now complete and on schedule.

\begin{tabular}{|c|l|l|c|c|}
\hline \multicolumn{2}{|c|}{} & Approved Spending Plan & Actual Spent to Date \\
\hline \multicolumn{2}{|c|}{ Phase / Budget Period } & Total & Total \\
\hline & From & To & & $\$ 305,297$ \\
\hline 1 & $9 / 1 / 02$ & $8 / 31 / 03$ & $\$ 379,729$ & 0 \\
\hline 2 & $9 / 1 / 03$ & $8 / 31 / 04$ & $\$ 400,188$ & $\$ 78,642($ as of $9 / 30 / 03)$ \\
\hline 3 & $9 / 1 / 04$ & $9 / 30 / 05$ & $\$ 420,000$ & $\$ 383,939$ \\
\hline \multicolumn{2}{r|r}{ Totals } & $\$ 1,200,000$ & \\
\hline
\end{tabular}

Cost Performance: Cumulative Expenditure Summary

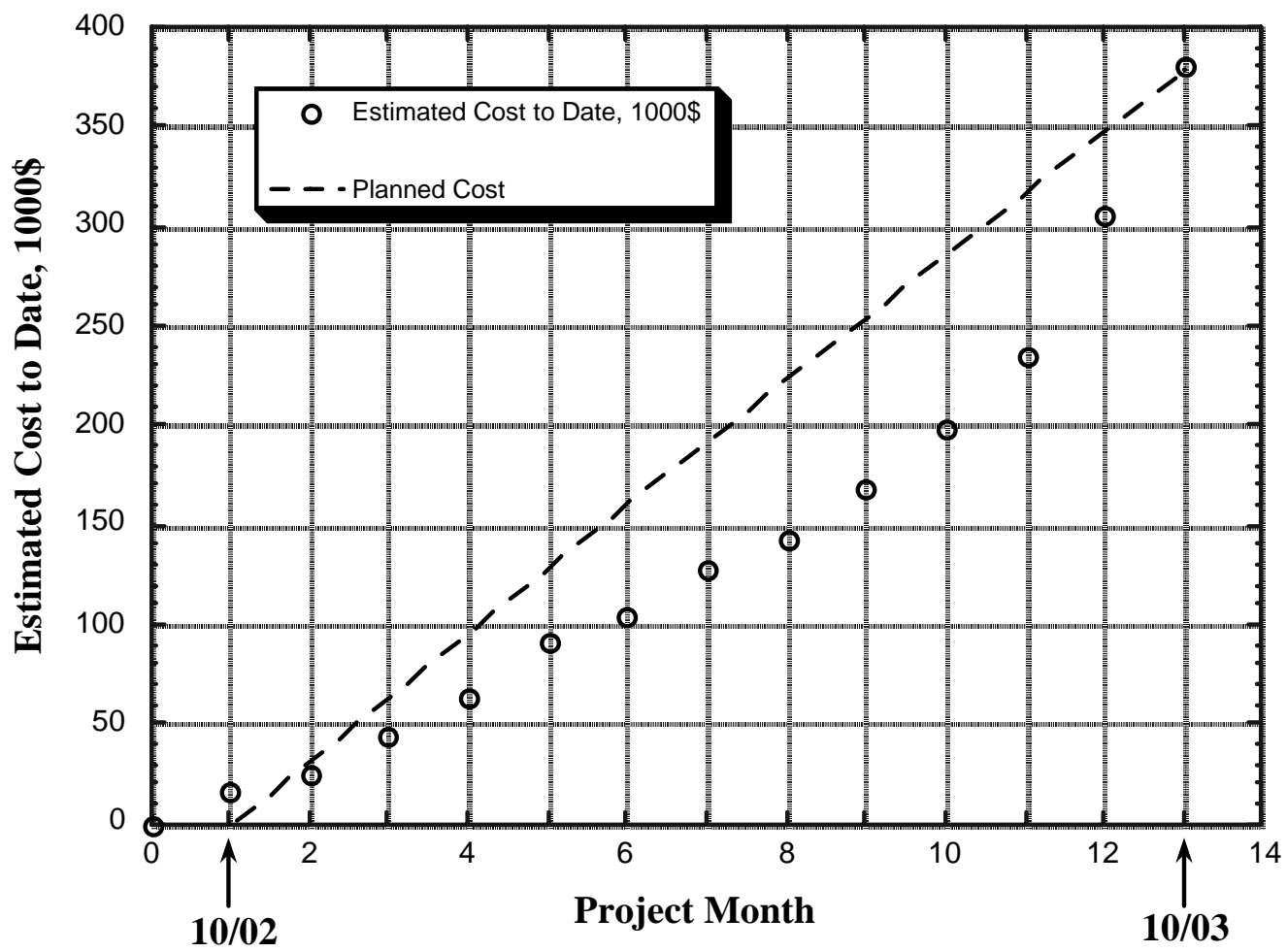

